OL 785

.W3

Copy 1

NSTINCTAnd INTELLGGNCE IN THE

XINIMXI KINGDOM REV. E. WASMANN S.J. 


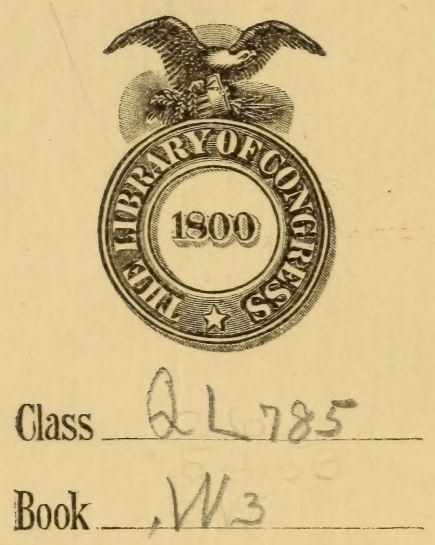

Copyright N.

COPYRIGHT DEPOSIT. 




\section{Instinct and Intelligence}

IN THE

\section{Animal Kingdom.}

A Critical Contribution to Modern Animal Psychology,

ERIC WASMANN, S. J.

Authorized Translation of the Second and Enlarged Edition.

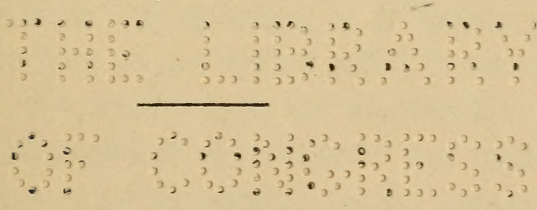

St. Louis, Mo., I90.3.

Published by B. HERDER,

I7 South Broadway. 


\section{Q $L 785$}

THE LIBRARY OF CONGRESS,

Two Copies Received JUN 101903

Copyright Entry pure $8-1903$ CLASS a XXX. No. 61377 COPY $B$.

COPYRIGHT 1903

BY

JOSEPH GUMMERSBACH.
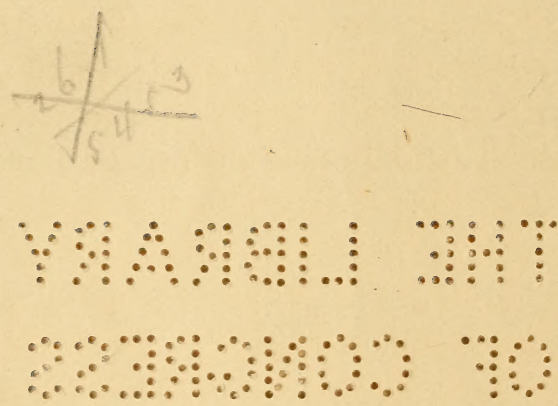

- BECKTOLD -

PRINTING AND BOOK MFG. CO.

ST. LOUIS, MO. 


\section{PREFACE TO THE FIRST EDITION.}

THE following essay is offered as a contribution to 1 comparative psychology. Its special purpose is to submit the manner in which modern animal psychology applies the notions of instinct and intelligence to a careful examination. In a former publication we endeavored to elucidate the doctrine of animal intelligence according to St. Thomas Aquinas. For this purpose we selected an example from insect life. ${ }^{1}$ Besides numerous smaller essays on the life of ants and their guests, which appeared mostly in German scientific periodicals, we have published a biologic-psychological work on Mixed Ant-Societies. ${ }^{2}$ It was principally in discussing the latter publication that representatives of modern animal psychology raised sundry objections to our distinction between instinct and intelligence. As, however, the exact meaning and use of these terms is the essential point of difference between the old and recent animal psychology, we deemed it appropriate to treat this question in a special paper in which the difficulties of our critics could be more closely investigated. We shall try, as far as possible, to avoid all abstract philosophical discussions; the more so, as the present essay must be adapted to the views of modern naturalists.

1) "The leaf-roller" (Rhynchites betulae). A scientific essay on Animal Instinct. Muenster, 1884.

$\left.{ }^{2}\right)$ "The Compound Nests and Mixed Colonies of Ants" (German). Muenster, 1891. 


\section{Preface to the First Edition.}

Consequently we have first to explain what we, and what our antagonists mean by instinct and intelligence. This will lead to a correct use of the terms. Secondly, we must examine the true relation of instinct to intelligence in animal life. This investigation will show, whether intelligence in its genuine meaning may be attributed to animals, or whether man is the only intelligent being in the created world. For the same purpose we shall soon publish a further essay on the comparative mental faculties of ants, of higher animals and of man, which will be in close connection with and rest upon the present work. 


\section{PREFACE TO THE SECOND EDITION.}

THE interest with which this essay was received, has made a second edition necessary. In order to do justice to recent objections of our scientific opponents, we had to enlarge it in various places. Still we confine ourselves to real and positive objections. Moreover, we have inserted a chapter on the different Forms of Learning.

The present work is closely connected with our Comparative Studies on the Mental Faculties of Ants and Higher Animals (German, second, enlarged edition, Freiburg i. Br., 1900). Besides, we desire to call attention to an essay written for Zoologists, and entitled "The Mental Faculties of Ants" (German). Zoologica, Heft 26, Stuttgart, I899. It may well serve as a supplement to the views we advanced in the above mentioned writings, as it supplies new material for argument, 


\section{REMARKS OF THE TRANSLATOR.}

MANY books on animal psychology, and in parI ticular, on the instinct of animals, have been written within the last quarter of the nineteenth century. However, the value of these publications is very different. Several authors have deceived themselves and their readers by dropping the chain of argument at the critical point, by evading the difficulty, and using logically unwarrantable, or otherwise obscure phrases. Very few, indeed, are plain and consistent. E. Wasnaann, well known in Germany as the famous ant biologist, is one of the few. With admirable surety of aim, and well skilled in controversial philosophy, he presses his subject home, sentence by sentence, he is never afraid to face the point at issue, and occasionally adduces an appropriate example, mostly taken from his own observation.

The object of this translation is to make Englishspeaking scientists acquainted with Wasmann's publications, which are considered in Germany as standard biological literature. The technical terms we have adopted are pretty nearly the same as those of Lubbock, Romanes, etc., in their scientific writings. We took this precaution in order to be better understood by modern scientists. The terms "understanding," "reason" and "intelligence," however, are used for one and the same physical entity.

In the "American Naturalist" (I901, p. 808), Prof. 
W. M. Wheeler, of Texas University, suggests, that a translation of Wasmann's psychological essays might prove useful for American readers. Prof. Wheeler's psychological views are, in general, very similar to those of Wasmann; but as he does not accept Wasmann's definition of instinct and intelligence, some critical remarks on his objections have been added by the author to the fourth chapter of this English translation of his book. Moreover, the reader will find some additional notes on the psychological views of Loeb and Garner.

We shall consider it an ample reward for our trouble, if even a few thorough scientists become acquainted through this translation with Wasmann's valuable publications.

Canisius College, Buffalo, N. Y., Dec. 3, I902. 



\section{CONTENTS.}

PAGE.

Preface to the first edition................. iii

Preface to the second edition................ v

Remarks of the translator................. vi

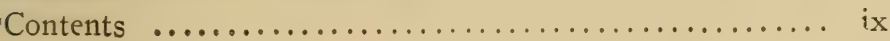

CHAPTER I.

Popular or Scientific Animal Psychology.............. I

The mania of modern "Animal Intelligence." Wundt's opinion of "Pseudo-Psychology." Fundamental principles of a scientific animal psychology.

\section{CHAPTER II.}

Instinct and Intelligence according to Modern Zoology...

Its definitions of Instinct and Intelligence examined and illustrated by examples. Darwin's views on animal intelligence. Modern zoology mistakes complex sensitive representations for intelligence. Examples prove that this notion of intelligence is untenable.

\section{CHAPTER III.}

What is Intelligence and what is Instinct?............

Intelligence and reason. Intelligence is the power of formal conclusion. Instinct is a sensitive impulse to actions that are unconsciously adaptive. Essential and unessential criteria of instinct. The power of sensitive perception and its faculties. Instinct is the adaptive disposition of the powers of sensitive perception and appetite, and constitutes as such the principle of the spontaneous actions of the animal. Senses and spirit.

\section{CHAPTER IV.}

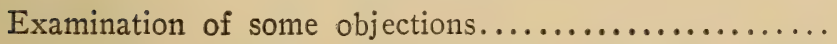

Popular psychology strongly opposed to a critical analysis of notions. Is Reimarus the originator of Modern Animal Psychology? Reimarus and the Animal Psychology of Scholastic Philosophy. Forel's Automatisms" and "Plastic Neurozymic Activities." Other objections of Forel. A charming criminal romance of ants by an anonymous critic. H. E. Ziegler and Modern Science. 


\section{Contents.}

CHAPTER V.

General Sense Images and the Power of Abstraction..... 75

Emery's objections against an essential difference between instinct and intelligence. Relation of the sensitive life of perception to the spiritual life of man. The "material conclu. sions" of animals. General sense images and their difference from general concepts.

\section{CHAPTER VI.}

Intelligence and Speech.......................

Emery's opinions on the relation of intelligence to speech. Their examination. Human speech is not the cause of intelligence, but intelligence is the cause of speech. The pretended "abstractions of the first order" in animals. Human speech and the so-called language of animals. Conclusions. Emery's last reply.

\section{CHAPTER VII.}

A Uniform Standard for Comparative Animal Psychology

Smalian's objections. The pretended "gradual difference" between animal and human intelligence. Can the psychic life of insects be compared with that of the higher animals? Sense organs and the nervous system of insects. The cortex of vertebrates and the by-brain of insects. Sensitive consciousness and spiritual self-consciousness. There is a uniform critical standard for Comparative Psychology. Bethe's new reflex-theory of ant life.

\section{CHAPTER VIII.}

The Different Forms of Learning................. I49

In view of biological facts, six different forms of learn. ing have to be distinguished, three forms of self-dependent learning, and three forms of learning through outside influence. All six forms of learning are found united only in man. In animals, both in ants and in the higher mammals, the third and sixth forms are missing. And as these two forms alone offer a real argument for intelligence, it is untenable to assume animal intelligence. 


\section{CHAPTER I.}

POPULAR OR SCIENTIFIC ANIMAL PSYCHOLOGY.

Clearness is the only way to truth.

$I^{T}$ is nowadays fashionable to admit animal intelligence, and it has become a mania to humanize the brute. It is considered unscientific to use the word "instinct," and even more so to explain all psychic manifestations of the animal from its instinctive sensitive life. On closer investigation, however, we soon notice whence this fashion originates. We become convinced that its proper home is to be found not in the truly scientific, but in the so-called popular scientific circles, especially those societies which have been instituted for the protection and love of animals, and gather their psychological knowledge of animal life from the works of such men as Buechner and Brehm. Having been led astray by these and similar writers, many try to solve the enigma of animal life by shifting their own range of thought into the brain of the brute. Then they innocently draw out their own ideas, and believe them to be the 1.ental activities of the animal, But genuine scientists, even adherents of the Darwinian theory of evolution, judge otherwise. With these men the point of discussion is a very different one. The question is not, whether the adaptive actions of animals have in general to be explained by instinct or intelligence, for these scientific opponents willingly acknowledge, that the psychic phenomena of animal life are mostly of an instinctive nature, whilst those which they ascribe to "intelligence" are understood to proceed from a faculty 
very different from the faculty of human beings. These opponents, as Romanes, Ziegler, etc., agree with us in deeming it unscientific and ridiculous to explain, as Brehm does, the adaptive activity that proceeds from the sensitive knowledge of animals by the "animals' own understanding." With true scientists, therefore, the gist of the argument will turn on the following two questions: First, is human "intelligence" essentially different from that of the animal, or only different in degree? Secondly, is it possible or not, that the human mind could have developed from the animal faculty of sensation?

But before commencing our comparative psychic investigation, it is of the utmost importance to establish some short and clear notions, according to which we shall have to decide, whether certain animal actions are instinctive or intelligent. True, nowadays, writers are not fond of exact definitions in this very line of science. "Why, everybody knows what is meant by instinct and intelligence; therefore, we need not tire our readers with philosophical definitions." In these, or in similar terms, they are wont to introduce their essays. However, this is fishing in troubled waters. No wonder, then, that after the perusal of such a "scientific examination," the reader is at a loss to see what the author has proven; for the author was at a loss himself.

Any reasoning man, much more any naturalist, who earnestly desires to investigate, and not to humanize the psychic faculties of the animal, will therefore agree with us in demanding a clear psychological analysis. Only those who assert with Alfred Brehm, that the notion of "instinct" is missing in their vocabulary, and 
bar out any other motive of animal [:sychology beyond "the animal's own understanding"1 are frightened by a critical analysis of psychological notions, and style it a "reactionary endeavor," through which modern animal psychology is again to be "shackled by the dogmatical fetters of mediaeval scholasticism." Let the correct answer to this objection be given by William Wundt, professor at the University of Leipzig, a prominent authority among German psychologists. It is all the more impartial, as Wundt does not seem to be acquainted with any of our former publications, and cannot reasonably be suspected of being influenced by the "scholastic reactionary party." Wundt thinks that modern animal psychologists deserve the reproach of too rashly making use of unfinished and inadequate concepts, ${ }^{2}$ and he thus continues:

"Bacon's comparison of the insufficient observation of nature by the Aristotelians of his day to the report of an ambassador, who based his knowledge of the measures of a government upon town gossip and not upon accurate examination, applies fairly enough to the animal psychology of our time. It is permeated through and through by the concepts of the every-day psy-

1) See "Brehm's Thierleben," 2d edition, Vol.-I; Ein Blick auf das Leben der Gesamtheit, p. $20 \mathrm{ff}$. In the recent (third) edition the whole tendential babble of Brehm on animal intelligence, unpolished in contents and form, has happily been omitted in the introduction to the first volume. Yet the psychological explanation of animal life, founded upon that collection of empty phrases, has, I am sorry to say, remained un. changed in the course of the work, even in the most recent edition. See also our review of the third edition in "Natur und Offenbarung," 37 (1891), p. $570 \mathrm{ff}$. and 40 (1894), p. $61 \mathrm{ff}$.

$\left.{ }^{2}\right)$ "Lectures on Human and Animal Psychology" (translated from the Second German Edition by J. F. Creighton and E. B. Titchener, 1896), Lect. 23, p. 341. 
chology, which is thought to suffice for the requirements of ordinary life, and too often also for the sciences which cannot do without psychological reference. The one great defect of this popular psychology is, that it does not take mental processes for what they show themselves to be to a direct and unprejudiced view, but imports into them the reflections of the observer about them. The necessary consequence for animal psychology is, that the mental actions of the animals, from the lowest to the highest, are interpreted as acts of the understanding. If any vital manifestation of the organism is capable of possible derivation from a series of reflections and inferences, that is taken as sufficient proof, that these reflections and inferences actually led up to it. And, indeed, in the absence of a careful anyalsis of our subjective perceptions we can hardly avoid this conclusion. Logical reflection is the logical process most familiar to us, because we discover its presence when we think about any object whatsoever. So that for popular psychology mental life in general is dissolved in the medium of logical reflection. The question whether there are not perhaps other mental processes of a simpler nature is not asked at all, for the one reason that whenever self-observation is required, it discovers this reflective process in the human consciousness. The same idea is applied to feelings, impulses and voluntary actions which are regarded, if not as acts of intelligence, still as affective states which belong to the intellectual sphere.

"This mistake, then, springs from ignorance of ex-

1) "Jener vulgaeren Psychologie" (German text.) 
act psychological methods. It is, unfortunately, often rendered worse by the inclination of animal psychologists to see the intellectual achievements of animals in the most brilliant light. . . . Unbridled by scientific criticism, the imagination of the observer ascribes the phenomena in perfectly good faith to motives which are entirely of its own invention. The facts reported may be wholly true; the interpretation of the psychologist, innocently woven in with his account of them, puts them from first to last in a totally wrong light. You will find a proof of this on nearly every page of the works on animal psychology."

The dangers hinted at by Wundt to which pseudopsychology may give rise in a scientific examination of the psychic faculties of animals are not at all new. More than a hundred years ago the elder Reimarus emphatically objected in his "General Considerations on the Instincts of Animals" to the undiscriminating humanization of animals, of which certain modern psychologists are so very fond. ${ }^{1}$ Many representatives of Christian views of nature have recently, and without regard to Reimarus, energetically protested against this extremely unscientific method of pseudo-psychology. ${ }^{2}$ Although Wundt's suggestions merely express an old truth, they are not, on that account, less instructive and less worthy of consideration; the more so, as Wundt knows their

1) "Allgemeine Betrachtungen ueber die Triebe der Thiere," 3d edition, Hamburg, 1773. See especially $\$ 23$.

2) "Seelenleben der Thiere" (3d edition, 1897), by Otto Fluegel, an adherent of Herbart's Philosophy. "Der Thierische Wille," by G. H. Schneider, a Darwinian zoologist who dedicated his work to Prof. Dr. E. Haeckel, as if he wished to prove, that "mediaeval" philosophers and theologians were not the only ones inclined to oppose the views of mod. efn animal psychology. 
importance from personal experience. On comparing the first edition of his "Lectures on Human and Animal Fsychology," with the second edition, which we have just quoted, it will not escape notice, that Wundt was formerly influenced in his views on animal psychology by the very "pseudo-psychology" which he now so justly condemns. Nevertheless, it can only redound to his honor, that he had the courage to free himself from the sway of that unscientific method; and we believe that other naturalists, who reason scientifically, might follow his example, without the least injury to their good name.

Let us, then, begin our investigation with a critical analysis of concepts.

The key to a scientific inquiry into the nature of the animal soul is evidently the soul of man. For we have no immediate insight into the psychic acts of the animai; we can only infer their existence and nature from the exterior actions which our senses perceive. We must compare these manifestations of the activity of the animal soul with the manifestations of our own psychic life, the interior causes of which are known to us from our inner consciousness. Consequently scientific psychology applies the same key as pseudo-psychology, but it follows critical methods. It does not forget, as the other does, the fundamental law of a rational explanation of nature which runs thus: We must explain phenomena in the simplest way possible, and we are not $\checkmark$ allowed to attribute to animals higher psychic faculties than are requisite for the explanation of definite and well-observed facts.

This is the only correct standard. It is applied in 
the following manner by scientific psychology in comparing the activity of the human soul with that of the animal. We perceive in ourselves two main groups of psychic processes: unconsciously adaptive and consciously adaptive, or instinctive and intelligent processes. When an infant feels the pangs of hunger and manifests this feeling by cries and signs, the connection between the bodily want of food and the psychic sensation thereof, between the soul's affection of uneasiness and the exterior act of its manifestation by the muscles in crying, is instinctive, it is unconsciously adaptive. On closer attention we find, even in every-day life, a great number and variety of psychic processes, in which the connection of interior feelings, or of exterior perceptions, with certain ideas, affections and exterior actions, is also unconsciously adaptive, independent of any act of deliberation or free volition. These psychic processes are the lowest and simplest forms of the activity of the human soul. Consequently we must not go beyond them in judging the manifestations of the psychic life of animals. We are not allowed to introduce deliberation and free volition for the sake of explanation, unless these simpler, unconsciously adaptive associations, prove to be inadequate. This is scientific psychology. Pseudopsychalogy, however, proceeds very differently. In order to explain the activity of the animal soul it has recourse at once to the highest psychic functions in man, to the logical processes of the intellect and to the free volitions of the will. The poet who idealizes may justly do so, but not the philosopher, nor the naturalist who reasons philosophically.

Which actions, then, are to be called instinctive? As 
the very name suggests, instinctive actions are those which spring from impulses of the sensitive appetite and are accompanied by sense perceptions and sensile feelings. These two qualities distinguish them from reflex motions. Lastly, they are unconsciously adaptive, and thereby totally different from acts of the intellect.

Everyone will allow, that instinctive actions are neither mere reflex phenomena nor intellectual functions. They are not mere reflex phenomena, for they contain, as experience teaches, a psychic element which cannot be eliminated without destroying their very essence. Reflex actions are those adaptive processes of a living organism, which solely, but essentially depend on the irritation of certain motory nerves. They are specified by it alone, whether this activity of the motory nerves be connected with an irritation of the sensory nerves or not. Indeed, this latter connection is quite unessential to reflex activity. Consequently sensation is not an essential element of reflex acts. Thus the regular pumping motions of the heart, which we call palpitations, and the peristaltic motions of the bowels during digestion are reflex actions; but they are not necessarily perceptible. Similarly reflex is the act of sneezing, which is caused by the irritation of certain sensory nerves of the organs of breathing, or the twitchings of certain motory muscles, which are produced by irritations of the spinal ganglia. Therefore reflex actions are due solely to an influence of the nerve mechanism, and the psychic element of sensation is not essential to them. But this is not the case in any process that is truly instinctive. For in all such actions sensation participates as a cause in producing the corresponding activity. Therefore we 
cannot exclude a psychic element from the definition of "instinct" without ignoring its very nature and taking it for a reflex motion, as was done by Herbert Spencer, ${ }^{1}$ who states that instinct is a "complex reflexactivity."

As some psychic element is essential to all it.stinctive actions, it can only be that element which distinguishes instinctive from intellectual functions. This is, however, the unconsciously adaptive connection of certain sensile affections with their corresponding activities. For the sake of illustration let us recur to our example of the babe whose cries are an instinctive manifestation of its feeling of hunger and its impulse for nourishment. Now, we do not call this manifestation intelligent, because the tiny screamer does not cry with conscious intention. It is quite unaware of the suitableness of its very suitable clamor. Therefore the consciousness of the end is the chief element which distinguiishes intelligent from instinctive actions.

Hence, the following principle established by Prof. H. E. Ziegler in an essay on the "Notion of Instinct"2 is by no means tenable: "We must omit the element of consciousness in trying to determine the notion of instinct in a useful manner." Ziegler gives his reason for this principle. "Who can ever know when a dog, a lizard, a fish, a beetle, a snail, or an earth-worm

1) "Principles of Psychology," Vol. I, Chapt. 5, p. 451. Romanes attacks this definition in his "Mental Evolution in the Animal Kingdom" (1885), p. 283.

2) "Verhandlungen der Deutschen Zoologischen Gesellschaft," 1892, pp. 121-136. The same lecture has been published as an appendix to his book: "Die Naturwissenschaft und die socialdemokratische Theorie." Stuttgart, 1893. 
performs an action with or without consciousness? It is always precarious in natural sciences to introduce an element which cannot be examined or identified empirically, as a constituent part of any notion." However, Ziegler overlooked the fact, that in critical discussions on the psychic activities of animals we are forced to start from the analogy of the same activities in man; otherwise our knowledge of animal psychology would be very limited. In our own psychic life, however, we know from experience the difference between intentional and unintentional actions, a difference which is equally characteristic of their exterior manifestations. But as this is so clearly the case in the psychic life of man, comparative psychology is forced to extend the distinction between intentional and unintentional actions to the psychic life of animals. Nor is this the only reason for doing so. For without this distinction animal psychology would merely become a department of nerve physiology. According to Ziegler the difference between instinctive and intelligent action consists in the fact that the former depends on hereditary nerve mechanisms, and the latter on the individual experience of single beings. Yet, reflex activities depend equally well on hereditary nerve dispositions; hence, according to Ziegler's definition, the difference between instinct and reflex activity would altogether disappear. Therefore it cannot be adopted. It is true, the possibility of hereditary transmission of the instinctive associations of perceptions-as was long ago the doctrine of Aristotelian Philosophy-is one of the distinctive features of instinct in contradistinction to intelligence; but it does not constitute the only, and much less the essential 
criterion of instinct. For reflex mechanisms are also hereditary; and even intelligence itself, taken as a faculty, is hereditary in the sense that all normal human beings enter into life gifted with this precious faculty. Hence the essence of instinct, in contradistinction to intelligence, should not be based so much on the possibility of hereditary transmission as on the want of intentionality. 


\section{CHAPTER II.}

INSTINCT AND INTELLIGENCE ACCORDING TO MODERN ZOOLOGY.

IN his above-mentioned essay Ziegler tries to explain the difference between instinct and intelligence in the following manner: "Those associations in the life of animals are due to intelligence which spring from impressions gained by individual sense perceptions; those, however, which do not depend on individual experience, are instinctive." This explanation, according to which only those psychic actions of the animal are said to be instinctive, which immediately arise from hereditary dispositions, whilst all those which presuppose individual experience are due to intelligence, is, by the way, not at all new. It might simply be styled the animal psychology of modern zoology, especially since the days of Charles Darwin. Let us therefore carefully examine, whether this view of the question corresponds to the demands of scientific psychology.

What is meant by "hereditary instinct"? Complex representations or combinations of certain affections with certain impulses that are inherited complete as such, do not exist. ${ }^{1}$ Only the psychic faculty, or the dis-

1) We have previously proved that the assumption of innate, cogni. tive images (species objective innatae), in order to explain instinct, is highly improbable, even from a mere psychological standpoint ("Der Trichterwickler," p. $154 \mathrm{ff}$.). It is still less probable from a zoological (somatological) point of view. as every possible instinctive representation would have to pre-exist in the embryonic disposition of the animal in a definite, material part or element (whether it be an Id or a Determinant of Weismann). 
position of the nervous system, from which those combinations originate, is inherited. From the possibility of hereditary transmission of this two-fold disposition springs what we call "hereditary instinct." Hence also innate instincts are due merely to a hereditary power of association. This argument, however, renders the difference between instinct and intelligence, which is urged by modern psychology, untenable; for the latter calls "instinct" the hereditary sensitive power of association, and "intelligence" the exercise of the same power thrown into activity by the sense perceptions of the animal. Let us substantiate this truth by an example.

A young chicken is frightened at the very first sight of a wasp and is afraid to peck at it. Quite in keeping with modern zoological theories, this abstention is doubtless due to instinct; for, even without any painful experience, the mere sight of the wasp excites the feeling of fright by dint of a hereditary law of association. Now, let us suppose that in its youthful impetuosity in search of food, the chicken did not carefully examine the inviting titbit and pounced on the wasp and had been stung before it had time to form that instinctive association. According to the psychology of modern zoologists, this identical chicken is said to act from intelligence, whenever it carefully abstains in future from pecking at wasps. But is not this an evident abuse of the word "intelligence"? The mere psychological analysis of the process furnishes a definite answer to this question. The very sight of a wasp immediately arouses, according to the innate laws of association of representations not only the image of the first wasp, but also the imagination of the pain which the chicken felt in 
consequence of its former impetuous, but disastrous attack; this complex representation excites the affection of fright, according to the same innate laws of association, and the wasp escapes unscathed and the chicken unstung. Essentially the same psychic laws underlie the actions in each case, in that of the chicken which was cautious at the first sight of the wasp, and in that of the same chicken which controlled its impetuosity after the painful experience of the wasp's sting. What right then have psychologists to ascribe intelligence in the latter case? From the standpoint of critical psychology both processes must be reduced to the same causes. It is merely an act of the sensile memory, which distinguishes the doings in the second case from those of the first. The sensile memory, it is true, is not instinct in the stricter acceptance of the term; but it clearly belongs to the range of instinctive sensation, and not to intelligence.

How then does it come to pass, that modern psychology speaks of "intelligence," when the chicken is induced by the wasp's sting to beware of all wasps in future? Simply because this pseudo-science takes sensile imagination for intelligence and arbitrarily puts the following logical syllogisms into the chicken's brain: That object has a striking resemblance to the thing which stung me yesterday; now, I don't want to be stung again: therefore I'll leave that thing alone today. True, the reasoning power of man is able to resolve the simple process of the sensile association of animals into a logical deduction; but this fact merely warrants the conclusion, that man is endowed with intelligence, and not that the animal possesses it. Hence we must 
acknowledge either that the animal psychology of modern zoologists arbitrarily substitutes "syllogisms similar to those of man" for the simple sense functions of the animal, or that it plays not less arbitrarily with the term "intelligence." Both alternatives can only be explained by the fact that, as Wundt correctly observes, modern zoology is not free from the influence of the pseudo-psychology.

In this connection it may be to the purpose to quote a passage from Charles Darwin's "Descent of Man," which illustrates the methods of certain psychologists in the Darwinian theory of evolution. "Of all the faculties of the human mind it will, I presume, be admitted that Reason stands at the summit. Few persons any longer dispute that animals possess some power of reasoning. Animals may constantly be seen (?) to pause, deliberate, and resolve. It is a significant fact that the more the habits of any particular animal are studied by a naturalist, the more he attributes to reason and the less to unlearnt instincts. In future chapters we shall see, that some animals extremely low in the scale apparently display a certain amount of reason."1

Now, it is not our intention to comment on Darwin's bold statement, that observers of animal life find more intelligence and less instinct in animals the deeper they search and penetrate. The highly praised intelligence of ants has proved the very contrary according to the observations of Sir John Lubbock, and during my observations of ant life I have arrived more and more at the conviction, that the very phenomena which appear at first sight most similar to intellectual actions resolve

1) “The Descent of Man," I (1871), p. 46. 
themselves, on closer examination, into the simplest instinctive processes. Altum's excellent studies on the life of birds, the classical observations of $\mathrm{H}$. Fabre on the brooding of Hymenoptera, and quite recently the researches of $W$. Wagner on the architecture of spiders have all led forcibly to the same conclusion. ${ }^{1}$ Our only reason for quoting the "Descent of Man" is to show, that in his endeavor to derive the mental faculties of man from the psychic faculties of the animal, Charles Darwin was preoccupied by the principles of pseudopsychology, which is unable to distinguish correctly between sense perception and intelligence. Darwin considers it self-evident that animals have intelligence, because he takes for intelligence any combination of sense representations which is brought about by individual experience. Consequently Wundt's verdict on the want of critical method in pseudo-psychology applies equally well to the "Descent of Man" by Charles Darwin.

The example of the chicken proves that the "intelligence" of modern psychology is no intelligence at all. It is merely an association of sense representations in which one element is derived from experience. This element is the feeling of pain caused by the wasp's sting. According to the laws of "contact association," as Wundt calls this combination of representations, it is reproduced as an image in the memory at the sight of any other wasp, and actuates the chicken's instinct of fear to avoid the wicked insect. There is not a shadow

1) "L'Industrie des Araneina." Mémoires de l'Académ. Impér. des Sciences de Pétersbourg (7) t. 40 (1894), n. 11. See also Emery's abstract in "Biologisches Centralblatt," 16, No. 3, S. $118 \mathrm{ff}$. 
of proof that this psychic process is due to intelligence. On the contrary, psychological analysis compels us to explain this so-called intellectual act by the same psychic laws which guided the chicken when it happily avoided being stung by the wasp the very first time they came into contact.

Should we then call the behavior of the chicken in the second case instinctive or intelligent? As its avoidance of the wasp springs from a sensile impulse and not from intellectual deliberation and is ruled only by sensitive knowledge, we must necessarily call it instinctive. Still it is not instinctive in the strictest sense of the term, because it contains an element of individual sensitive experience. It is, however, undoubtedly instinctive in a wider sense, and we are far more justified in extending the notion of instinctive actions to those which contain an element of sensitive experience than is modern psychology in making the notion of "sensitive experience" in the animal coincide with the notion of "intelligence." The latter conception leads to obvious contradictions, as the following examples clearly demonstrate.

In full accord with other psychologists who have recently written on animal life, the English scientist George Romanes ${ }^{1}$ calls only those adaptive actions of the animal instinctive which are "antecedent to individual experience," and designates as intelligent all the rest which result from an experimental source. (P. I7.) Now, only a few pages above (P. I3) the same Romanes explained the difference

1) “Animal Intelligence," 5th edition, London, 1892. 
between instinct and reflex activity by the following examples. A new-born infant does not close its eyes at the approach of a dangerous object; it only learns to do so by and by, as the result of experience. Thence Romanes concludes that the closing of the eyes at the approach of danger was originally an instinctive and not a mere reflex activity, which it gradually becomes by repeated exercise. Again, Romanes calls the sucking of a new-born infant a mere reflex activity, because it does not, in his opinion, contain a psychic element. But only when a babe has repeatedly experienced the pleasure of sucking and then begins to seek its mother's breast, are we justified, according to Romanes, in designating its action as instinctive in the proper sense of the word.

Now, according to his own statement and the views of modern animal psychologists, this "properly instinctive action" evidently falls under the definition of intelligent and not of instinctive activity, as it is precisely the individual experience of the babe that in their theory renders these actions "intelligent." Therefore, Romanes, with all other modern animal psychologists must either designate the instinctive closing of the eyelids on the part of a babe that is a few days old and its searching for its mother's breast as "intelligent actions," and that is absurd, or, they must acknowledge that their notion of intelligence cannot be defended.

The latter alternative is surely preferable. The psychic development of man clearly shows that many actions which presuppose an individual sense experience can be instinctive in the wider sense of the term. A burnt child shuns the fire and proves the truth of this 
proverb by simple associations of representations, long before it has arrived at the use of reason.

Thus, we again arrive at the inevitable conclusion, that the notion of intelligence of modern animal psychologists cannot be maintained in face of a critical analysis. It is unsound and has been falsified by the influence of "pseudo-psychology." It is wrong to style all those psychic actions "intelligent" which presuppose the experience of the animal, just as it is wrong to designate only those as "instinctive" which do not depend on experience.

Does a young dog, that sniffs at a bone for the first time and feels impelled by the enticing odor to crunch it, act from intelligence or from instinct? The answer of every modern psychologist will evidently be: From instinct; for the dog does not know by experience that bones taste well. But if the same dog finds a second bone, and its previous experience of pleasure in gnawing the former bone helps to whet its appetite, then "intelligence" is said to cooperate side by side with instinct. Or when a young ant, say Formica sanguinea, meets for the first time a genuine guest, a Lomechusa strumosa, living in the same nest, and on touching the beetle with her feelers perceives an agreeable odor and Immediately begins to lick the beetle, she is said to act from "instinct ;" but when she licks it a second time, after having once tasted the very agreeable flavor of the ethereal matter secreted from the yellow hair-tufts of the beetle, "intelligence" is said to have a part in this second and in all subsequent acts. Is it not obvious that we have to do with an abuse of the term "intelligence"? The only idea to be conveyed by the term is an asso- 
ciation of sense representations in which one element is taken from experience. This association, however, is of an instinctive nature, because it follows the laws of unconscious association which belong to the sphere of sensitive life; it has absolutely nothing to do with intelligence in its proper meaning.

Thus it is evident from these two examples that modern animal psychology not only makes an arbitrary use of the term "intelligence," but also that it shows no little inconsistency in the explanation of psychic animal activities. The dog that was induced by the smell of the first bone to crunch it, made in the very act the sensitive experience that the bone had a pleasant taste. The ant, likewise, that was instinctively led by the smell of the Lomechusa to lick it, enjoyed at once the sensitive experience, that her action was highly agreeable. Consequently, the actions of the dog and of the ant became, in that very moment, according to modern psychology, intelligent instead of instinctive actions; for the sensitive agreeableness of the respective taste perceptions is an clement of experience, and this element of experience caused the dog and the ant to continue their formerly instinctive actions. Hence it follows that instinctive activity ceases to be instinctive in the very moment its cxecution begins, and is changed into an intelligent action. Consequently exterior instinctive actions cease to be possible, they become at once intelligent; for the performance of any instinctive activity is agreeable to the animal, or averts displeasure from it, and it is precisely on account of this agreeble sensation that the animal performs those very actions. To repeat it once more: whosoever establishes the sensile experience of 
the animal as an essential criterion of intelligence, is logically forced to declare that all instinctive exterior actions of the animal are intelligent. But this consequence is untenable and will hardly be admitted by any rational naturalist. Therefore, the modern notion of animal intelligence which involves this consequence is cqually untenable and false.

A similar proof that this conception of animal intelligence leads to inextricable contradictions, could be easily furnished, and illustrated by many examples. But we would never come to an end and would have continually to repeat the same "ceterum censeo." Let one illustration suffice. For this purpose we choose the so-called animal instinct of cleanliness, ${ }^{1}$ because the sensile experience of the pleasure caused by a given action is intimately connected with this instinct and closely related to the feeling or perception which excites the action. This stimulus consists mostly in an irritation, a painful itching of the skin, which animals try to soothe by such actions as licking, scratching, etc. Now, any psychologist will allow that animals as well as man perform these actions instinctively, when they feel the irritation. Yet, a more accurate analysis of the process makes it evident that the consistent zoologist ought to say: "The animal begins, at least for the first time, to scratch itself instinctively, but in the same moment its action becomes intelligent; for the element of experience, the pleasure which arises from the action, is the proper motive of its continuation and repetition; and all

1) See P. Balliou, "De l'instinct de la properté chez les animaux," 2d edition. Bazas, 1895. 
actions that are catsed by the sensile experience of pleasure or pain, are intelligent-ergo."

But let us return to the term "intelligence" and investigate its proper meaning which has been obscured by pseudo-psychology. The question of the notional constituents of this term is not an empty verbal contention, nor a dispute about trifles, but an elementary question of the utmost importance for scientific animal psychology. 
WHAT IS INTELLIGENCE, AND WHAT IS INSTINCT?

WHT is "intelligence"? According to the etymological meaning of the term, and the concept hitherto attached to it by the scientific psychologists of all ages, intelligence-intellect, understanding-exclusively signifies the power of perceiving the relations of concepts to one another, and of drawing conclusions therefrom. It essentially includes the power of abstraction, the faculty of collecting from a number of single representations that which they all have in common, and, thereby, of forming general concepts. It includes furthermore a deliberative power which recognizes the relation between means and end, between a subject and its actions, and, consequently, endows the intelligent being with self-consciousiness and with rational, free activity.

Of late the attempt has been frequently made to represent intellect and reason as two different faculties, and "intellect" but not "reason" was attributed to animals. Yet, such a separation cannot be admitted. He who is endowed with intellect, necessarily possesses reason, and he who has no reason cannot have an intellect. This is evident from the following considerations.

In as far as it differs from intellect, reason signifies the power of adapting means to ends, and of acting with a certain purpose, reasonably. This meaning of the word is sanctioned by general usage. It conveys nothing beyond the power of practically adjusting one's actions to the theoretical knowledge of the intellect. An- 
other difference between intellect (intellectus) and reason (ratio) consists in the fact, that the former signifies the immediate insight into a truth and the latter the power of drawing conclusions from the truth that has been perceived. ${ }^{1}$ But this is immaterial to our present question, ${ }^{2}$ as both distinctions imply only a notional, not a real difference between intellect and reason, which are obviously not two different entities, but only different manifestations of one and the same mental power. He who possesses intellect is able to perceive the relations that exist between different things and to draw conclusions from them; consequently he is able to grasp the relation between means and end, to adapt the former to the latter; he is able to act reasonably, and therefore he possesses reason likewise. Hence it is obvious that all those who ascribe intellect to animals, are logically forced to attribute reason to them.

The "Reform Philosopher" Immanuel Kant has, it is true, excogitated another difference between intellect and reason. ${ }^{3} \quad$ Still in calling the former a power of

1) See Thom. de Aq., Summ. theol. 1 q. 59, a. 1 ad 1: "Intellectus et ratio differunt quantum ad modum cognoscendi; quia scillicet $i n$. tellectus cognoscit simplici intuitu, ratio vero discurrendo de uno in aliud." This distinction between intellectus and ratio, commonly held in Scholastic Philosophy, is not quite covered by the distinction between intellect and reason made by modern usage, since the intellectus is more perfect than the ratio, whilst vice versa the reason is more perfect than the intellect.

2) In as far as the power of drawing conclusions (ratio) implies an imperfection in opposition to the immediate perception of truths (intellectus), it is apparently not a characteristic note of intellect in general, but only of an imperfect intellect, and as the pretended intellect of animals is not supposed to be more perfect, but less perfect than that of man, this moment is of no importance in our present investigation.

${ }^{3}$ ) "Kritik der Reinen Vernunft" (Kants Werke 2, Leipzig, 1838), p. 280. 
rules, and the latter a power of principles, he departs from the old distinction only in word. But when he adds that reason is endowed with notions not acquired from the intellect, he makes a new, but a wrong and inconsistent statement, which he has entirely failed to substantiate. Anyhow, it has no bearing on our present consideration, especially as it will hardly find an advocate among modern zoologists, who try not only to derive the concepts of reason from those of the intellect, but even the concepts of the intellect exclusively from sensitive experience.

Thus we are fully justified in considering intellect and reason as synonymous, as far as their reality is concerned. Romanes, ${ }^{1}$ one of the most prominent representatives of modern animal psychology, is of the same opinion. He regards both faculties as manifestations of one and the same mental power of ratiocination. Still he would like the term "intellect" to be applied more to the lower, and "reason" more to the higher degrees of those manifestations.

Modern animal psychology does not seem to be aware of what is meant even by the lowest grade of "a power of formal reasoning." Otherwise it is hard to understand, how so many animal psychologists of moderate tendency agree with us in mercilessly condemning those who "humanize" the psychic faculties of the animal, and still ascribe to it a power of formal reasoning which differs only in degree, but is essentially of the same nature as that of man. They decline to equip the animal with "syllogisms similar to the human,"

1) "Animal Intelligence," p. 14. 
but forget that any, even the simplest formal syllogism, is "a syllogism similar to ours," and will never cease to be so, as long as psychological notions are submitted to a critical analysis. A confusion of ideas evidently underlies the modern phrase of "different degrees" of intelligence. ${ }^{1}$ Otherwise modern animal psychologists could not ascribe to animals a power of formal reasoning and deny it in the same breath.

Although Romanes concedes that intelligence is a power of formal reasoning, he nevertheless wants all those activities of the animal, which result from sense experience, to be regarded as intelligent. This is the criterion of distinction between instinct and intelligence, which he and nearly all modern zoologists strenuously defend. But it has been adequately proven, that this criterion is untenable. For even in human beings there are activities due to sense experience, which plainly result from mere combinations of sense representations and not from formal syllogisms; and as it is these very combinations that modern animal psychology calls "the intelligence of animals," we must reject this view of animal intelligence as absolutely uncritical, and trace it back with Wundt to the fatal influence of that "pseudo-psychology", which wantonly changes the actions of the animal psyche into logical processes of thought. Such a distinction between instinct and intelligence must be abandoned.

How are we, then, to distinguish instinct from intelligence in the psychic life of animals. The answer to this

$\left.{ }^{1}\right)$ See Reimarus, "Allgemeine Betrachtungen ueber die Triebe der Thiere," Nos. 15, 16, 123. Even Alfred Espinas ("Des Sociétés animales," $2 \mathrm{~d}$ edition, 1878 , p. 202) avows that it is wrong to take the cognitive power of the animal for a "moindre degré de raison." 
question is contained in our former statements. All spontaneous actions are instinctive which are not due to intelligence; consequently all those spontaneous actions of animals which do not manifest a porier of formal abstraction must be referred to the sphere of instinct.

But what is instinct? ${ }^{1}$ It is the principle of those actions which we call instinctive. These actions are due to impulse (p. 7) and emanate from the natural inclinations of the sensitive appetite; they are not reflex phenomena but "spontaneous actions,"2 because they are performed under the influence of the imagination and sensitive emotion; they are not intelligent actions, because they are carried out without consciousness of the purpose of the respective activity. In a being which possesses instinct and intelligence, one and the same exterior action can be partly instinctive and partly intelligent, as it is in man. But we are not allowed to admit the cooperation of intelligence in the actions of animals, before we have proved the impossibility of explaining them by instinct alone.

Consequently instinct signifies an impulse of the sensitic'e appetite to certain objects and acts, the suitableness of which transcends the range of knowledge of the agent that performs them. This is the first and proper meaning of the word "instinct." It signifies secondly the peculiarity of sensitive cognition, by which the sensi-

1) We cannot possibly dwell upon the innumerable old and recent definitions of instinct.

$\left.{ }^{2}\right)$ This is the reason why sight, hearing, smell, and in general all the activities of sensitive cognition as such and apart from their relation to the exercise of the sensitive appetite, are not "instinctive actions," but only the elements of such activity. This suggestion indicates the solution of a difficulty raised by different critics against our division of spontaneous activities. 
tive appetite is guided. ${ }^{1}$ This peculiarity consists in representing as pleasant to the sentient being what is really useful to it, and simultaneously guiding its physical powers to attain that object. ${ }^{2}$ This is the reason why all instinctive activity is unconsciously adaptive. Owing to this peculiarity the formal object of instinctive knowledge seems to transcend the range of sensitive cognition and to contain relations which are not perceptible to the senses. ${ }^{3}$. Consequently the scholastics styled it "species insensatæ", and called the cognitive power of the animal "the power of appreciation" (vis rstimativa), ${ }^{4}$ because it endowed the animal with a

1) Thus we read in the Conimbricenses (Commentarii Coll. Con. imbricens, S. J. in 8 libros Physicor. Aristotelis (1592), lib. 2, c. 9, q. 4, a. 2): Instinctus brutorum nihil aliud est quam operatio phantasiae, determinata ad judicium convenientis aut incommodi, determinansque appetitum ad fugam vel prosecutionem. Haec assertio est philosophorum communis.

$\left.{ }^{2}\right)$ As far as the use of these powers is not predetermined by innate nerve mechanisms, and only needs actuating by definite sensations.

3) The following example is often used as an illustration: The sheep recognizes in the wolf not only an object of certain color and dimension, but also its natural enemy which it must avoid. This latter relation is the species insensata. On the species insensatae see espec. Suarez, "De anima," I. 3, c. 9, n. 5, 12, 13.

4) Suarez, "De anima," I. 3, c. 30, n. 7: "Aestimativa describitur sensus interior potens apprehendere sub ratione convenientis et discon. venientis . . . haec siquidem operatio communis etiam est omnibus animantibus" (man and brute) .. . "cuius munus est movere appetitusn sensitivum, qui non nisi a ratione convenientis vel disconvenientis movetur. Ideo ergo aestimativa dicitur, quia de rebus ipsis aliud aestimat, quam quod exterius apparet." And Thomas of Aquin had previously observed (Summ. Theol. I. 2, q. 4, a. 2 ad 2): "Apprehensio sensitiva non attingit ad communem rationem boni, sed ad aliquod bonum particulare, quod est delectabile. Et ideo secundum appetitum sensitivum, qui est in animalibus, operationes quaeruntur propter delecta. tionem." Therefore, what is objectively useful must be represented as subjectively pleasant to the animal by its instinctive power of cognition. This combination of the useful with the pleasant, which is brought about by the suitable disposition of sensitive cognition and appetite, constitutes the real nature of instinct, as we shall at once proceed to demonstrate, 
certain likeness to man and made it fully competent to direct its own activity in a suitable manner.

Consequently instinct signifies both from an etymological and historical point of view, a sensitive impulse which induces a being to perform certain actions the suitableness of which is beyond the perception of the agent that performs them. ${ }^{1}$

It is instinct that induces the male larva of the stagbeetle (Lucanus cervus), before its transformation into a pupa, to produce a cocoon, the size of which is far greater than that of the pupa, and thus to provide in advance for the length of the future antlers of the imago which is to come forth from that larva. It has never even seen a developed stag-beetle, and no amount of "reflection" on its part could hit upon the clever idea of its eventual destiny to become a male stag-beetle with mighty antlers on its head. It is instinct that impels the female of the leaf-roller (Rhynchites betulæ) to make an incision into a birch-leaf after an extremely ingenious mathematico-technical problem, that was-by the waynot introduced into human science before 1673 , and then to roll up that leaf in the shape of a funnel as a depository for its eggs. ${ }^{2} \quad$ Neither by experience nor by reflection could the little weevil gain an idea of that problem, nor could it even know that it would lay "eggs" at all, from which young leaf-rollers would eventually develop. It is instinct that makes the young bird which is unac-

1) We say expressly: "the suitableness of which is beyond its per. ception," for the immediate object to which any instinctive activity is directed and this activity itself are the subject matter of sensitive cognition.

$\left.{ }^{2}\right)$ See Debey, "Beitraege zur Lebens und Entwicklungsgeschichte der Ruesselkaefer aus der Familie der Attelabiden," Bonn, 1846. Was. mann, "Der Trichterwickler," Muenster, 1884. 
quainted with any nest of its own species, collect after pairing little stalks and blades of grass and similar material for a warm nest, in which its fledglings are to be hatched; for neither by experience nor by thought or reflection could it know before its first season of breeding, that it would even lay eggs, and that these eggs would have to be hatched, in order to produce a new generation of its own kind. It is due to instinct, when a dog that suffers from tape-worm eats Artemisia absinthium, although it otherwise never touches this plant; for a study of medicine would be requisite to hit upon such a suitable treatment by its own experience. It is instinct, finally, that causes the new-born babe to express its feeling of hunger by crying and seeking its mother's breast ; ${ }^{1}$ for it could not possibly have previously recog. nized by experience or its own thinking the suitableness of its cries and its attempts to suck.

What is it, then, that essentially characterizes these different instinctive actions? It is the circumstance that their suitableness lies beyond the perception of the respective agent. The unconscious suitableness (adaptiveness) is, consequently, the essential criterion of instinctive, in contradistinction to intelligent actions.

Not without purpose was it pointed out in each of the previous examples that the respective agent not only lacked experimental knowledge of the suitableness of its acts, but that it likewise was unable to attain that knowledge by means of its own deliberate reflections. Animal psychology considers in a one-sided manner only the former point of view, and neglects the latter.

1) This example was used by St. Thomas of Aquin (2, dist. 20, q. 2, a. 2 ad 5). 
The human mind has made great inventions and discoveries by arriving through speculation at the knowledge of facts which were not known from experience. No one will, on that account, ascribe these discoveries to instinct and not to intelligence. Thus it is likewise a wrong and one-sided proceeding on the part of modern zoology to assign individual sense experience as the essential criterion of intelligent, in contradistinction to instinctive actions.

Nevertheless, we do not intend to deny that other auxiliary criteria of instinctive actions exist beyond the essential criterion which we have just established. One of these secondary marks is the complete perfection with which many instinctive actions are performed, without previous practice or experience on the part of the animal, so that they need not be learnt, but depend almost entirely on inherited dispositions. Another auxiliary character of instinctive actions is the constant uniformity with which they are performed by almost every individual of the same species. Yet, these two auxiliary marks are by no means essential criteria. For there are a few hereditary instincts that require previous practice and hence individual experience for their perfect development. Thus the so-called "raptorial" instincts of cats must be gradually developed through the instinctive "playfulness" of the kitten, which does not so far perceive the purpose of an amusement that is meanwhile only pleasant to it. ${ }^{1}$ Moreover, the exercise of hereditary instincts in members of the same species is modified by the variety of individual dispo1896)

1) See Gross, "The Play of Animals" (German, 2d edition. Yena, 
sitions, and the differences of the sense perceptions that arouse individual instinctive impulses. Hence it is that specific uniformity forms only a changeable and by no means essential characteristic of instinctive actions. We may indeed state, that those manifestations of psychic life in animals which are performed by all members of a species according to hereditary laws and without previous experience in a constant and uniform manner are certainly due to instinct and not to intelligence; but we are not allowed to invert the proposition and say that only those manifestations of psychic life in animals are instinctive which are performed by all members of a species according to hereditary laws, and without previous experience in a uniform manner, whilst all the rest are intelligent. Such an inversion would be false logic; for its legitimacy must first be proved. Yet, neither Ziegler nor Romanes nor any modern psychologist has ever demonstrated that only the hereditary and the specifically uniform psychic activities of animals are of an instinctive nature.

Very different, however, is the distinctive character which we have established. It alone holds good, exclusively of any other. For we are not only allowed to say: Those spontaneous actions must be regarded as instinctive in which the agent is not conscious of the purpose of the act, but we have proved that only these actions must be considered as instinctive, whilst the rest are intelligent. Consequently we can express the criterion of instinct and intelligence in the following manner: only those spontaneous actions of animals are to be called intelligent in which conscionsness of the end can be proven, all the rest have to be regarded as in- 
stinctive; for intelligence and consciousness of the end. ${ }^{1}$ are identical realities.

We are not allowed to attribute to animals higher psychic faculties than their actions manifest. This incontestable principle of scientific psychology not only entitles but forces us to regard only those spontaneous actions of animals as intelligent in which consciousness of the end, the power of formal reasoning and of mental abstraction manifest themselves clearly and without a shadow of doubt. All other actions, however, which can be fully explained by the laws of combined sense perceptions must be counted as instinctive, and not as intelligent. There is no possible intermediate member.

The foregoing deductions lead to the only legitimate conclusion which can be maintained in a critical estimate of the psychic life of animals. All those psychic actions of animals are instinctive that spring from their sensitive powers of perception and appetite, and for the adequate explanation of which it is not necessary to appeal to intelligence in its full and proper signification.

Whilst instinctive, in contradistinction to intelligent actions, have the essential characteristic of not emanating from individual deliberation, and consciousness of

1) By consciousness of the end we understand the perception of the final relation, which Thomas of Aquin ("Summ. Theol." I. 2, q. 6, a. 2) appropriately describes: "Perfecta quidem finis cognitio est, quando non solum apprehenditur res, quae est finis, sed eiam cognoscitur ratio finis et proportio eius, quod ordinatur ad finem ipsum." The formal consciousness of the end which we called the essence of intelligence is not identical with adequate consciousness of the end, which comprehends the knowledge of all the ends which can possibly be attached to a certain action; for, in order to have a formal (real) consciousness of the end, it suffices, that any one purpose of the action be perceived and aimed at. 
the end on the part of the agent, their positive essence and their characteristic peculiarity consist, in contradistinction to reflex motions, in being due to impulse and in being determined and directed by the sense knowledge of the animal. Hence, they are caused by the powers of sensitive perception and appetite, and the hereditary disposition of this twofold power is their source and principle.

To the powers of sensitive cognition which guide

- instinctive actions, evidently belong not only the $e x$ terior senses (sensus externi) sight, hearing, taste, smell, and touch, the last of which comprises all the sensations of the skin, but also the interior sense (sensus internus), which perceives the interior states of the agent and feels the pleasant or disagreeable impression which the object of the exterior sense perception makes upon it. Hereto must be added the power of sensitive imagination (phantasia) and a sensile memory (memoria), which reproduces exterior sense perceptions and interior sensile feelings, and combines them one with the other and with new sense perceptions according to the nature and the laws of sensitive imaginations. Because the interior sense, the sensitive imagination and memory represent as pleasant to the agent what is objectively useful for its preservation and that of its kind, and thereby induce it to perform instinctive actions which they guide and regulate, they endow the animal moreover with a sensitive power of appreciation (vis aestimativa.) ${ }^{1} \quad$ Yet, this power of appreciation is not a new reality, it is only

1) We have developed our views on the power of appreciation in animals more fully in the seventh chapter of our book "Der Trichter. wickler" (Rhynchites betulae). 
distinguished in name from the interior sense and from the sensitive powers of imagination and memory, and these, in turn, differ only in name, not in reality from one another: they are different manifestations of the activity of one and the same power of sensitive cognition.

It will interest modern men of science to learn that Thomas of Aquin attributed to animals the powers of sensitive perception and appetite in the very same terms as we have done, and that he divided the interior sense powers in a similar manner. ${ }^{1}$ This fact alone is weighty evidence for the truth, that the cherished and unceasingly repeated reproach of modern scientists against scholastic philosophy of making a machine of the animal, in letting it be exclusively guided by a "blind instinct," is due to a total ignorance of the teachings of that philosophy which it has become fashionable to disparage and discredit.

Consequently the instinctive actions of animals are divided into two head groups: into instinctive actions in the strict, and into instinctive actions in the wider acceptance of the term. As instances of the former class we have to regard those which immediately spring from the inherited dispositions of the powers of sensile cognition and appetite; and as instances of the latter those which indeed proceed from the same inherited dispositions, but through the medium of sense experience. The additional fact that a dog or an ant avails itself in the furtherance of its innate instincts of new combinations of representations which it has acquired from sense experience by the aid of these same in-

1) "Summ. Theol.," I. q. 78, a. 4. The question whether those four faculties differ in reality, or only in name, is of minor importance. 
stinctive dispositions, by no means destroys the instinctive nature of the respective psychic processes, nor does this fact render them "intelligent."

What then is instinct, this mysterious principle of instinctive actions? In its inmost nature, instinct is the hereditary, suitable (adaptive) disposition of the powers of sensitive cognition and appetite in the animal. For it is from this disposition that the sensitive affections (passions), as well as the various exterior activities elicited by the acts of the sensitive appetite, derive their origin; this disposition likewise governs their performance in conformity with their respective laws. It includes not only the specifically peculiar suitableness (adaptiveness) which appears in the activity of artificial instincts, but also the suitableness of the whole range of manifestations of sense life which are more or less common to all animals. This suitable disposition of sensile cognition and appetite explains, on the one hand, the keenness of instinctive perception which is often so marvellous and apparently surpasses human intelligence. For this reason it was styled in scholastic philosophy "ris aestimativa," and "participatio quaedam rationis," while more recent philosophers called it an "analogum rationis" (Wolff), a "power of divination," "clairvoyance," "immediate knowledge." On the other hand it explains the not less striking blindness and narrowness cf this very same instinctive cognition which places it in palpable contrast to intelligence, and clearly manifests that the profound wisdom and premeditation displayed in instinctive activity cannot possibly arise from any reflection and deliberation on the part of the animal. The hereditary adaptive disposition of sensile cognition 
and appetite ${ }^{1}$ which we call instinct, is furthermore specifically appropriate, it differs in the different kinds cf animals. Whatever is naturally suitable for the preservation of a peculiar species, and for the attainment of its special purpose and destination, is made pleasant to that species by its specific disposition of faculties, and thus the irrational being can work out its natural end merely by its sensile cognition and appetite. Man, too, has an instinct; but he has more than instinct, he has also intelligence and volition; these it is that he must follow, if he wishes to attain his end and to lead a life worthy of a human being, and disdains to lower himself to the level of the brute.

This hereditary disposition of sensile cognition and appetite which is in reality the very root and source of instinct can be considered from a psychic or a somatic point of view. It is psychic in as far as it is founded in the nature of the animal soul; but it is somatic in as far

1) We could advance several quotations from scholastic philoso. phers of former ages to show that this view of instinct is not new. (See p. 45, note 1.) George de Rhodes S. J. ("Philos. Peripatet." 1671 lib. 2, disp. 17, q. 6, sect. 6, p. 493) says: "Videtur ergo illum (instinctum) nec esse qualitatem ullam superadditam phantasiae bruti, nec species a Deo indita sed esse ipsum sensum internum bruti, quatenus vim habet apprehendendi aliquid ut conveniens vel disconveniens, et sic illud appetendi aut refugiendi." How the objectively convenient is represented to the animal through its sense-cognition is explained by $\mathrm{P}$. Lossada S. J. ("Cursus Philos. Coll. Salmanticensis" [1735] p. 3, disp. 5 , c. 4 , No. 128) in the following way: "Avis ergo, dum paleam colligit reipsa utilem ad nidificandum, non cognoscit utilitatem ut talem, sed aliquam insensatam rationem delectabilis apprehendit in motibus ipsis aut actionibus colligendi, deferendi et collocandi apposite ad nidi fabri. cam. Quod autem sic apprehendit pro tali tempore, provenit ab instinctu seu determinatione naturae." In other words: It comes from the natural disposition of its sensile cognition and appetite which we call instinct that the objectively convenient is represented in a suitable manner to the animal as subjectively pleasant. 
as it is most essentially connected with, and dependent on the specific condition of the nervous system, of the organs of sense perception, and of the exterior instruments and vegetative organs of the animal body. Its somatic nature, above all, will be more and more elucidated by the progress of modern biology, physiology and anatomy, although the exact nature of instinct will forever remain an enigma. The progress of science will, at any rate, make the invention of "animal intelligence" appear more and more as a Deus ex machina which can never be brought to fit into the essential elements of psychic animal faculties. Scholastic philosophy is, without doubt, correct when it reduces the whole life of the animal to a life of sensitive instinct.

It is a known fact that all scholastic schools answered the question: Are animals guided by their natural instinct (Utrum bruta solo instinctu naturali agantur?) in the affirmative without reserve. ${ }^{1}$ This answer can only be understood in the supposition that' as often as the term "instinct" was used in contradistinction to intelligence, it was not taken merely as a constituent part of the sensitive power of cognition and appetite, but as the adaptive, natural disposition of animal sensation, which constitutes the vital principle that governs the spontaneous actions of the animal. ${ }^{2}$ Otherwise the answer could not have been simply affirmative, without essential restrictions; for apart from and beyond inherited, instinctive knowledge scholastic

1) See also J. J. Urraburru, S. J., "Instit. Philos., Psychol." P. 1 (1894), p. 843 seq.

$\left.{ }^{2}\right)$ In Scholastic terms "the specific principle of animal purposiveness" (apprehensio et expansio specifica). 
philosophy ascribed to the animal a sensile memory (memoria sensitiva), and a power of perfecting inborn instincts through sense experience (expectatio casuum similium); it acknowledged in the animal not only complete hereditary talents for certain activities, but to a certain degree talents and abilities acquired by sense experience and by practice (habitus acquisiti). ${ }^{1}$ Hence in stating that the animal was guided merely by its natural instinct, scholasticism apparently used the term instinct in our broader meaning.

The previous discussions make it evident that instinctive life in reality coincides with sensitive, whilst intelligence is identical with mental life. Instinct signifies the peculiarity of the powers of sensitive cognition and appetite, whilst intelligence expresses the peculiarity of the mental power of cognition and stands in inseparable relation to free volition, the corresponding mental power of the spiritual appetite. Consequently the question, whether animals possess intelligence as well as instinct, is, in reality, identical with the other: Do animals possess a mental, besides a sensitive, life?

In modern animal psychology the term "mental faculties" has been grossly misapplied. The "tendency of materialism which is to obliterate as much as possible the differences between the animal psyche and the human mind has led to the denial of essential differences between sensile and spiritual faculties. It ignores the rules of critical analysis. Moreover the modern theory of evolution which demands the "natural" development of man from the animal as a "postulate of science," has

2) See S. Thomas, "Summa theol.," 1, 2, q. 50, a. 3 ad 2. 
contributed not a little to this confusion of ideas. Manifestations of spiritual faculties were understood, in the scientific psychology of former times, to include those psychic actions which transcend the sphere of sensitive cognition and appetite: namely, intellect and free will. The pseudo-psychology, however, of such men as Scheitlin, Brehm, and other "modern animal psychologists," and, among them even Charles Darwin, classifies as "mental activity" every act of the sensile memory, of the sensile imagination, and every manifestation of the sensitive affections. Thus it comes to pass that popular psychology speaks of an "animal mind" in the same way as of the "human mind." It forgets that mind exclusively signifies a principle of mental life, a principle of intelligence and of liberty. Let us restore their original meaning to these terms. It has been corrupted by the pseudo-psychology of our days.

How even zoologists who are skilful observers, but unable to keep free from the pernicious influence of popular psychology, have been liable to fatal errors of judgment in their psychological deductions, is aptly illustrated by the following example taken from Haacke's "Creation of Man and His Ideals" (German, Yena, I895.) In order to prove that pursuits and struggles for "ideals of truth" and for knowledge of general truths were to be found even in the animal kingdom, Haacke relates the following interesting observation (p. 388):

"The Makis, a kind of animal belonging to the Prosimia, are very fond of having tobacco-smoke blown on to their faces. The effect of the smoke upon their olfactory organs apparently calls forth an agreeable itching of the skin; for, as soon as it is blown towards their 
nostrils, they begin to scratch themselves all over the body. Their enjoyment of the smoke is apparent, for they do not try to avoid it, but on the contrary direct their nostrils towards the person who emits the smoke of his cigar. When they are thus once accustomed to enjoy the pleasure of tobacco at regular intervals, it is not necessary to approach them with a burning cigar or pipe, but the pretence of blowing at them is sufficient to make them stretch forth their faces. And, finally, the mere act of blowing at them is enough to make them scratch themselves. Consequently, they drew the conclusion from the experience of the past, that anybody who pretends to blow smoke from his mouth, does so in reality. Of course, this was a wrong generalization, but such mistakes are well known to happen even to human beings. It is enough that so lowly organized brutes as Prosimia can make generalizations."

From these observations Haacke wishes in full carnest to prove that "mental processes of generalization" are to be met with in animal life. Yet, scientific animal psychology is unable to accept such phenomena as a proof of mental generalizations. They are nothing more than combinations of a sensitive imagination. They are totally different from mental powers of abstraction, and even furnish a conclusive proof of the 11tter impotence of animals to make "mental generalizations" at all. By mistaking combinations of sensitive representations (sense images) for general concepts, and by erroneously identifying the two, Haacke himself made a wrong generalization; an occurrence which is indeed not very uncommon to modern animal psychologists. Let us, accordingly, submit the psychic processes 
which Haacke observed in the Makis, and classifies as thental generalizations, to a critical analysis.

On account of the pleasant irritation of the nerves produced by the tobacco-smoke which 'Mr. Haacke repeatedly blew at them, the Makis regularly felt the necessity of scratching themselves. The constant connection of the olfactory perception of the smoke with a feeling of itching and the consequent impulse to scratch themselves, was apparently due to instinct, to the inherited disposition of their sensitive cognition and apFetite. But the olfactory perception of the smoke was not less regularly preceded by the sight perception of some one approaching and emitting smoke towards their nostrils, and by the subsequent perception of the sense of feeling. In consequence of its frequent repetition this double impression of the sight and of feeling became so intimately connected with the subsequent processes that all of them finally formed one constant process of association, which spontaneously led from the first link in the chain of psychic activity to the last, even when several intermediate links were missing. The interior sensile imagination supplied the missing links which were originally an experience of the outer senses, and replaced these exterior perceptions by images of the sensitive memory. This is the only natural explanation of the fact that the Makis at last stretched forth their heads and prepared for the subsequent operation of scratching, when persons only pretended to blow at them, and that they were induced to scratch themselves merely by a perception of feeling, even without the olfactory perception of the smoke.

This whole psychic process consists solely of sense 
perceptions, feelings, sense images, of images of the sensile memory and of acts of the sensile appetite, and evidently belongs to the sphere of sensitive instinct. Such instinctive activities of animals are due to complex sense representations and are, as they always were, called in scholastic philosophy "expectatio casuum similium." It would hardly have befallen a savant of antiquity or of the Middle Ages to ascribe such psychic processes in animals to a power of mental abstraction. This feat was reserved to modern animal psychology which looks down with contempt upon the "old school philosophy," and imagines it can do better without it. Well, Haacke's "mentally generalizing" Makis prove what absurd achievements are the result. Through an erroneous and arbitrary method of interpretation he first endowed his Makis with a mental power of abstraction, then he dissolved their whole process of sensitive association into a series of logical conclusions and finally maintained that it was the animal which had thus concluded, whilst apparently it was Mr. Haacke himself.

Had the good Makis been able to "think" at all, they would have been clever enough to scratch themselves only when a person approached with a burning pipe or cigar and then blew the smoke at them. The intelligent Makis could not have failed to perceive the relation between cause and effect, and ought to have made the following conclusion: Tobacco-smoke is never in evidence, unless a burning pipe or cigar is in sight; now it is only tobacco-smoke that produces such a pleasant sensation of tickling upon our epidermis; therefore we shall not scratch ourselves when Mr. Haacke approaches without a pipe or cigar, and only blows air on 
to our faces. Thus the very facts, from which a superficial observer infers a mental power of abstraction in animals, not only turn out to be pseudo-arguments in favor of animal intelligence, but can be turned into effective arguments against it.

In the same manner as Haacke's "mentally generalizing" Makis, numerous other instances which have been advanced by modern animal psychologists such as Darwin, Brehm, Perty, Romanes, and are supposed to furnish convincing evidence of the existence of intelligence and spiritual faculties in animals, could be subjected to a critical analysis. We would constantly meet with the same result: If combinations of sense representations are deliberately taken for "mental generalizations," then, of course, it is very easy to talk of the "intelligence" and "spiritual faculties" of animals. But these terms are empty words. Any reasoning naturalist will readily concede that we have not built our comparative psychological discussion upon the phrases of pseudo-psychology, but upon an unprejudiced analysis of the relative psychological concepts. And upon this foundation we shall now have to examine: Do animals possess intelligence as well as instinct? Do they possess beyond and above their sensitive, also spiritual faculties? 


\section{CHAPTER IV.}

EXAMINATION OF SOME OBJECTIONS.

DARTISANS of modern animal psychology will perhaps raise a "vehement opposition" to our distinction of instinct and intelligence. This has previously been done by some critics of our former publications." ${ }^{1}$ However, a vehement opposition makes impression only by the weight of its arguments. And this is but just and fair, for objections do not deserve consideration further than they are supported by solid reasons. These objections are prompted not so much by logical difficulties as by a certain indefinite feeling which has gradually developed under the influence of popular psychology and become nowadays the fashionable standard of criticism. A clear analysis of psychological concepts is avoided, because the possible consequences are dreaded. Apprehension evidently exists that the close approximation of man and animal, both of whom are generally regarded as essentially of the same nature, might appear to be an illusion ; and, perhaps, it is anticipated that between man and brute a wide and momentous gulf might be revealed which demands of man a far higher degree of morality than is taught in "Brehm"s Thierleben." For this reason some desire to banish all critically tenable distinctions between instinct and in-

1) For instance in the "Naturwissenschaftlichen Rundschau," 7 (1892), No. 12, in the review of our book, "Die zusammengesetzten Nester und gemischten Kolonien der Ameisen." 
telligence from the territory of animal psychology and do away with them as so many "artificial barriers." Eut they forget that in calling only those abilities of animals "instinctive" which are transmissible as such, and designating as "intelligent" those which have been acquired or perfected by sense experience, modern animal psychology erects a new barrier between instinct and intelligence. This is a purely artificial barrier, and we had to reject it. It was erected upon false psychological foundations. But our distinction between instinct and intelligence rests on firmer ground. It is ratural, not artificial, because it really coincides with the barrier that actually exists between the two psychic faculties of man and animal. An "opposition" that is merely "vehement" in clamor, but not in argument, can effect nothing against it.

Nor does the statement refute us, that according to our theory animals are exclusively guided by a "blind instinct." In the preceding chapter we have set forth what we understand and must understand by instinct, when we penetrate deeper into the essence and nature of instinctive processes. Instinct is the hereditary adaptive disposition of the power of sensile cognition and appetite in the animal. It is blind only in as far as instinctive actions are not governed by rational deliberation; it is not blind in as far as those actions are determined and influenced by the exterior and interior sense perceptions of the animal. Those who try to impugn our theory of instinct by attacking a "blind instinct" fight against windmills.

But, so they say, since the epoch-making work of 
Herm. Reimarus ${ }^{1}$, it has become a settled truth that animals possess intelligence as well as instinct. Let us examine this dazzling objection.

In the first edition of his "Lectures on Human and Animal Psychology" (Leipzig, I863, Lecture 29, P. $490^{2}$ ), William Wundt writes literally as follows: "The founder of modern animal psychology is H. S. Reimarus. We owe to him the establishment of the modern concept of "instinct." In his opinion, all actions of the animal are essentially determined; he ascribes to animals feelings, obscure representations, memory and imagination, but denies them intelligence and reason. This view of the psychic life of animals has, in the main, been dominating till now, and has especially gained ground in the minds of common people, although a great number of writers were against Reimarus' opinions. In their study of the psychic life of animals they started from the principle: explain as much as possible from analogy to the psychic life of man." In the second edition, which was issued in 1892 , this whole passage is missing; and for good reasons. Wundt had learned meanwhile that Reimarus was not the originator, but, on the contrary, a decided opponent of the so-called

1) "Allegemeine Betrachtungen ueber die Triebe der Thiere, hauptsaechlich ueber ihre Kunsttriebe," 3. Ausg., Hamburg, 1773. Since the issue of the first edition of this work a detailed essay on the "Animal Psychology" of Reimarus has been published by Dr. Ch. Chr. Scherer ("Das Thier in der Philosophle des H. S. Reimarus," Wuerzburg, 1898. See likewise "Stimmen aus Maria-Liach," 56, 1899, $91 \mathrm{ff}$.). It entirely agrees with our views on the relation of the Hamburg Philosopher to modern Animal Psychology.

$\left.{ }^{2}\right)$ The second edition of the German has been translated into English by J. E. Crighton and E. B. Titchener, New York; MacMillan \& Co. (London: Swan Sonnenschein \& Co.), 1896. 
modern animal psychology. It is by no means the correct and critical opinion of Reimarus on the difference between instinct and intelligence, and on the want of 1 cason in animals, that has "gained ground in the minds of common people," nor has his opinion become "dominating" in modern animal psychology; but the very contrary has taken place. The very writers alluded to by Wundt towards the end of the above passage, those I say who arbitrarily humanized the animal ${ }^{1}$ and accredited it with intelligence and reason, are the true originators of modern animal psychology, which Wundt himself formerly professed, while he now condemns it without mercy as the "psychology of the crowd."

As Wundt has candidly acknowledged the error of his former opinion on the relation of Reimarus to modern animal psychology, it may be hoped that those who on his authority still declare Reimarus to have been "its originator," will arrive at a truer conviction, and will likewise acknowledge their mistake.

Another prominent representative of modern animal psychology, Maximilian Perty, ${ }^{2}$ expresses himself as follows on the work of Reimarus:

"An as yet unsurpassed writer on the psychic life of animals is the elder Reimarus, who has the merit of having clearly understood the difference between instinct and intelligence. He regards as impulse (Trieb) 'any natural efforts that tend to the performance of

1) To these belonged at the time of Reimarus, besides Condillac and Leroy, especially Erasmus Darwin, the grandfather of Charles Darwin. See the I. Vol. of his "Zoonomia." Cf. also Kirby and Spence, Introduct. to Entomology 2 (5th edition), $463 \mathrm{ff}$.

2) "Ueber das Seelenleben der Thiere" (2, Aufl.), p. 8 ff. 
certain actions,' and he distinguishes mechanical, ${ }^{1}$ imaginative and spontaneous impulses. Imaginative impulses extend partly to present, partly to past facts; spontaneous impulses spring one and all from pleasure or displeasure, and they are either natural, or derivative impulses. He subdivides natural, spontaneous impulses into the general impulse of self-love, and into particular impulses, the latter of which are partly emotional, partly artificial impulses. . . According to Reimarus the powers of soul and body in animals are more accurately defined as regards their objects as well as the nature of their agency, than they are in man. There is nothing in the outward behavior of animals that indicates more than indistinct and obscure apprehension, or forces us to accredit them with proper concepts, judgments and deductions; there is much, however, that manifests the very contrary ; animals, therefore, do not think."

Even Perty, who, as a modern psychologist, entertains the conviction that animals do "think," is forced to confess that Reimarus has nothing to do with that modern animal psychology according to which animals possess an intelligence which is essentially identical with human reason, and differs only in degree. For Reimarus was not so superficial as to regard all actions of the animal which were due to sense experience as intelligent. Whoever claims Reimarus for this schoo! of psychology has evidently not read his works at all,

1) The "mechanical impulses" of Reimarus respond to what we call reflex-mechanisms. The "imaginative impulses" comprise the acts of sensile cognition. The "spontaneous impulses" are the instinctive impulses which spring from the sensile appetite and which he understands in the same way as we do. 
and especially not the twenty-seventh and the follow. ing paragraphs of chapter the second, nor paragraphs II6, II9, I22, I23 of chapter the ninth. In these chapters Reimarus shows that there is not only a difference in degree, but also in essence between sensitive cognition and intelligence, and that animals are endowed with instinct, but not with intellect. We earnestly recommend the study of these chapters to all those modern animal psychologists who acknowledge the work of Reimarus to be an achievement as yet unsurpassed in the line of animal psychology.

Reimarus was not the first to understand and deduce the difference between instinct and intelligence. On carefully studying his "Allgemeine Betrachtungen ueber die Triebe der Thiere," and on comparing his opinions with Aristotelian views of animal psychology, as they are contained in the Summa Theologica and other works of St. Thomas Aquinas which bear on the psychic life of animals, the conviction is forced upon us that Reimarus plainly developed to their last consequences the vieres of Aristotle and of mediaeval scholasticism on animal psychology. With Thomas of Aquin Reimarus ${ }^{1}$ ascribes to animals, at least to the higher genera, ${ }^{2}$ besides the outer senses, an inner sense, a sensile memory and the sensile powers of imagination and estimation, with the sole difference that Reimarus formulates the latter powers somewhat differently, and refuses to recognize the sensile memory of animals as a memory in the proper sense of the

1) S. Thom., "Summ. theol., 1, q. 78, a. 4; 1, 2, q. 4, a. 2 ad 2, and in different other places-Reimarus Nos. 11-18.

2) See in lib. 12 Metaph. I. 1, lect. 1. 
word. ${ }^{1}$ Furthermore, as Thomas of Aquin ascribes to animals sensuous affections (passiones) which are similar to those of man, so does Reimarus. ${ }^{2}$ With Thomas of Aquin he $e^{3}$ lays particular stress on the hereditary, artificial abilities of animals, for the sake of explaining their psychic life, and ${ }^{4}$ attributes to animals only sensile cognition and sensile appetite, but denies intelligence and free-will. Both of them ${ }^{5}$ insist, on the other hand, upon a certain analogy which exists in many instances between the instinctive life of animals and the intelligent and free activity of man (participatio aliqua rationis, libertatis). With Thomas of Aquin Reimarus ${ }^{6}$ describes instinctive impulses as definite natural aptitudes (determinationes naturae),

1) Cf. Reimarus Nos. 14, 17, 18, 178. The reason is, because $R$. believes that memory essentially includes a power of reminiscence which recognizes the past as past; a power which naturally presupposes a comparison of representations and a judgment on their reciprocal relations. Yet, he distinctly declares (No. 178), his readiness to ascribe to animals a memoria sensitiva, if it is understood as a mere reproduction of antecedent representations and their combination with present apprehensions. But Aristotle and Thomas of Aquin had long ago drawn a clear distinction between memoria and reminiscentia, and attributed only the former, but denied the latter to animals. Therefore the opinion of Reimarus in reality coincides with their view.

2) S. Thos., "Summ. theol.," 1, 2, q. 31, a. 3 and a. 6; q. 35, a. 6; q. 40 , a. 3 ; q. 41 , a. 1 ad 3 ; q. 46 , a. 4 ; 3 , dist. 26 . q. 1, a. 1.-Reimarus, Nos. $43,44$.

3) S. Thom., "Summ. theol.," 1, 2, q. 13, a. 2 ad 3.-Reimarus, Nos. 85-143.

4) S. Thom., q. 24 "De verit.," a. 2;-Reim. 27.31; 119.123.

5) S. Thom., q. 24 and 25 , "De verit." a. 2; 3, dist. 27, q. 1, a. 2; "Summ. theol.," 1, 2, q. 24, a. 4 ad 3; in lib. 12 Metaph. I. 1, lect. 1 (prudentia de regim. pricip. I. 1, c. 1 (naturalis industria).-Reimarus, No. 26 and other places.

$\left.{ }^{6}\right)$ S. Thom., 2, dist. 25, q. 1 , a. 1 ad 7 ; q. 18 De verit., a. 7 ad 7 . -Reimarus, Nos. 140-143. 
and $^{1}$ acknowledges and maintains the existence of final causes in the workings of nature. And finally he agrees with Thomas of Aquin ${ }^{2}$ in tracing back the stitable instinctive dispositions of animals to the power and wisdom of a personal Creator who deposited them in the nature of the animal. In discussing these questions of animal psychology Reimarus naturally enters far more into particulars, because he treats this subject in a special work, whereas Thomas of Aquin could only touch them incidentally in other productions of his eminently speculative genius.

In his "Allgemeine Betrachtungen ueber die Triebe der Thiere," a book highly appreciated by modern animal psychologists, Reimarus has logically evolved the animal psychology of Mediaeval Scholasticism. Indeed, we may unhesitatingly assert that Reimarus attained such excellent results in animal psychology, because he followed out the scientific psychology of Aristotelian philosophy. The philosophy of Decartes which swerved from that of Aristotle, made a mere machine of the animal. Modern animal psychology, on the other hand, went to the opposite extreme by arbitrarily humanizing the brute. Scornfully despising the "old school systems of the scholastics," and trying to tread its own unbeaten path, it has gone astray, so much so, that it is obliged to seek aid from the unscientific notions of "popular psychology" and to fight shy of any and every analysis of psychological concepts.

Moreover these remarks will serve as a refutation

1) S. Thom., "Summ. theol.," 1, 2, q. 1, a. 2.-Reimarus, Nos. $150,151$. No. 1.

2) S. Thom., 1, 2, q. 46 , a. 4 ad 2 ; q. 13 , a. 2 ad 3, etc.-Reimarus 
of another objection ${ }^{1}$ which has been advanced against our psychological views of animal life, namely that "the antiquated views of scholastic philosophy" did not keep pace with the advance of modern biology. We need not enter upon this difficulty. It has been brushed aside. True, our age is far superior to the middle ages in the observation of nature and in detail of science. A man like Thomas of Aquin would be the first to candidly acknowledge and duly appreciate the results of modern observation. Yet, on the other hand, it must be granted that modern science can still learn from the great thinkers of antiquity and of the middle ages in the line of philosophical explanations of animal life.

We now come to a series of objections which another critic, Dr. Aug. Forel, Professor at the University of Zuerich, has raised against our psychological views of animal life. ${ }^{2} \quad$ Forel is Professor of Psychiatry, and a prominent expert in questions of ant life and of the human brain. He belongs to the school which regards psychology as a mere question of nerve physiology, because it acknowledges no other realities than the functions of brain-cells. According to Forel's "monistic" views, the whole world is the product of the nerve activity of our brain, below which lies an "im-

1) Cf. Karl Mueller, in the periodical "Natur," 25th Oct., 1884 (p. $512 \mathrm{ff}$.), in the discussion of our book, "Der Trichterwickler," (Rhyn. chites betulae), eine wissenschaftliche Studie ueber den Thierinstinct.

2) In a lecture on "Brain and Soul," in the 66th Meeting of Naturalists at Vienna, 26th Sept., 1894 (p. 28 ff.). See also our reply in "Biologisches Centralblatt," 15 (1895), 644. Forel has recently de. veloped his views on Comparative Psychology in a work published in "L'Année psychologique," 1896: "Un apercu de Psychologie comparêe." But as they are essentially the same as those contained in the above quoted lecture, we need not enter upon his later publication. 
penetrable metaphysical substratum," the only "thing as such." Therefore, in his opinion, "the everlasting dualistic strife between materialists and spiritualists is absolutely without object." "Everything is soul, just as everything is force and matter. Not one of these inseparable notions is more fundamental, or higher than the rest, because they are identical."1

If all notions are really identical, then, indeed, there is no possibility of critical distinction between them. If we and the whole outer world are only a product of the nerve activity of our brain cells, the reality of which we can no longer account for, we have arrived at absolute skepticism, a point at which all scientific controversy has an end. Thus, while this "monistic consideration of the world" affords undoubtedly the best protection to modern psychology, because it serves as a safeguard from any attack that is based upon a critical analysis of notions, it necessarily involves its own destruction, because it abandons, at least from a logical point of view, all objectively scientific knowledge of the phenomena of nature.

After these preliminary remarks let us enter upon Forel's defence of animal intelligence. He attaches great importance to the circumstance that not only "automatisms of instincts," but what he calls "plastic neurozymic activities" are a factor in animal life. Forel avows that the human soul is more plastic than the animal soul, but he also maintains that the latter is not without "plasticity." The souls of the higher monkeys are extremely plastic, capable of development and training, and endowed with few instincts. Very plastic are

1) See e. g., p. 27 and 28. 
also the souls of elephants, dogs, seals, and dolphins. And even in lower animals, whether they be endowed with specially complicated instincts or not, a slight degree of plasticity can be recognized on closer inspection. Lubbock tamed a wasp, and I succeeded in taming a Dytiscus. Even in ant life I have identified sevcral cases of plastic neurozymic action. Still, the difference between the plasticity of the soul in an insect and an Orang-Utang is immensely wider than that which intervenes between the soul of an Orang-Utang and that of man, especially of individuals of an inferior race. No one can deny this whose vision is not obscured by prejudice."

"In Natur und Offenbarung (I89I) my worthy friend and opponent in metaphysical questions, the Jesuit Professor Eric Wasmann tries to oppose these views in his Psychology of Mixed Ant Societies. ${ }^{1}$ Yet his sagacious ingenuity failed him for once. It is certainly an easy task to ridicule the superficial anthropomorphic interpretations of the animal soul given by such men as Brehm, Buechner and others, and to refute them victoriously. But, in order to deny ant intelligence, Wasmann attributes to these insects ratiocinations similar to the human, which, of course, are far beyond them."

What Forel, as a nerve physiologist, calls by the new name of "plastic neurozymic activities," exactly coincides with what scientific psychology knew long ago as the perfecting of innate instincts by the sense

1) This is the title of the second-last chapter of our book: "Die zusammengesetzten Nester und gemischten Kolonien der Ameisen," Muenster, 1891. 
experience of the individual. It is, therefore, identical with the erroneously called "intelligence" of modern psychology. Such plastic neurozymic activities undoubtedly underlie all intelligent actions, but they occur also in innumerable activities of instinctive sentiency. Not a single act of the sensile memory is conceivable without "plastic neurozymic activity." Therefore the substitution of the novel term "plastic neurozymic activity" is no proof whatsoever for animal intelligence. Moreover the point at issue in our discussion of the difference between instinct and intelligence is by no means the question, whether higher animals are able to perfect their innate instincts by individual sense experience in a greater degree than lower animals-a fact which we never disputed-but, whether every suitable action of the animal that is due to sense experience must be accepted as an intelligent action, or not. This is the question which must be answered. Forel, however, evades the solution by stating that only prejudice and blindness could deny the numerous plastic neurozymic activities of higher animals. We cannot accept this statement as a final answer, but must in turn, demand of our learned friend Professor Forel a closer consideration of the analysis of psychological concepts.

But what about the objection that we attribute to ants "ratiocinations similar to the human," which are, of course, far beyond them? The answer flows spontaneously from our previous psychological analysis. Fore $^{1}$ belongs to that class of moderate modern animal psychologists who, on the one hand, join us in pro-

1) Beside the previous quotation see also his little essay, "Ameise und Mensch, oder Automatismus und Vernunft." Zuerich, 1889. 
testing against the humanization of the animal and still humanize it themselves by allotting to it a power of formal reasoning different indeed from human reason in degree, but not in kind. Now we have proved in detail (in Chapters 2 and 3), that any and every power of formal reasoning necessarily implies ratiocinations similar to the human." Therefore, the avowal that animals are unable to make ratiocinations similar to the human is equivalent to the statement that they do not possess a power of formal reasoning-that they have no intelligence. Hence we must persist in our demand: give the terms their proper meaning, and do not trifle with the term "intelligence" by substituting at random contrary significations. Such a procedure renders all scientific animal psychology impossible, and paves the way for an indiscriminate humanization of the brute.

A passage of another work of Prof. Forel on the sense perceptions of insects, a work valuable, indeed, for psychology and biology alike, ${ }^{1}$ proves the truth of this assertion. From the fact that ants and other insects are able to connect different sense perceptions in a suitable manner and not unfrequently make use of former sense experiences on subsequent occasions-a fact for which we shall furnish copious evidence from personal observation in our "Vergleichende Studien lieber das Seelenleben der Ameisen."2 Forel draws the following conclusion: "Donc les insectes raisomment, et les plus intelligents d'entre eux, les hyménoptères sociaux, surtout les guêpes et les fourmis, raisonnent

1) "Expériences et remarques critiques sur les sensations des insectes." 2d part (Recueil Zool. Suisse, 31 Mars, 1887), p. 237.

$\left.{ }^{2}\right)$ An English translation of which will soon follow. 
même beaucoup plus qu'on n'est tenté de croire, quand on observe le mécanisme régulièrement reproduit de leurs instincts." Now this fact which induces Prof. Forel to state that these insects "reason," implies nothing beyond the association of sense representations, which follows the hereditary laws of instinctive sentiency. Forel does not prove that ants really make formal conclusions whilst these associations of representations are going on. But it was precisely this that he had to prove. For the so-called material conclusions, or such processes of cognition as we can resolve into formal syllogisms, occur even in those activities of animals that are directly due to the hereditary disposition of animal instinct. Nor does Prof. Forel deny that they are merely instinctive.

Consequently, in stating that "les insectes raisonrent," Forel either ascribes to animals "ratiocinations similar to the human," or he uses the term "raisonner" in a wrong sense. Moreover it is untenable to construct, as Forel does both here and elsewhere, an artificial contrast between the "mechanism" or the "automatism" of instinct and the manifestations of this mechanism which have been brought about by "plastic neurozymic activities" or, in other words, by the sense experience of the animal. They belong to one and the same range of sensile perception. There is no real contrast between them, but only between instinct and intelligence in the proper sense of the word. Nor can the anatomy of the brain ever demonstrate the true nature of intelligence; it can be gathered only from a clear analysis of psychological concepts.

Our worthy friend, Prof. Forel, continues in his 
criticism:1 "It is, furthermore, asserted (by Wasmann) that cultural development is a condition of intelligence. Now, the rate of cultural development in man is rapidly progressive in the higher races, whilst it is enormously slow in the lower. Higher animals can be tamed and are docile. This fact indicates a germ of capability of cultural development. Higher mammals most decidedly profit by past experiences, and even utilize them to some extent in teaching their young. The gulf between this stage and the lowest germs of cultural development in man is not so very wide. Yet, in order to throw more light on this question, one should not, as Wasmann did, compare ants immediately with man, but carefully follow up the scale of animal life and proportion one's demands on the capacities of the animal soul to the development of its brain. Besides, an intimate dealing with animals soon leads to the recognition of definite individual characters amongst them, ${ }^{2}$ such as those which Delboeuf observed among his tame lizards and described so eloquently. He pointed them out to me, so that I am convinced of the fact. Embryos, so to say, of talent, geniuses, heroes of will-power as of the contrary are found among individuals of one and the same species. Who is not acquainted with aristocratic and proletarian dogs and horses? Of course, here as elsewhere, one

1) “Gehirn und Seele," p. 28.

2) "I was often able to observe indications of individual differences of character even among ants of the same colony; some were more irritable, others more active, others more thievish; there were more cowardly and more bold, more vivacious and more phlegmatic individuals. I have likewise noted changes in behavior which were due to past experience and repeated observations." 
must be careful to avoid anthropomorphic exaggerations."

In order to do justice to this mountain of objections, let us examine them carefully one by one.

First of all, the cultural development of man and the taming of higher animals are said to be different in degree and not in kind. Now, we have nowhere stated, as Forel implies, that cultural development is a condition of intelligence; on the contrary, we have always maintained that intelligence was a necessary condition for cultural development, and that the latter was a necessary result, and consequently a good criterion of intelligence. We willingly admit that the rate of cultural development is different with different nations and races; but we do not admit that the docility of animals represents even a lower degree or a "germ" of the cultural development of man. The one is essentially different from the other, and docility can never become cultural development. This is evident from the following considerations. It is easier to tame and train higher than lower animals because their powers of outer and inner sense perception, their sense organs and their brains are relatively more similar to the human. Owing to this similarity, human intelligence trains the animal by combinations of certain signs to perform a specified feat. The trainer imprints, so to say, mechanically his own processes of thought into the sensile memory of the animal. But the latter never learns to think, it never learns of itself and apart from outer help to compare given representations one with the other, or to draw new conclusions from their reciprocal relations. Whoever has devoted his time to 
the training of animals, will be able to endorse this assertion. This fact which is so important for a critical estimate of the psychic life of higher animals, was perhaps illustrated in the most interesting manner by the lessons given by Lubbock $^{1}$ to his clever poodle Van. Even some lower animals can be tamed to a certain degree, although it is far more difficult for our intelligence to gain a directing influence upon their sense representations, because they differ from us so widely in size, in their sense organs and in their nervous system. Nevertheless, a hornet was tamed by P. W. Mueller, and I succeeded in taming an ant of the wild and warlike species Formica rufibarbis. Further information on this experiment is to be had in my "Vergleichende Studien ueber das Seelenleben der Ameisen und der hoeheren Thiere.",

While, therefore, the taming of animals is due to the intelligence of man, who impresses the respective combinations of representations upon and into the sensitive knowledge of the animal, the cultural development even of the lowest races, always commences with the individual understanding of the people, that undergoes the process of mental development. The instruction which it receives from higher cultivated men, only serves, as it were, as a stimulating force. Prof. Forel happened to overlook this essential difference between the docility of animals and the cultural development of man. Otherwise he could never have asserted that the

1) Lubbock, "On the Senses, Instincts and Intelligence of An. imals" (London, 1889), Chapt. 14.

$\left.{ }^{2}\right)$ See also "Die psychischen Faehigkeiten der Ameisen" (Zoologica, Heft 26, Stuttgart, 1899), p. $82 \mathrm{ff}$. 
docility of higher animals betrayed the "germ" of cultural development.

We willingly admit that higher animals accumulate experience which they subsequently utilize. Indeed, not only the higher, but all animals are more or less able to gather and to profit by sensitive experience, because they all possess a more or less perfect sensile memory. But we have proven, that these applications of sensitive experience cannot be regarded as acts of "intelligence."

It can also be maintained to some extent that higher animals "teach" their young. They perform certain actions in presence of their offspring, and thus unintentionally show them how to do the same; whilst under the impulse of their instinct of imitation the young do what the parent animal did and thus they "learn." But Forel nowhere proves that in performing such suitable actions the parent animal intended to instruct its offspring, as human parents do when they instruct their children. Indeed, the interpretation of the stimulus given to the imitative instincts of the young by the example of their parents as an act of instruction which is equivalent to teaching among human beings, is undoubtedly an arbitrary humanization of the animal. But then Forel's assertion that "the gulf between this stage and the lowest germs of cultural development in man is not so very wide" is absolutely untenable. By the way, the pseudo-psychology of Brehm, Buechner, etc., which is so sharply condemned by Prof. Forel, has dealt with this so-called "instruction and teaching" among animals in such an arbitrary manner, and has been influenced in doing so by such hostile tendencies 
that careful scientists should trust such reports only with very great reserve. ${ }^{1}$

Furthermore, Forel does not find it appropriate on our part, to compare ants "immediately with man," in our critical examination of "ant-intelligence." Yet, in our book on compound nests and mixed colonies of ants, the question was, whether the so-called intelligence of ants was or was not essentially of the same kind as that of man. Consequently it appears necessary to compare ants with man, and not with spiders, birds, or dogs. Moreover, we did not fail to add now and then in our critical discussion on ant-intelligence some remarks that are equally applicable to all animals; whilst in the present work, as well as in the "Comparative Studies" we have done so in still fuller measure.

We also readily grant that animals, especially higher mammals, have as Forel remarks, "individual characteristics," and in our "Comparative Studies" we hope to record many convincing examples from our own observation of the individual differences that appear in the characters of ants of various species, e. g., the ravenous Red Ant (Formica sanguinea). But, pray, what proof do these examples furnish of "intelligence" and of "spiritual faculties" in animals? Why, even the innate dispositions of the powers of sensile perception and appetite have their individual differences and variations which are essentially connected with the differences of bodily organization; in other words, with "individual variability." Moreover, these innate psychic differences are liable to increase to a remarkable extent,

1) See Altum, "Der Vogel und sein Leben" (6. Aufl.), p. 208 ff. 
owing to the various sense experiences of single individuals. These two circumstances unquestionably afford a more scientific and simpler explanation of the so-called individual characters of dogs, horses, lizards, and ants, than is offered by ascribing differences of character to them similar to those which exist in human beings. However, Forel does not accept this shift, as he expressly deciares. Anyhow, he can hardly avoid admitting that his appeal to "embryos of talents, of genituses of will-power and their contrary," in individuals of several species of animals, has proved nothing against our views of the psychic faculties of animals.

Another critic $^{1}$ expresses his satisfaction that we have restored to the term "instinct" its due rights and ciaims. Still, he thinks that at least a wee dose of true and genuine intelligence should be conceded to ants in order to facilitate the explanation of various facts. $\mathrm{He}$ attempts the following proof :

"The manifold phenomena of ant life apparently furnish examples of some power of thought. A few years ago I observed in the Gruenewald, near Berlin, a colony of the large hill ant (Formica rufa) in full activity. The nest was situated on a path in the wood. The ants moved rapidly to and fro on a track trodden out by themselves. It led for several yards from the nest into the wood to a fir tree. Returning to their nests, the ants dragged all sorts of provisions-flies, small larvæ, pieces of plants, etc. Suddenly I observed two ants returning from the wood and dragging a

1) In a discussion of our book: "Die zusammengesetzten Nester und gemischten Kolonien der Ameisen," in the "Naturwissenschaftliche Rundschrift”'(Berlin), 7, No. 25, vom 16 Juni, 1892. 
spider on one side of the track. They approached the nest to a distance of about half a yard, when they suddenly changed the direction and moved away from the nest. This seemed to suit the wishes only of one ant, for the other tried in vain to pull the spider in the opposite direction. Finally they reached a considerable distance from the colony when the second ant let go and made off, whilst the first continued to move farther away with her booty. This singular procedure aroused my suspicion, when 10! suddenly three ants came rushing to the rescue, assailed their selfish ${ }^{1}$ companion and tried to drag the dead spider in the direction of the nest. Thereupon the thievish ant redoubled her efforts and, for a moment, succeeded in offering effective resistance. But at last the three police ants got the better of her. Having abandoned her prey, the thief remained alone and ran aimlessly to and fro, whereas the others were in high spirits on approaching the nest with their booty. Two of the three ants that were so concerned for the welfare of the community soon committed the fat morsel to the care of the third, which dragged it to the nest, where it was speedily received by the crowd. They pulled the dead spider to one of the openings that led into the inner apartments of the large nest. What then followed, escaped the notice of the interested observer.

"Now, if my interpretation be right, it follows that the ant which was suspected of fraudulent practises, wished, humanly speaking, to set aside some food for her own use without regard for the general interests of

1) Italics ours, 
the colony and the common welfare; it follows further, that her companion whose weakness prevented her from frustrating this selfish design, applied to the police, and that these officers of the law were soon on the spot, understood the state of affairs and thwarted the thief's plan. The companion which ran to the nest was probably one of the three, and perhaps it was she who finally conveyed the prey to her kinsfolk, when the protection of the police ants seemed no longer necessary. Instinct alone does not offer a sufficient explanation of these facts, and that is why I have related them."

Is it possible to take exception to this attractive proof of intelligence in ants? Let us see, whether the case is exactly as it is represented by our critic in the "Naturwissenschaftliche Wochenschrift."

According to his "interpretation," a member of the colony intended to set aside part of the prey for a private larder, because her daintiness surpassed her affection for her companions. What would psychologically follow from this fact? Nothing more than a proof that ants possess the power of sensile perception and appetite. In the present case, one sensile perception prevailed over another. But all further conclusions are unwarranted. What right, then, has our critic to imagine that the first ant was suspected of "fraudulent practises," was a "thief," and "humanly speaking," intended to accumulate a separate store for herself? These terms convey much more; they ascribe to ants a knowledge of "mine" and "thine," which is based upon deliberation; they insinuate a knowledge of "property" and of "duty." But, pray, where are the proofs for these gratuitous assertions? The truth is, that the observer 
has arbitrarily shifted his own moral concepts into the brain of the animal.

It is precisely the same with the police ants whose aid is said to have been invoked against the "thief." When an ant draws the sensitive attention of her companions to herself by rapidly tapping them with her feelers, so that they follow her and take part in a certain undertaking, her mode of procedure cannot be compared to a human appeal for help, much less to a summons of the police. The whole interpretation is arbitrary and an obvious humanization of the brute.

But apart from the above-mentioned anthropomorphisms, the whole observation was misinterpreted by the observer. No expert in ant life will question this statement. For it is simply unheard of, and contradicts the observations of all ant-biologists, as Huber, Forel, Lubbock, André, McCook, Moggridge, Adlerz, Janet, etc., that any single ant should try to hide a part of her booty and deprive other members of the colony in order to gratify her own gluttony. If it be allowed to draw general conclusions from facts-and no naturalist will dispute such a legitimate deduction-we can boldly state, that any similar egotistic action on the part of an ant is a physical impossibility; it contradicts a law of nature.

But the case is still more hopeless, because it happened to be a hill ant (Formica rufa) which was branded as a "thief." This very species is distinguished for its social traits, and the single individual is absorbed in the community in a far higher degree than is the case with ants of any other species, even as a slave in strange colonies. In an observation nest of the ravenous Red 
ant (Formica sanguinea), which I shall describe late: on in detail, I kept Formica rufa together with three other Formica species as so-called slaves. Formica rufa, however, regularly distinguished herself from the other species by the eagerness with which she endeavored to carry into the interior of the nest any object that attracted her.attention, be it a particle of food or a guest (Lomechusa strumosa) which wished to be fondled. To impute a selfish theft to a hill ant is biological nonsense.

What the critic actually did see is confined to the few facts, that one hill ant tried to drag a spider in a different direction to the beaten track and away from the main nest; that, finally, several other ants arrived from the colony and dragged the booty homeward. The observer ought to have carefully followed the "thievish" ant. Then he might have noticed that a party which originally belonged to the main colony, had founded a branch settlement nearby, to which the pretended "thief" kelonged, and towards which she naturally tried to drag the spider. The larger nests of hill ants often have one or more sister nests, and whoever observes the proceedings of ants can easily witness similar events at spots where the path from the main colony crosses the track to a sister nest. But to embellish an isolated, incomplete and misinterpreted observation into a romantic. "detective story," which is finally brought to a crisis by the interference of the "police," is surely one of the most splendid exploits of modern animal psychology.

However, we would wrong the gentleman by asserting that he told his attractive ant story in full earnest. It appeared to us from the very outset that he meant 
it as an ingenious satire on the stale and worn-out "arguments" for animal intelligence. He surely intended to show the readers of the Naturwissenschaftliche Wochenschrift by an interesting example, how brilliant a proof of ant-intelligence can be fabricated from an observation which is easily explained by "simple instincts." And as we know that the critic is an entomologist of name, we prefer this explanation as the most appropriate.

In his otherwise well-meant criticism of the first edition of our two publications "Instinct and Intelligence in the Animal Kingdom" and "Comparative Studies of the Psychic Life of Ants and Higher Animals," Prof. H. E. Ziegler ${ }^{1}$ made a statement which cannot be passed over in silence. In the first of these works, we examined his notion of "intelligence," and came to the result that what he called animal intelligence was nothing more than the exercise of hereditary instincts, governed and modified by individual sense experience. Furthermore, we dwelt in the second work on his attempted proof for the psychic development of our social customs from the gregarious habits of higher animals. Ziegler replies to our argumentation in these words: "I shall answer Wasmann neither here nor elsewhere, for his objections arise solely from his firm adherence to scholastic psychology. It is a principle with Wasmann to distinguish the actions of man from those of animals, because in his view the former are always conscious and free actions. But I hold, with many other naturalists, that it is impossible to discern

2) In "Zoologisches Centralblatt," 1897, No. 26. 
how much consciousness or self-consciousness accompanies the actions of animals, and that the so-called free will of man is only the play of stronger and weaker motives. Therefore I admit the lawfulness of the supposition that a gradual development has taken place from the soul of the animal into that of man."

Now, it is not our intention to discuss the famous question of the freedom of the human will, a question which is not solved by Mr. Ziegler's assertion that free will is "only the play of stronger and weaker motives." Nor do we take notice of his erroneous statement that, in our view, all activities of man are governed by self-consciousness and free will. But we must necessarily test the two principal points of his reply. $\mathrm{He}$ states that our objections against modern animal psychology arise solely from our firm adherence to scholastic psychoiogy; that no naturalist can tell how much self-consciousness accompanies the psychic actions of animals; and that, consequently, an essential difference between human and animal faculties cannot be substantiated.

That his first assertion is erroneous has been abundantly shown by Prof. W. Wundt, a scientist who is certainly not a partisan of scholastic psychology. Nevertheless, in the second edition of his "Lecture on the Human and the Animal Soul," he has arrived at the very same results as we did in regard to modern animal psychology. He is of the opinion, that this modern definition of intelligence is due to a want of critical method in interpreting an association of sense representations for intelligence; he affirms that no animals, the higher vertebrates not excepted, are endowed with 
genuine intelligence, the power of logical thought. Therefore scholastic psychology cannot be held responsible for these results. Our attitude towards modern animal psychology rests, on the contrary, on an unprejudiced, critical examination of biological facts, which forces us to uphold an essential difference between instinct and intelligence, between the psychic faculties of man and animals.

The second point of Ziegler's reply is, that no naturalist can tell how much self-consciousness accompanies the psyhic actions of animals, and that it is impossible to establish an essential difference between their psychic faculties and those of man. If naturalists had no other source of knowledge than what they see, feel, hear and smell, then this difficulty would be to the point. But this supposition annihilates any and every reasonable investigation of nature. Naturalists have not only sense faculties, but also an intellect, with which they must infer the causes of facts from their external appearance. This principle is theoretically acknowledged and practically followed by all naturalists in all branches of science. Therefore, it must also hold good for comparative animal psychology. If animals do not manifest activities which demand the assumption of selfconsciousness, we are not allowed to ascribe it to them, because simpler causes explain the phenomena; and if the assumption of self-consciousness contradicts other activities, we must say that animals have none. Otherwise we would act uncritically and not as reasoning naturalists. But this is identical with the assertion of an essential difference between the psychic faculties of man and those of the animal. 
To those who disapprove of our distinction of instinct and intelligence may be added Prof. W. M. Wheeler of Texas University. He has developed his views in a recent paper on "The compound and mixed nests of American ants." ${ }^{\prime}$ Admitting our psychological explanation of nearly all the facts observed in ant life, Prof. Wheeler maintains that he cannot adopt either our "psychological definitions" or our "psychogenetic reservations."

Let us examine his reasons. Prof. Wheeler does not admit our distinction between instinct and intelligence, because he thinks that we take the term "instinct" in too wide a sense, by including under it "both the instinct and intelligence of other authors." Therefore he prefers to restrict the term intelligence to those actions of the animal "which imply choice on the part of the individual organism."

We included, it is true, under "instinct sensu lato" not only those sensitive activities which are directly based on inherited mechanisms, but those also which are due to the sense experience of the animal. Still, we have never confounded the two. Otherwise we could not have restricted the term "instinctive sensu proprio" to sensitive activities which are based on inherited mechanisms. On the other hand we maintain that these two kinds of activities are not and cannot be essentially different, because all actions that are instinctive sensu proprio necessarily contain at least one eiement of sensile experience, the sensual agreeableness of the respective action (vide Chapt. 2). Therefore both kinds of activity belong to the same general class

1) "American Naturalist," 35, 1900, No. 418, p. 808 ff. 
of instinctive actions sensu lato; and it is consequently erroneous to call the former "instinctive," the latter "intelligent." This is the mistake made by modern psychology.

Only those actions are "intelligent" which contain a new and a higher psychic element, and this element is "choice." But, then, our definition of intelligence coincides with that of Prof. Wheeler. How are we to explain this seeming contradiction? "Choice" in the true sense of the word, not in the perverted meaning which "pseudo-psychology" has given to it, necessarily Fresupposes intelligence sensu stricto; for choice demands a selection which cannot be achieved without a faculty that is able to reflect, and all reflection essentially presupposes a power of abstraction. Therefore we are forced by the simplest laws of logic to conclude that no choice is possible without a power of abstraction.

Consequently, Prof. Wheeler is mistaken in refusing to admit our definition of intelligence as "a power of abstraction or ratiocination." By calling "choice" the distinctive mark of intelligence, he has given our definition in another form. Therefore he, too, must exclude from the term "intelligent actions" all those activities which can be adequately explained by the laws of sensitive association without the aid of formal election or abstraction.

Let us apply these conclusions to Prof. Wheeler's icieas on psychogenesis. He arrived, he says (p. 813), "at the same conclusion as Wasmann, that there are no evidences of ratiocination in ants." Hence we may say that Professor Wheeler has found no evidence of intelligence in ants. For intelligence supposes ratio- 
cination. But Prof. Wheeler seems to be wrong when he adds: "This conclusion, however, even if it be extended so as to exclude all animals except man from a participation of this faculty, does not imply the admission of a qualitative difference between the human and animal psyche, as understood by Wasmann." For if we exclude the faculty of ratiocination from all animals except man, we necessarily exclude them from a participation of intelligence. Man is then the only intelligent being in opposition to all animals whose powers are merely of a sensitive nature. But this implies an essential difference between man and beast. Prof. Wheeler appeals in vain to the individual evolution of mental life in children, where the exercise of the sensitive precedes that of the intellectual faculty. For the human soul has different powers, those of the sensitive and those of the spiritual order, and the exercise of the latter presupposes the evolution of the former without changing their essential difference. "Show us the animal," we say to Prof. Wheeler, "which becomes or has become man in the same way as the human child develops its mental faculties, the spiritual after the sensitive, and we shall admit the correctness of your phylogenetic psychogenesis of man." 


\section{CHAPTER V. \\ GENERAL SENSE IMAGES AND THE POWER OF ABSTRACTION.}

SCIENTIFIC animal psychology differs from pseudopsychology by its critical analysis of concepts, without which it cannot obtain true scientific results. The necessity thereof is acknowledged by prominent zoologists. Still only a single critic, Dr. Charles Emery, Professor of Zoology at the University of Bologna, ${ }^{1}$ has been found among modern zoologists who deemed it worthy of attention.

From the very outset Emery openly declares his conviction that animal intelligence exists. "I am convinced," he says, "that the mental activities of animals differ chiefly in two points from those of man: I. In the far inferior degree of animal intelligence; and 2. in the want of speech, an essential instrument of the human power of abstraction." In spite of this preliminary remark, we never met with a more thorough and accurate criticism. We shall try to discuss it in the same thorough and careful manner.

"The exaggerated descriptions of animal intelligence," continues Emery, "and the humanization of animals by Buechner and others, made it easy for

1.) In an article: "Instinct und Intelligenz der Thiere. Bemerk. ungen zu E. Wasmann's neuestem Werke: 'Die zusammengesetzten Nester und Gemischten Kolonien der Ameisen." ("Biologisches Centralblatt," 13 , No. 4 und 5 [1.Maerz, 1893], S. $150 \mathrm{ff}$. See also my reply in the "Biologisches Centralblatt," 15, No. 17 (1. Sept., 1895), S. 642 ff. 
Wasmann to deny animal intelligence; for the greater part of the so-called intelligent actions of animals can by no means claim that title. By the way, a similar remark had previously been made by Forel in speaking of ants. But, are there no facts which go to prove the intelligence of certain animals? The ànswer depends upon how we define instinct. It is Wasmann's merit to have opened the way to a more earnest discussion of the question by his explanatory remarks."

"Wasmann understands by instinct not only the socalled blind impulses which the animal possesses antecedent to all experience and as innate properties, but also the power of performing those suitable actions which are due to experience, to memory, and to associations of sense images. Such actions are not to be regarded as intelligent, because they do not transcend the realm of sense perceptions. Intelligence exists, according to Wasmann, only where general concepts are met with, consequently only in those actions which demand a power of abstraction. Man alone can abstract; at least we know of no action of animals which can not be explained in a simpler way than by assuming a power of abstraction. Man is also endowed with instinct, and acts instinctively, when his mental activity is restricted to associations of sense images. Therefore Wasmann regards the greater part of what goes for "intelligence of animals" as a special form of instinct which differs from innate impulses in being due to experience and in being acquired by the individual animal. The difference between man and animal consists in this, that the latter has nothing beyond its innate impulses and those which have been acquired and are due to asso- 
ciation of sense images, whereas the former has the additional faculty of forming general concepts by abstraction and of applying them for further inference."

It must be acknowledged that Emery wished to understand us, and, therefore, did understand us; an acknowledgment which is not equally applicable to all our critics. Following our arguments closely and́ without distorting or avoiding them, he has clearly and distinctly explained the real point of difference which separates us from the representatives of modern animal psychology.

Let us then examine Emery's objections against cur distinction of instinct and intelligence. The first is the following:

"We ask what is meant by an association of sense images," and what is understood by a "power of abstraction"? How are they to be distinguished one from the other? An example will help to illustrate our meaning. Uncivilized people are fond of glowing colors. Thus in the languages of many tribes the same term is said to express the color which we call "red" and the notion of "pretty." Consequently, the sense perception of "red" is connected with the feeling of "pretty." Hence the wish arises to possess any object of that color. The whole process consists of an association of sense images and of feelings called forth by those images. In this instance man acts just as a dog would which, after an olfactory test of a piece of meat, is induced to devour it through the combined sense and memory images produced by the odor of the meat, the gratifying taste, and its own feeling of hunger. Now I could just as well have arranged these processes in 
the form of syllogisms. The abstract concepts of red, pretty, and the odor of meat, which had been gathered from a chain of single apprehensions, would have occurred in the formation of the various propositions. These general concepts exist alike, if not explicitly, at least implicitly, in the mind of man and in that of the dog. But man can formulate them orally, and thus they become real abstractions. Herein alone consists the difference $:$ it is a mere formal one. In man as well as in the brute concepts or cognitions are formed by way of induction, by summing up successive experiences, eliminating every special and heterogeneous, and retaining every common and homogeneous element. In this way all general concepts are abstracted."

This is indeed one of the most solid objections which can be urged against our distinction of instinct and intelligence. It can be briefly summed up in the following three points :

I. In the process of human cognition complex sense representations and mental abstractions convene without definite boundary lines; consequently we are not allowed to deny the power of mental abstraction to animals, if we accredit them with the faculty of forming complex sense representations.

2. Even the processes of sensitive associations in animals contain, at least implicite, syllogisms; now, between such improper conclusions and the proper conclusions of human intelligence ${ }^{1}$ there is no essential

1) The former are generally classified as material, and the latter as formal conclusions (material reasoning-formal reasoning). But, as Emery uses the term "formal" in a different sense, we shall avoid it, in order to prevent misunderstandings. 
or interior, but merely a formal, an unessential and exterior difference. Therefore the power of cognition in animals is not essentially different from that of man.

3. The socalled general sense images of sensile perception and the general concepts of mental cognition are essentially the same; they represent different degrees of one and the same power of abstraction. Therefore they cannot be wholly denied to animals.

Let us carefully exämine these three difficulties. We begin with the first.

Man possesses instinct and intelligence, a sensitive and a spiritual life. While the sensitive life of animals only purposes to subserve the gratification of corporal wants and thereby tends to preserve the individual as well as the species, it has a higher purpose in man. It serves as a foundation for the natural activity of his spiritual powers. ${ }^{1}$ The spiritual powers of cognition and volition, and not the sensitive powers, as in animal life, are the highest and the primary principles of man's end and aim. His sensitive life is not complete in itself; it is a part of something that is higher. This explains the intimate connection that exists between the sensitive and the spiritual life of man.

Because man has a sensitive-spiritual life, and spiritual knowledge must first receive its object from sensitive perception-nihil est in intellectu, quod non antea fuerit in sensu-it is self-evident that sensitive representations are most intimately blended and interwoven with spiritual cognitions, and their subsequent abstractions and conclusions. Intelligence must form its general concepts from what is offered by sense representation,

1) See St. Thom., "Summ. Theol.," 2, 2, q. 167, a. 2. 
it must compare these concepts one with the other. Thus it is enabled to "think." According to the schoastic theory of cognition of St. Thomas Aquinas the sensile imagination must continually assist intelligence in its activity by furnishing a "phantasm." ' Hence the only way of grasping the idea of the "spiritual" is by denying the properties of things perceived by the senses: by eliminating extent and divisibility we conceive its characteristic note of "simplicity," and its "spirituality" by thinking of its interior non-dependence on matter both in existence and action. No representative of aristotelian philosophy has ever denied that sensitive and spiritual life in man are most intimately connected in their specific activities. However, this close connection does not exclude their essential difference. ${ }^{1}$ Spiritual cognition is not satisfied with what sensile cognition apprehends. It goes a step further. Sensile cognition is confined to an individual object with all its exterior qualities, it is restricted to things present in space and time, the concrete representation of which is reproduced by the sensile memory and combined with new perceptions, according to the laws of association of sense representations. But this is far from constituting a thought. Our intelligence proceeds essentially further in its act of cognition. Let us explain our meaning by the very example chosen by Prof. Emery.

If the mental process of the savage were restricted to his finding "pretty" whatever has a "red" color, to the pleasure excited by its perception and, consequently, to his search for, and collection of all objects that are

1) See the excellent work on this matter: P. Bonniot, S. J., "La bête comparée à l'homme." Paris, 1889. 
red, we would rightly say that he acts only from instinct; he acts like an irrational animal would act which feels pieasure at the sight of red things. But there are no such savages; their existence is a mere fiction. Even the most uncivilized human being takes an essential step further in his mental activity. He recognizes the red object as a cloth or as glass beads, as a piece of clothing or an ornament, as an object of trade or barter; he knows its real or presumed value, he recognizes its purpose. He thus distinguishes between the red color and the object, between the object and its owner; he discerns means and ends; in short, he perceives the relations of the objects of his sense perceptions to one another and to himself, he compares these relations and draws his conclusions to which he adapts his mode of action. The abstract perception of relations, however, essentially presupposes a mental power of abstraction. We have evidently much more than an instinctive combination of concrete sense representations and feelings.

For the sake of comparison let us recur to the dog that connects the representations of "the odor of meat," "the gratifying taste," and "the feeling of hunger," and then "acts" accordingly. His sensile memory retains the phantasm of a former piece of meat, and of his previous gratification through this object, of this certain odor and of this certain appearance. This is why the dog, under the impulse of his sensile appetite, looks for another piece of meat when he is hungry, and then devours it with voracity. But, has he, on that account, a general concept of meat, which represents it as an object of nourishment, or a general concept of the means which serve to attain that desirable object. If that 
were the case, he would not fail to perceive, how men get meat for money, and he would arrange his behavior accordingly. He would keep and hide any coin that he might casually find, or he would steal from his master, in order to use the money in exchange for meat. Then he would run to the butcher's with the coin in his mouth, he would lay it upon the counter and point with his paw to a specially delicious-looking sausage, he would look cunningly at the owner of the tempting morsel, or emit a knowing bark in order to manifest his desires. I can scarcely think that Emery, or any other modern animal psychologist, is able to record such facts, or would even earnestly as much as venture to think them possible. True, a dog can be trained to fetch meat regularly from a certain butcher, and to carry a basket with the money in it. But this only shows, as we have previously stated in refuting Forel, that man is able to impress his own intellectual conclusions into the sensile memory of the animal by mechanical training. Consequently it is evident, that the animal has no intelligence of its own; otherwise some particularly clever dog which had often undertaken errands for his master, would undoubtedly have found the clue to the evident connection between the money and the meat, and thereupon have acted independently and for his own interests. However, no dog has ever done so, in spite of all possible occasions of developing his so-called intelligence during the course of several thousand years through his constant companionship with man; he does not do it, because he cannot; and he is not able to do so, because he can only connect conerete sense representations according to the laws of in- 
stinctive association of representations without grasping their relations, and without rising to self-consciousness; in short, because he possesses only a sensitive and not a spiritual power of cognition.

How is it, then, with Emery's first difficulty: As sensitive associations of representations and spiritual abstractions are most intimately connected with one another in the psychic life of man, we cannot simply deny the existence of these abstractions in the psychic life of animals? But why not? Emery's conclusion is clearly unwarranted. We are not allowed to attribute higher faculties to animals than they manifest, and as the manifestations of their mental activity do not transcend the sphere of sensitive life, it is unlawful to ascribe intelligence and spiritual faculties to them, although both these activities are found and are intimately connected in man. This is what a scientific and critical psychology postulates.

Let us now turn to the second point in Prof. Emery's objections: that syllogisms are contained at least implicitly in the sensitive associations of animals: that there is no essential, but only an exterior difference between the so-called material and the proper (formal) conclusions of the human intellect: that, consequently, the cognitive power of animals is not essentially different from human intelligence.

We readily admit, that the combinations of sense representations in animals are implicitly equivalent to formal conclusions. Yet, we positively deny, that there is only an exterior and unessential difference between such a process of cognition and the explicit conclusions of the human intellect. A careful examination of what 
is meant by material and formal conclusions will at once elucidate our meaning. A material conclusion (inference), a iudicium materiale, ${ }^{1}$ as scholastic philosophy called it, is a complex sense representation which can be resolved into a formal ratiocination by the human mind. The very use of the term "material conclusion" is an acknowledgment of the conviction that animals do not "think." It is a proof of the intelligence of man, who can form the material conclusions of animals into proper syllogisms, and not of an intelligence of the brute. ${ }^{2}$

But in saying this we do not wish to assert, that the power of making conclusions is essential to intelligence as such. On the contrary, the very necessity of deductive thought is a proof of imperfection in the human understanding. ${ }^{3}$ The divine intellect which beholds all truth in one single, eternal intuition, does not require the beggarly means of a cognition which advances gradually and only step by step. Nor is the faculty of the human intellect exclusively confined to deduction, but necessarily presupposes the intuitive cognition of the first fundamental principles. Moreover, it often follows an abbreviated method in its process of reasoning; it uses the enthymeme instead of the syllogism; and, in general, the quicker the power of perception, and the more active the mind, the shorter and terser all mental deductions will evidently become. But, there is a difference between these abbreviated intellectual

1) About iudicium materiale, virtuale or implicitum see also Urraburru, Psychol. P. I., p. 848.

$\left.{ }^{2}\right)$ See also Reimarus, pp. 39 and 40 , and ff.

3) See above p. 37 , note 2 . 
conclusions and the so-called material conclusions of animal cognition, as great, as is the difference between day and night. The former are the result of intelligence, of which they are a more perfect activity than is required for the formation of full and complete syllogisms, the practice of which they presuppose; the latter are not the result of intelligence, but rest upon the laws of instinctive association of representations which essentially belongs to the sphere of sensitive cognition.

Nor are these material conclusions restricted to those sensitive combinations of representations in the psychic .ife of animals, in which one or more elements are taken from individual experience, but comprise those also which are immediately due to innate, instinctive dispositions. Let us again recur to the example of the dog. When he smells a bone for the first time, and the odor excites his appetite, he acts instinctively in attacking it at once. For he had so far no experimental knowledge of the delicious marrow contained in that bone. This is quite in accordance with the doctrine of modern animal psychologists. Still, a "material conclusion" is evidently contained in that process of sense perception, and can be clearly resolved into the following syllogism: Whatever emits an odor that excites my appetite, must taste well; now, this object emits such an odor: therefore it must taste well: ergo I shall at once crunch it. If then, the power of forming "material conclusions" is reason enought to ascribe intelligence to animals, as many moderns and among others Tito Vignoli, ${ }^{1}$ really do, then

1) "Ueber das Fundamentalgesetz der Intelligenz im Thierreich" (German edition, Leipzig, 1879), Chapt. 6. 
we must necessarily designate all instinctive activities as intelligent. But this is apparently inappropriate. Hence it is equally illogical to style those combinations of representations which are due to sense experience, intelligent, because they contain "material conclusions."

The fundamental reason, why the material conclusions of sensitive cognition can be resolved into formal deductions, is the fact, that they involve regularity which can be grasped and cast into syllogistic form by the intelligence of man. Nor does this apply only to the material conclusions of sensitive cognition, but to all processes in nature, which are the embodied expression of the regularity of a natural law. It holds good for the vegetative processes in animals and plants, for the laws of crystallization, of chemical affinity and atomicity, as well as for the cosmic laws which govern the motions of the celestial bodies. By perceiving the relation between cause and effect in these phenomena and by discovering the laws which govern them, human intelligence can resolve these natural processes into logical deductions. Thus even the digestive activity of organic life which retains certain parts of matter as lymph for the formation of blood, while it secretes other parts as useless, can be analyzed into a long chain of ratiocinations. Only substances of a definite chemical composition are fit for the formation of blood; this substance is such a chemical composition: therefore the organism must use this and no other substance for the alleged purpose. All natural laws are, as it were, embodied ratiocinations. But the fact that the laws of nature are adapted and constantly directed to a given purpose, does not warrant any other conclusion, than 
that the first cause of the world and of its harmony must be intelligent. Otherwise the adaptability of these laws and their constant direction to a certain end could not be sufficiently accounted for. ${ }^{1}$ Yet, nobody will conclude, that atoms, crystals, and plants possess intelligence. Nor is it in any way different with the material conclusions (material reasoning) of sensitive cognition in animals. They only furnish a proof of the intelligence of a Supreme Being who has suitably created the sensitive nature of animals, and a proof of the intelligence of man who is able to resolve these material into formal conclusions, and thereby to make out and decipher, as it were, the Creator's ideas which $\mathrm{He}$ has embodied in His creatures. They are no proof whatsoever of the intelligence of animals.

This discussion will have made it plain that an essential and profound difference decidedly exists between material and formal conclusions, a difference which modern animal psychology tries in vain to narrow down or to cover up. The faculty of formal reasoning in man is the foundation of his whole mental activity; it soars beyond the mean level of sensitive cognition in animals; upon it rests the gift of speech, the mental evolution of individuals, the cultural development of nations, the possibility of science. Such a difference cannot rightly be styled unessential and merely exterior.

There still remains the third point of Emery's objection: the so-called general sense images and general concepts of animal and human cognition. They are

1) See the beautiful passages of S. Thom., 1, 2, q. 13, a. 2 ad 3; q. 40 , a. 3; "Summa c. Gentiles," 1, 3, c. 24 (quodlibet opus naturae est opus substantiae intelligentis). 
said to be essentially the same, and to represent only different degrees or stages of one and the same power of abstraction. Consequently, this power should not be totally denied to the animal.

What are general sense images? --When a harrier scents a hare, it is guided in chasing it by a "general sense image," as we say, or by a "general phantasm" of that animal; for it does not track the same hare which it pursued sometime ago, but another animal of the same species, whose individual qualities are as yet unknown to it. What is the characteristic of this "general sense image," this "general" phantasm of a hare in the dog's brain? As we do not share a canine nature with the animal in question, we must necessarily try to solve this problem from the analogy which exists between the general sense images of animals and those of our own sensile imagination; nor must we omit to pay due regard to the differences which prevail between the outer senses of man and those of the dog. When a sportsman sallies forth to shoot hares, and pictures to himself the object of his quest, this sense representation will always contain the image of an absolutely specified hare with its individual and special properties. It is "gen'eral" only in so far as the modifications which distinguish this imaginative hare from all other individuals of its species, are only obscurely represented, and belong, as it were, to the background of the image, whereas the properties which are common to all hares, the size of the body, the long ears, the color are, so to say, in the foreground of the representation. Or, perhaps our sportsman pictures to himself an unusually big and beautiful hare which he would be delighted to bag. 
Then the image is even still less "general," because it represents a very specified hare of such excellent qualities as are scarcely possessed by any hare in reality. What must we conclude from this fact? It follows, that the imagination of man is never able to picture a hare in general, but only a concrete and individual animal of these or those qualities. This representation is either nothing more than a vivid reproduction of former sight perceptions, in which case the "general sense image" is a concrete and individualized image of the memory, or special features which have been taken from former sense perceptions, are added to the original representation by the combining and producing power of the imagination, and result in a fascinating picture of an idealized hare,-in which case the "general sense image" is again decidedly concrete and individual. Therefore, a general sense image of a hare does not exist, nor can it possibly exist. Whosoever takes the trouble to reflect on this subject, and carefully examines the representations (phantasms) which arise in his own memory and fancy, will be forced to acknowledge it. So much for the sense images of man.

But of what nature is the "general sense image" in the brain of the harrier? The elements of olfactory perceptions are, without doubt, the chief constituents of sense representations in canines, whilst general sense images consist mainly of sight perceptions in man. Consequently, the scent will take the first place in the sensile memory of the dog; but its object will be individualized, as is the case in our sense images, it will be that of a definite hare, and not the scent of the hare in "general." Now, when the dog sights another animal 
of the same species, a combined "sense image" which results from the prevailing scent perception and from a former sight image will immediately be produced in his brain. We may call this new representation a memory image, if we chiefly consider the reproductive activity, or an image of the fancy, if we choose to dwell ori the combining power of sensile perception. But the fancy of animals does not posses the procreative power of selection of the human fancy, nor its productive quality of reconstruction. There are no artists among animals nor geniuses of art as among men. ${ }^{1} \mathrm{Nev}^{-}$ ertheless we may justly apply the term "fancy" to the combining activity of their sensitive imagination. Now, what does this image of the memory-or of the fancy, represent to the dog? Perhaps a hare in general? By no means. Its object is a concrete and individual hare, which can be called "general" only in an improper sense, in as far as its individual features are obscurely and indefinitely outlined, but never general in the proper acceptance of the term. For it is absolutely impossible for any sensitive power of perception to represent only the specific properties and omit all individual differences.

The fact, that this falsely called "general" sense image is indistinct in individual features, explains why the dog chases any hare he happens to come across, and not only this or that individual animal. Still, it is certainly true, that the sensile imagination of man and

1) The activity of the sensitive imagination displayed in the case of many art instincts could best be compared with the productive activity of the human fancy. (See "Der Trichterwickler," S. $156 \mathrm{ff}$.). In a similar manner this holds good for the nest building instincts of birds. 
of animals can omit concrete circumstances of time and space. The sensile memory often reproduces only those elements of the object, to which attention was more closely drawn in former sense perceptions; for they have mostly made a deeper impression than the accompanying circumstances, and are, consequently, more easily reproduced. Thus also those qualities of the object come out most clearly and distinctly in its reproduced image, which made the strongest impression in the original sense perception, while the rest are discarded. The saying, therefore, that the sensile imagination is able to abstract from circumstances of place and time, means nothing beyond the assertion, that the stronger sense impressions are more readily and sharply reproduced than the weaker. This is all that can be said on the power of abstraction of the sensile memory and imagination.

It is true, I am able to imagine the various colors, as "green," "red," "blue," and, in general, any definite color, or, rather, any object of a definite color, without picturing to myself a specifically limited surface, or a definitely limited body. Consequently it might seem as if the sensile imagination were endowed with the faculty of abstracting the colors of an object from its extension. Still, the explanation we have just given is equally applicable to this phenomenon. For, if it were a question of abstraction in the proper sense of the word, we ought, vice versa, to be able to fancy an object of definite extension without any definite color. However, this is impossible. In reproducing a sight perception our imagination seems to be able to discard the definite extension of a colored object, because color 
is the primary and peculiar object of the sense of sight, whereas extension is only one of its secondary objects, for the perfect perception of which it needs the assistance of another sense, namely, that of touch. ${ }^{1}$ This is also the reason, why in one and the same act of the imagination the element of color can be clearly reproduced, whilst that of extension is expressed in an indistinct and obscure manner.

Therefore, we may state that a sensitive power of abstraction does not exist; for there are no "general," but only "individual and concrete sense images," in which individual features come out more or less distinctly, and, consequently, produce a greater or less individual similarity. In accordance with the laws of sensitive associations, this similarity arouses in the huntsman, when the hare rises, that exciting pleasure he takes in his sport, the first source of which, even in man, is the sensile and not the spiritual appetite. On the analogy which exists between this sensitive element in the psychic activities of man and of animals, we must base our judgment of their psychic life. Whatever transcends this sensitive element is found only in man, and not in the animal.

And what is it that transcends this sensitive element? It is the general concepts and conclusions of ihe intellect. The activity of the intellect is not merely confined to sense perceptions and sensile phantasms; it does not merely connect them one with the other according to the laws of instinctive association of representations, it goes much further: it compares the dif-

1) For this reason scholastic philosophy called color a sensibile proprium, and extension a sensibile commune. 
ferent sense representations, examines their similarity and dissimilarity, their objective coherence and noncoherence, it searches into the casual relations which link them together or to the sentient subject: it thus rises to general concepts and draws conclusions by connecting them. This logical and mental activity of the intellect, and this alone, involves a power of abstraction in the proper sense of the term. Intelligence alone distinguishes between essential and unessential, between specific and individual properties, between the characteristic marks of the genus and of the family, it alone is able to conceive the hare as a member of a certain zcological system. Now, if such a conception surfasses even the powers of the sensile imagination of man, how much more is it beyond those of the animal. The elder Reimarus hinted at this truth, when he wrote: "The instinctive knowledge (of animals) seems to recog nize not only single objects, but also species and genera. For the dog can distinguish fruit from meat, and tame animals from heasts of prey; an ox or a sheep can distinguish any poisonous herb from healthy fodder; the male of any animal can distinguish the females of the same species from those of another. Have they, then, general concepts? Have they separate representations of the similarity of different single objects? Have they a genealogical table of objects laid out in their brains? By no means, as is evident from the foolish errors they are liable to commit. When they experience the same feeling as the result of the most different objects, they deem those objects identical." 1

1) "Allgemeine Betrachtungen ueber die Triebe der Thiere," 3d edition, Hamburg, 1773, p. 33. 
Of course modern psychologists have tried to demonstrate, that monkeys have some knowledge of the systematic relationship which prevails in the animal kingdom. Yet, these would-be proofs are based on nothing more solid than some observations which show that monkeys have a similar dread of blind worms, lizards and turtles as they have of poisonous snakes. The behavior of these monkeys is easily explained by the exterior similarity of dangerous and non-dangerous reptiles, and is fully understood from the laws of sensitive association. It implies a monstrous lack of judgment to infer from such observations, that monkeys possess an idea of zoologicai relationship. Nor does this lack of critical acumen become less ridiculous from the fact, that not only a Brehm, but even such men as Charles Darwin were liable to it. It only shows the real worth of "proofs" advanced in favor of the "descent of man from the animal."'

More thorough psychologists who, with Emery, acknowledge the necessity of a clear analysis of psychological concepts, will avow, that such proofs of animal intelligence are untenable. But it is equally tuntenable to claim that the general sense images differ from the general concepts of the intellect only in degree, and not in kind. We can therefore briefly sum up our points of argument:

General sense images do not exist, they are even im-
possible. Intelligence alone can form general concepts; therefore, no spiritual powver of abstraction is in question in the so-called general sense images of animals. They

1) "The Descent of Man," I. Chapt. 3, n. 111. 
Gencral Sense Images and the Power of Abstraction. $\quad 95$

lend no evidence whatsoever to the plea, that instinct and intelligence, or, that the sensitive life of animals and the spiritual life of man differ only in degree and not in kind. On the contrary, our discussion makes it evident, that there is an essential difference between them. 


\section{CHAPTER VI.}

\section{INTELLIGENCE AND SPEECH.}

\section{ACCORDING to Emery the difference between A human and animal cognition consists chiefly in}

the possession and non-possession of speech. He distinctly states that sense and memory images develop into genuine abstractions through oral articulation. "This is the only difference. It is a mere formal one." However, we have shown that the difference between material and formal conclusions, between general sense images and genuine abstractions is not unessential nor merely exterior, but one that arises from the totally different natures of the sensitive and the spiritual, of the powers of cognition in the brute and in man. This at once overthrows Emery's second objection concerning the importance of speech. Still as he is by no means the only one who maintains these views on the relation of speech to intelligence, ${ }^{1}$ we deem it necessary to treat

1) More than a century and a half ago Christian Wolff advocated similar opinions. "Vernuenftige Gedanken von Gott, der Welt und der Seele des Menschen," etc. ( 8 Aufl. Halle, 1741, the first edition was issued 1720), No. 834: "Wir pflegen den Dingen insoweit sie einander aehnlich sind, und also entweder von einer Art seyn, oder zu einem Geschlechte gehoeren, einerley Nahmen zu geben. Und durch Huelffe dieses Nahmens sondern wir gleichsam ab, was sie mit einander gemein haben. Und sind dann die Woerter oder auch andere Zeichen das Mittel dadurch wir allgemeine Erkaentniss erlangen." In our opinion Wolff does not wish to assert with several modern philosophers, that general knowledge is a consequence of word formation, but only that its acquirement is essentially facilitated by the latter. See No. 867: "Da die Woerter zur Deutlichkeit der allgemeinen Erkaentniss dienen: hingegen aber die Vernunft sich auf die Deutlichkeit der Erkaentniss gruendet, so befoerdert die Sprache oder auch der Gebrauch anderer Zeichen die den Woertern gleichgueltig (gleichwertig) sind, oder sie sogar oefters ueber- 
the objection more in detail. After having falsely ascribed a power of abstraction to animals, Emery continues:

"The power of abstraction in man far surpasses that of the animal, as the former is endowed with speech, an essential instrument, which is wanting to the latter. It is through the word that general impressions or concepts, such as "red," which have been abstracted from a number of sense perceptions, become in turn a concrete, phonetic or graphic sense image, and can without regard to their origin be used in combination with other general concepts which have been abstracted in a similar manner, and be made perceptible to the senses. We combine red, blue, green, yellow, etc., to the higher concept of "color," and consider color, weight, odor, etc., as the "properties of things." Thus we rise higher and higher, from abstraction to abstraction, to the lofty regions of metaphysics, to a sphere as inaccessible to the animal as that of arithmetic. The history of mathematics can serve as an illustration of the constant progress of the human mind through advancement in symbolic means of expression. In a similar manner the character of its language produces the peculiar genius and poetry of each individual nation."

"Consequently the main difference between the mental faculties of man and of animals consists, in my opinion, in the fact that man can speak. He uses

treffen, den Gebrauch der Vernunft." Language is, according to Wolff, a very important, yea, a necessary means for man to arrive at the normal use of his understanding; still it is not the cause of reason, but, vice versa, reason is the cause of speech. Now, what holds good for the individual, holds good for the whole race; and this is why mankind did not become reasonable only with the development of speech. 
language not only to communicate his feelings and experiences to his fellow men, but still more to extend and to generalize his knowledge through phonetic or graphic memory images or symbols. This raises him to an immeasurable height above the highest animal. However, I cannot deny a slight power of abstraction to animals. Probably it does not go beyond abstractions of the first order, those which immediately resuli from sense perceptions and feelings, and in the human being refer to the properties of things, to feelings and emotions. Higher animals, as dogs and monkeys, are able to connect such general notions with sense perceptions of the present, and with memory images of the past, and, thereby, to act intelligently not only in appearance, but in truth. If we possessed a scale of abstractions, we might possibly assign a limit. But who can specify the capability of a dog or a monkey in acquiring general knowledge? Can a certain animal gather the notion of color in general from the notions of the single colors? or the general notion of the bird from the memory images of various feathered creatures? or is it unable to do so? We do not know, and probably never shall know."

"This is not the place to treat on the origin of language, but we can justly inquire, whether animals possess anything that can be compared with articulate speech in man. Animals manifest their feelings by spontaneous motion and sound. They utter calls. It is difficult to determine in how far such utterances are the result of unconscious impulse or of rational intention. The latter seems to me not to be so very improbable, at least in single cases. But be it as it may, 
any cry or any gesture renders a state of emotion or feeling perceptible to the senses, and if such perceptions be stored up in the memory, they could possibly become a symbol of the psychic condition of another animal, even when that condition is not outwardly manifested. Consequently it is imaginable, though not strictly proven, that in these memory images animals possess something similar to the phonetic symbols of human speech. Still, animals do not seem to have improved their phonetics beyond the reproduction of emotions (feelings) and other unconscious sounds. They do not possess speech in the strict sense of the word."

"Let us briefly sum up the points of our discussion. The answer to the question, whether animals possess instinct only, or also intelligence, depends, as we said, on the definition of those mental faculties. In my view we cannot deny a limited pozer of abstraction to animals. Man has advanced its boundaries further and further by developing articulate speech. Now, if we restrict intelligence to what can be accomplished by the help of phonetic-graphic symbols of speech, then man alone possesses intelligence and animals do not. If, however, we wish to consider intelligence as the power of gathering general concepts from the manifold images gained by experience, and of using them for conscious, suitable actions by combining them with present sense perceptions, and if we regard as instinctive only those actions which are unconsciously adaptive, then animals are also intelligent, although in a limited degree."

"Allow me for a moment to allude to the religious point of view. That which distinguishes man from the brute, is speech; it alone can be regarded as God's gift.

\section{L. of G.}


Through the possession of speech man has attained a higher development of his mind. The history of language is simultaneously the history of man and of human intelligence."

The following main points can be traced in Emery's exposition on the relation of speech to intelligence:

I. The intellect of man was not only developed by the help of language, but his high intelligence is the consequence, not the cause of the existence of human speech.

2. Higher animals also possess abstractions of the first order, and therefore they act intelligently not only in appearance, but in truth.

3. Animals possess something that can be compared to human speech. Yet, they are devoid of speech in the strict sense of the word.

4. Not only what can be accomplished through the aid of phonetic-graphic symbols of speech must be regarded as intelligence, but also the power of forming general concepts and the power of consciously adaptive action.

We shall shortly prove the first of these four points to be untenable. The second we have previously refuted in demonstrating that Emery's "abstractions of the first order" are nothing more than general sense images, complex sense representations and sensile affections of animal instinct. We fully acknowledge the truth of the third and fourth points. But we infer therefrom the very opposite conclusion: that animals have no intelligence.

Let us take up the different points as far as necessary. 
I. What is the real relation between human speech and human intelligence? True it is, that speech is a most useful instrument to quicken and develop intellectual culture in the individual and in entire nations. Our daily experience proves this to be the case. It may be gathered from the study of child-life, and it is confirmed by the history of nations. The introduction of graphic language is, so to say, the first step towards a higher degree of cultural development. Speech obviously facilitates abstract thought. For the very fact that most of our representations and notions are acquired through verbal and graphic signs, renders the activity of the understanding, the comparison of ideas and logical deductions far more simple and safe. Again, when a child of six years is taught to read, the knowledge of the word often precedes that of the concept. The latter must first be explained by the teacher and brought home to the child which, without some previous knowledge, cannot even grasp the explanation, nor the meaning of words which are as yet unknown. The causal relation between speech and intelligence is, therefore, the very opposite of the view favored by Emery: Speech is not the cause of the high intelligence of man, but his high intelligence is the cause of speech. Speech is only the condition of the normal development of the human understanding in the individual as well as with entire nations. Intelligence, on the other hand, is the cause of speech and not merely its condition. A simple analysis of any sentence, as: "The leaves are green," will clearly prove the truth of this position. In this sentence "green" is affirmed as predicate to the subject "leaf." Now, this oral assertion presupposes 
a judgment of the intellect which combines the concepts "leaf" and "green" and affirms the latter as a property or condition of the former. Otherwise the sentence "The leaves are green," would be an inane and meaningless assertion.

Consequently it is clear that the verbum oris (the oral or phonetic, and graphic expression of our concepts and ideas) presupposes the verbum mentis (the concept of the intellect and the idea itself), and does not produce it. As a concept of the intellect, the idea "leaf" is, prior to its oral utterance, a real general concept; it is a genuine abstraction which was originally gathered from the sense perceptions and sense phantasms of innumerable single leaves. Likewise the concept "green" is a real general and intellectual concept, a real abstraction, before it is used in oral discourse; it was abstracted by the intellect from different green objects with their variegated shades of that color, and then raised to a general concept. Therefore it is wrong to say with Emery that general concepts of the intellect "grow into real abstractions only through oral utterance."

The doctrine of Aristotelian philosophy, that the verbum mentis precedes the verbum oris, is therefore in full harmony with common sense. There must first be a concept in the mind, before it can be expressed by the mouth. And, if this priority is not observed, the saying of a German poet holds good, that words come to the rescue where ideas are wanting. The Traditionalism of de Bonald and of his school, during the first half of the nineteenth century, has in vain tried to shake this fundamental truth of the old theory of 
cognition. It was overwhelmed by evident contradictions against common sense which it could not avoid. And even Max Mueller was unsuccessful in his attempt to revive it in a more up-to-date form. ${ }^{1}$

To quote a modern naturalist, W. Preyer, ${ }^{2}$ on the relation of speech to intelligence: "In reality it was not speech that produced intelligence, but it was intelligence that invented speech; and even in our times the newborn infant is endowed with more intelligence, than skill for speech. Man does not think, because he has learned to speak, but he learned to speak because he thinks." As surely as we must affirm: Nihil in intellectu, quod non antea fuerit in sensu, so surely must we say with Regnaud: ${ }^{3}$ Nihil in dictu, quod non antea fuerit in intellectu.

It may then be regarded as an established fact, that speech is not the cause of the high intelligence of man, but that the high intelligence of man is the cause of speech. Nor are the phonetic-graphic symbols of sound indispensable, even as a condition, for the development of individual intelligence. We call to mind the case of Laura Bridgman; who at the age of two years, after a severe illness, became entirely deaf and blind, and almost lost the senses of smell and taste. With her in-

1) On the synergastic theory of Noirée and Max Mueller see Dr. Alex. Giesswein, "Die Hauptprobleme der Sprachwissenschaft in ihren Beziehungen zur Theologie, Philosophie und Anthropologie" (Freiburg I. B., 1892), S. 169 ff. Also Gutberlet, "Der Mensch" (Paderborn, 1896), S. $368 \mathrm{ff}$. On the speechlessness of isolated children see Rauber, "Homo sapiens ferus" (Leipzig, 1885), and Gutberlet, especially page $261 \mathrm{ff}$.

2) "Die Seele des Kindes," (3. Auflage), S. 295.

3) Regnaud, "Origine et philosophie du langage" (Paris, 1888), p. 293. See also Giesswein, especially p. 162. 
telligence, which was not impaired, the sense of touch alone was left to the afflicted child. . It is astonishing what human intelligence was able to accomplish in her case, even without the normal assistance of exterior sense perceptions and speech. In spite of the extremely limited means of communication by the sense of touch, Dr. Howe succeeded in gradually leading the afflicted girl to a perception and knowledge of surrounding objects, and even in teaching her to read and write by means of embossed type. The following passage is taken literally from Dr. Howe's report : ${ }^{1}$

"The first experiment was made by taking the articles in common use, such as knives, forks, spoons, keys, etc., and pasting upon them labels, with their names embossed in raised letters. These she felt carefully, and soon, of course, distinguished that the crooked lines s-p-o-o-n differed as much from the crooked lines $k-e-y$, as the spoon differed from the key in form. Then small detached labels with the same words printed upon them were put into her hands; she soon observed that they were the same as those pasted upon the articles. She showed her perception of this similarity by laying the label k-e-y upon the key, and the label s-p-o-o-n upon the spoon.

"Hitherto the process had been mechanical, and the success about the same as that of teaching a very knowing dog a variety of tricks. ${ }^{2}$

1) Taken from Sir John Lubbock, "On the Senses, Instincts and Intelligence of Animals" (3d edition, London, 1889), p. 275.

2) In reality Howe's success was decidedly greater. This will be understood when we remember that the girl was entirely blind and deaf. The clever poodle Van did not succeed to the same degree in profiting by Lubbock's instructions, in spite of its excellent organs of sense perception. 
"The poor child sat in mute amazement, and patiently imitated everything her teacher did. But now her intellect began to work, the truth flashed upon her, and she perceived that there was a way by which she could herself make a sign of anything that was in her cwn mind, and show it to another mind. At once her countenance lighted up with a human expression. It was no longer as a mere instinctive animal; it was an immortal spirit, eagerly seizing upon a new link of tnion with other spirits. I could almost fix upon the moment when this truth dawned upon her mind, and spread its beams upon her countenance; I saw that the great obstacle was overcome, and that henceforth nothing but patient and persevering, but plain and straightforward efforts were necessary."

What was this beam of light that brightened the dreary darkness of this poor creature's mind shut off from communication with the sensile world? Was it speech? No, it was intelligence; intelligence that invented speech as a means of communicating with other rational beings.

In contrast with the case of Laura Bridgman let us now consider the training of a higher animal which was endowed with excellent faculties of sense perception. Lubbock exerted all his ingenuity to teach his clever poodle $\operatorname{Van}^{1}$ how to think. He gave it lessons in reading, by having the word "food" and other words which represented ideas congenial to "dog intelligence" printed in large letters on different slips. He then trained Van to fetch the card with the label "food"

1) Lubbock, op. cit., p. 277: "Van and his cards." 
when it wanted nourishment, or another card with the word "out" when it wished to take its constitutional. After long and tiresome attempts at training, Lubbock succeeded with a small number of words. The concrete combination of the sound perception "food" with the sight perception of a certain arrangement of letters was gradually imprinted into the sensile memory of the poodle, combined with which was the experience of being fed, when its master mentioned "food." Thus it happened that with the feeling of appetite the phantasm of the label "food" was reproduced in Van's imagination. But this is quite in keeping with those laws of sensitive association of representations which Wundt calls "contact association." This is why the dog fetched the label "food" when it felt hungry. We find therefore that our clever poodle Van combined certain sense images with corresponding affections, both of which had been gained by experience; and, furthermore, we find phonetic and graphic symbols, the elements of oral and written language. Now, if Van had been endowed with intelligence, and were it merely a "limited intelligence of a dog;" the latter ought to have been developed by the help of speech and been stirred up to independent activity. Nevertheless this did not happen. The dog's activity did not rise above combined sense representations mechanically impressed on its mind by the human intelligence of its teacher. It did not contribute in the least to its own further development. Nor did it ever occur to Van to instruct its little friend Patience, its mistress' lap-dog, in the new-fangled language; nor did dear little Patience hit upon the obvious idea of imi- 
tating Van's example and fetching the label "food," when she felt hungry; although, as we are told by Lubbock, Patience had often seen that Van was rewarded with a piece of bread for bringing that very label. This "idea" did not occur to Patience, although it was obviously the connecting link between the food and the label; nor did Van communicate it to her. Why not? The only answer worthy of an unprejudiced psychologist is: Because neither Van nor Patience possessed a spark of individual intelligence. The only intelligence manifest in the transaction was that of their master and teacher, Sir John Lubbock.

The experiments in the well-known case of Voit, ${ }^{1}$ which prove the possibility of intellectual thought without the help of words are of peculiar interest in our present inquiry. Owing to a lesion of his skull, Voit had lost his memory to such an extent that he could find the names of objects present to his senses only by writing them down. As he gradually grew incapable of making any motion required in writing, be it of his hands, feet, or even of his tongue, he was absolutely unable to find the necessary word. And, still, in this state of "graphic enchainment," he perfectly understood the connection between different objects, even without the help of the corresponding term. Thus being asked for a word applicable to a guitar and a trumpet that were shown him, he shook his head in the negative; but on being asked whether both objects belonged together, he immediately nodded. However, he was only

1) "Zeitschrift fuer Psychologie und Physiologie der Sinnesorgane," 2, 260 ff. See also Gutberlet, op. cit., p. 369. 
able to find the term "musical instrument" after having been "unchained." In view of this fact, A. Pick ${ }^{1}$ remarks: "Although Max Mueller denies the possibility of thought without speech, Voit's "understanding without words" "proves more than entire volumes of theoretical discussions."

In treating these examples we have sufficiently disproved Emery's objection, that human intelligence was developed from the power of speech, and that speech was the cause of intelligence. Let us now briefly sum up the results of our examination:

It is erroneous to state that general concepts of the intellect grow into genuine abstractions only by being expressed in language. It is equally crroncous to assign the possession of phonetic-graphic symbols of steech as the real canse of the high power of abstraction in man. The very contrary is true. Words are the expressions or manifestations of thought, human speech is the expression of his intelligence. Without his intelligence man would never have attained the gift of speech, and even if God had miraculously bestowed it on him, human intelligence would have been the necessary presupposition for its acceptance. In other words: do away with intelligence, and you do away with all logical possibility and psychological necessity of language. The logical possibility: for mihil in dictu, quod non antea fuerit in intellectu. The psychological necessity; for nobody tries to express concepts which he does not have; and all who have intelligence, will unfailingly experience the necessity of communicating

1) "Zeitschrift fuer Psychologie und Physiologie der Sinnesorgane," 3,54 . 
their thoughts to other intelligent beings, that is, they will experience the necessity of language. ${ }^{1}$

II. Properly speaking, there is no necessity of alluding to Emery's second assertion that higher animals have at least abstractions of the first order, and act intelligently not only in appearance, but in truth, because this statement is sufficiently explained by his error in taking so-called general sense images for genuine abstractions. The former have nothing to do with a spiritual power of abstraction; they are only the foundation, the raw material, as it were, of its characteristic activity. Hence, Emery's "abstractions of the first order in animals" are no abstractions at all, nor do they belong to the sphere of intellectual life, but to the instinctive activity of the senses. It is true that "abstractions of the first order" are met with in man which are undoubtedly abstractions in the proper sense of the word. To this class belong our first intellectual concepts and judgments on the properties of things that can be perceived by the senses, as: "The leaf is green," "Sugar is sweet." Such intellectual concepts and judgments presuppose complex sense representations, from which they are abstracted. But does the fact that general sense images in man develop into proper abstractions of the first order furnish an argument for the same process in the psychic life of animals? Emery does not substantiate his assertion by a single proof. Consequently we are justified in saying that it is an arbitrary humanization of the animal. Even Emery in-

1) This is also confirmed by the fact that some children framed a language for themselves (see Giesswein op. cit., p. 195 ff., and Gutberlet, p. $378 \mathrm{ff}$,), 
sinuates this truth in answering a question he had put: "Does a dog or monkey gather the concept of 'color' in general from the notions of the single colors, and the notion of a bird from the memory images of various feathered creatures? Or is it unable to do so? This we do not know and probably never shall know." He professes not to know whether higher animals have any general concepts beyond abstractions of the first order; but in that case it is inconsistent on his part to admit any genuine abstractions in the psychic life of animals, even those of the first order; for the latter necessarily contain a general concept in the strictest acceptance of the term. It is an essential element of every true comparison. If we cannot know whether a dog derives the notion of color in general from the notions of the single colors, then we do not know whether it forms the general notion of "red" or "green" from the concrete manifestations of these colors in the objects of its sense perceptions.

But we are forced to take a step further. As abstractions of the first order in man essentially presuppose a real power of abstraction, and as there are no reliable manifestations of such a power in animals, we must conclude that animals have no intelligence. For, even an abstractive power of the first order must manifest itself in formal intellectual judgments, and this power of inference must necessarily influence and show itself in the activity of the animal. Consequently, if we find no outward manifestations of such a power we are not allowed to say: we know of no abstractive power in the psychic life of animals, but must assert that animals have none. 
And furthermore it is impossible to possess abstractions of the first order without the natural inclination to communicate them to other beings of the same kind. But a communication of general notions on the properties of things perceptible to the senses essentially implies the use of language similar to that of man. Why then are dogs and monkeys without it? That they have none, is admitted even by Emery. But we inquire further: why have they none? We cannot shove this embarrassing question aside by merely referring to the different structure of the larynx in man and in the higher animals. For nothing more would be required of them than a mutual agreement and definite arrangement of their inarticulate sounds as arbitrary signs or symbols of their general concepts and abstractions of the first order. The result would indeed be a rough and disagreeable language, very deficient in words and constructions, still a language similar to that of man. Very many dogs and monkeys are able, as we know, to vary and modulate the sounds they utter according to various sensile affections of which these sounds are the immediate expressions. What then is wanting to establish a language? It is not the want of sounds, but of the possibility and necessity of mutually combining and intelligently arranging these sounds as arbitrary, conventional signs of their concepts and ideas. If animals really possessed genuine abstractions, even those of "the first order," the possibility and necessity of a language would be the immediate result. Consequently, from the lack of language even in the highest mammal, we can and must infer the lack of intelligence. 
It is true that not only the higher but likewise many lower animals, and especially insects which live in colonies, have something that can be compared to human speech. But this is not the place to discuss the nonsense that has been written in recent times about the pretended language of animals in pseudo-scientific circles of America ${ }^{1}$ and Europe. Moreover it would be unjust to Mr. Emery, to place him on a level with such psychologists as Hosea Ballou, I. Bregenzer and R. L. Garner. Consequently we may well pass on to the third point of Emery's argumentation.

He agrees that the analogon of human speech which is found in animals, is altogether different from the language of man. The latter is the result of a conscious, intelligent combination of certain sounds with certain general concepts and judgments. On the other hand, Emery finds it "difficult to determine" in how far the use of inarticulate sounds depends on an unconscious impulse in animals, and in how far it depends on a rational intention. The latter seems to him "not so very improbable," at least in some cases. However, such vague unsubstantiated conjectures cannot claim any consideration in a critical discussion of psychic life. Whatsoever proofs he alleges, do not at all bear on his

1) We must add a note on a book published some years ago in America by R. L. Garner on "The Speech of Monkeys." Mistaking the inarticulate chattering of monkeys for a true language by which they manifest and communicate their sensitive feelings, poor $\mathrm{Mr}$. Garner dreamt that he could prove the existence of monkey "speech," and possibly interpret it. All German critics who have taken notice of Mr. Garner's book in scientific reviews, concur in the well-founded reproach that the author has no idea of the rules of scientific psychology, and is utterly devoid of critical judgment. Even W. Marshall, who translated the book into German, was compelled to confess that the author suffers from an exuberant imagination. 
conjecture, but only show the existence of sentiency in animals, not that of intelligence. We find it not only probable but self-understood, that the cries of pain uttered by any animal of a higher species and heard by another of its own kind, cling to the sensile memory of the latter animal, and are liable to become, as it were, manifestations and signs of a psychic condition which cannot be directly perceived by the senses. But such signs have nothing to do with "intelligent determination" in animals, on which the use of calls and cries is said "sometimes" and "probably" to depend. Once free from the tyrannizing influence of the theory of evolution which postulates a priori the maintenance of such probabilities, it is not difficult to realize that this conjecture is not only void of any solid foundation, but that it is positively false. If the combination of these inarticulate sounds with one another and with certain sensile states of feeling and sense perceptions, were really due to "intelligent determination," animals would not only be endowed with something that could be compared to human speech, but with speech itself. This they do not possess, as Emery himself acknowledges.

There exists a perfect parallelism, that is demanded by nature, between the cognitive and appetitive powers and their manifestation through signs which can be perceived by the senses. This parallelism is as remarkable in man as it is in the brute. In the stage of infancy, and before all use of reason, the babe manifests its psychic impressions and feelings by inarticulate sounds of Dain, joy, desire and pleasure. Even adults act in a similar way, and in the first outburst of passion gencrally give inarticulate utterance to those vehement 
affections in which the activity of the sensitive appetite prevails. But when sober reflection is restored, when reason gains its sway and the superior appetite predominates, the same adults manifest their psychic life by phonetic or graphic symbols which are properly arranged in thought and expression. They speak or write a rational language according to logical and grammatical rules. This parallelism clearly shows that the animal possesses only a sensile and not a spiritual perception and appetite, and explains why its perceptions and affections are never expressed by arbitrary symbols, but only by those immediate and natural signs which follow the instinctive laws of sensitive association of representations. Moreover many animals are forced hy the circumstances in which they live to communicate their sensitive perceptions and affections to other sentient beings. A dog will scratch at a closed door and bark and whine, until it is opened. Such methods of communicating sensitive affections belong to the same class of natural signs as the mating sounds of animals, the chirping of crickets, the knocking of certain beetles (Anobium), or the different melodies of birds. The alarm cries of certain animals against enemies, and the cries by which other animals of the same species are warned of impending danger belong to the same category. Even the socalled feeler language of ants which is not immediately connected with the propagation of species or with individual needs of self-preservation, but subserves manifold wants of social cooperation, to an extent not met with in any species of higher animals, even this means of communication which bears the most resemblance to 
human speech, does not ascend above the level of immediate, natural, spontaneous and sensile signs, it is not determined by individual deliberation.

It cannot be denied that all these different forms of "animal language" exhibit an analogon of human speech. Still they are essentially different. Pseudopsychology may ignore this difference: scientific psychology must acknowledge it. Animal language is never the result of an intelligent reflection on the part of the brute to use arbitrary, fixed, sensitive signs which have been conventionally agreed upon as the fit expression of psychic experiences with the view of being understood by other animals. It is simply the outcome of the laws of sensitive instinct which imply with physical necessity the use of a certain sound, or a certain tap of the feelers to express and communicate a certain sensitive affection. The language of ants published in our "Vergleichende Studien," offers further proofs of this conclusion. These remarks will, I trust, suffice to clear up the true relation between speech and intelligence.

The question of the origin of human speech and the attempt to explain it by development from the natural vocal utterances of the higher animals, is a thorny, and even a hopeless chapter in the modern theory of evolution. All the explanations of $\mathrm{Ch}$. Darwin and of his school were so weak and frail that they immediately collapsed before the adverse criticism of modern linguists." "I may exert my intellect as much as I like, and I may strain my memory as much as I like, I can-

1) See Giesswein, op. cit,, 2d part, ch. 2, and Gutberlet, "Der Mensch," ch. 5 . 
not understand, how speech should have developed from anything which animals possess, even if we granted them for this sake millions of years." Would that these words of Max Mueller ${ }^{1}$ were taken into consideration by advocates of the modern theory of evolution.

As a matter of fact, there is a vast and momentous difference between the so-called language of animals, and that of man. Even Emery admits it. And we fully agree with him in considering language as one of the principle marks which distinguish the psychic faculties of man from those of the animal. But we go further and assign as the reason of this difference between the perceptible expression of human and animal psychic faculties the fact that the animals have no intclligence, that they have only a sensitive and not a spritiual life, whereas man is endowed with both.

Let us finally proceed to compare our conclusions with those which Emery drew from his discussions on speech and intelligence. "If," he says, "we restrict intelligence to what can be accomplished by the help of phonetic or graphic symbols of sound, then man alone possesses intelligence, and animals do not. But, if we call intelligence the power of gathering general knowedge from a number of single perceptions, and of applying it to consciously adaptive actions, then animals are also intelligent, although in a limited degree." We are very far from restricting intelligence to what can be accomplished by the help of phonetic or graphic symbols of speech. We still maintain our previous position, and characterize intelligence as the power of forming

1) "Das Denken im Lichte der Sprache" (German edition, Leipzig, 1888), p. 149. 
general concepts and conclusions out of sense perceptions, and of applying them to consciously adaptive actions,-and instinct as the principle of unconsciously adaptive activities in the psychic life of animals. Our definitions of intelligence and instinct coincide with those of Emery. How, then, does it come that he draws the very contrary conclusions? The reason is, because he errs in taking complex sense representations for general concepts, and falsely ascribes "abstractions of the first order" to animals. We have proved that he is wrong in doing so, and consequently we infer from the same premises the correct conclusions: that animals have no intelligence, not even "in a limited degree."

And now permit me also to allude for a moment to the "religious point of view." Language distinguishes man from the animal, but this is only an external difference. The real difference consists in intelligence which is wanting to the brute. Man does not become man by his speech, but by his intelligence, which is the logical and psychological presupposition of speech. The breath of the Divine Spirit through which the human organism became a human being, is the spiritual soul of man. It is the natural image and likeness of God, which raises man, the crown of the visible creation, to a height far above the animal, and enables him, a sensitive-spiritual being, to link the material world to the spiritual in himself and in his human nature.

Our worthy critic Mr. Emery ${ }^{1}$ has recently raised some new objections to our preceding discussion. $\mathrm{He}$ summarizes them in the following propositions:

1) "Instinct, Intelligenz und Sprache" ("Biologisches Centralblatt," 18 [1898], No: 1, S. 17-21). 
"I assert against Wasmann:

I. "That it is very probable, though not proven, that animals form general (abstract) notions from their sense perceptions. And, as it is equally difficult to prove the contrary, it is not admissible to draw a sharp line of separation between man and animal on the ground of such a premature judgment."

2. "That in certain cases animals undoubtedly perform not only adaptive, but consciously adaptive actions."

3. "That language, as the logical employment of sense perceptible symbols for abstract concepts, is the chief characteristic mark of human intelligence. By language I understand the whole complex of those cerebral activities which cooperate in the formation and employment of words and depend on definite cerebral structures. Language is both the product of intelligence and a means of furthering it."

To these propositions I reply:

We are not allowed to ascribe to animals higher psychic functions than they evidently manifest. Now, as even Emery himself admits, it is impossible to prove that animals form general concepts from their sense perceptions. The reason is, because all manifestations of their psychic life can be satisfactorily explained without this assumption. Therefore we are not forced to attribute the power of abstraction to them. This is not a "premature statement,"on the contrary, it is well founded. The probability which Emery maintains for the sake of suggesting the presence of such a power in animals is without any foundation in facts, and the interpretation of the examples which he enumerates ( $\mathrm{pp}$. 
I8 and I9) in support of his opinion, comes from his error in taking general sense images for genuine abstractions, a mistake which we have abundantly refuted. Emery finds it very probable that a dog can perceive the identity of color between the green-colored bench and the bushes in the garden. But such a judgment essentially presupposes an abstract notion of the elementary perception of "green." The dog undoubtedly perceives the similarity of the two green colors, because both of them produce a similar sense image in its sensile imagination. But it is contrary to all scientific probability that it reflects on this similarity that it forms the general concept "green" by abstraction, and uses that Idea for a formal judgment. Such suppositions are, to say the least, improbable, because the similarity of the respective sense images fully suffices to explain the actual behavior of the dog. To ascribe anything more to it is an arbitrary humanization of animals. Ants, $a s$ is known, are endowed with well developed compound eyes. They too perceive the similarity between their own color and that of those guests which belong to the so-called mimicry type. ${ }^{1}$ For without this perception the similarity of color could not accomplish its biological purpose, which is to aid the guests and to be of profit to them. Yet, who would conclude that ants reflect on this resemblance and reason as follows: an animal that is colored similarly to ourselves must either bc of our species or, at least, be friendly towards us; therefore let us favor those guests which are colored similarly to ourselves? Emery will probably admit

1) More particulars are given in our work: "Die psychischen Faehigkeiten der Ameisen" ("Zoologica," Heft, 26), p. 41 ff. 
that it is an unjustifiable humanization of ants, to credit them with the power of forming abstract notions and of using these notions in acts of reasoning. But why, then, ascribe this faculty to dogs? There is no more reason for doing so than in the case of ants. We can just as easily explain any biological facts connected with dog life without this assumption.

Moreover, Emery overlooked an important point in our previous discussion; for we argued against the assumption of general notions in animals not only negatively, but from positive reasons. We did not only show, that we are not forced to ascribe a power of abstraction to the dog, but that the employment of general notions in its subsequent activity would necessarily improve and develop its perceptive process, if it really possessed the power of abstraction. But such an improvement is absolutely unknown. Consequently it is wrong of Mr. Emery to call it inadmissible to argue a sharp line of separation between man and brute on the ground of the want of general notions on the part of the animal.

2. He asserted further "that in certain cases animals undoubtedly perform not only adaptive, but consciously adaptive actions." If "conscious adaptation" is taken in the sense of formal consciousness which results from the abstract knowledge of the relation between means and end, then the proposition is apparently false, because there is no power of abstraction in animals. The examples he has adduced (p. 19) in support of his assertion, prove absolutely nothing in favor of such a conscious adaptation. We readily admit that a dog scratches the door, because it wants 
to come in; and we likewise admit that, on finding the pantry door shut, a cat tries to get in, if possible, by some other known entrance, because she is allured by the fascinating imagination of the dainties to be had in that apartment. However, it would be wrong to infer a formal, conscious adaptation in the animal from these facts. They are fully explained by the working of the sensile memory which combines in one whole the end in view and the means to attain it, and thus directs the activity of the animal to that end. The dog had often made the experience,- and at first merely by chance,that a door gives way or opens when scratched by its paws; likewise the cat had often made the experience that dainties were to be found in a certain apartment and that different ways led to that room. These examples contain nothing more than associations of several sensitive phantasms which are the result of experience, and the objects of which bear the same relation to one another as means to an end. But this association of phantasms is far from being "formal, conscious adaptation." The latter does not only include the concrete connection between means and end, but the perception of their abstract relation. The first of these two elements belongs to the sphere of sensitive instinct and is contained in the association of phantasms to which we have just referred; the latter belongs to the sphere of intelligent life; the first we must ascribe to animals, because it is necessary to explain their actions; the latter we must deny, because it would be an arbitrary humanization of the brute. The assumption of a formal, conscious adaptation in animals is not only not demanded, but positively contradicted by facts. 
Similar reasons to those which Emery adduces in favor of "conscious adaptation" in dogs and cats, could be equally well alleged for ants. When they cannot enter their nest by one opening, they seek another which is known to them; when they feel hungry, they make a companion who has just come home with a well filled stomach, feed them, and therefore tap its head with their feelers and stroke its sides with their forelegs. Indeed, when they feel hungry, many Myrmecophiles, especially of the genus Atemeles, imitate in a surprising manner this habit of their hosts. ${ }^{1}$ Such facts would justify the conclusion that these animals act not only adaptively, but also with conscious adaptation. $N^{\top}$ evertheless it is now universally acknowledged that the sensitive instincts of ants and of their guests are sufficient to explain this seemingly conscious activity on their part. And, as pseudo-psychology is only too ready to humanize higher animals, we must be so much the more on our guard in interpreting their actions.

3. We need not dwell on the third point of Emery's reply in regard to the relation between intelligence and language. He has expressed it more correctly than he formerly did by describing speech "both as a product of intelligence and as a means of furthering it," and he locates the "chief characteristic mark" of human intelligence in the possession of speech. Still he should have added that the power of speech in man is not only the result of "special cerebral structures," but chiefly the result of his spiritual soul.

T) On this "active mimicry" see our paper, "Die Myrmekophilen and Termitophilen," Leiden, 1896 ("Compte Rendu du 3me Congrès International de Zoologie," p. 410-440), p. 432 and ff. 
But Mr. Emery prefers to ignore this "mysterious spirit," as he calls the human soul (p. I9), and breaks off all further controversy by the final declaration (p. 2I):

"It is to no purpose, on my part, to continue my controversy with Wasmann. The divergence of our views is due to a totally different conception of the world and of human nature. The main question, whether the human mind presents only a higher development of a disposition found in the animals, or whether, on the contrary, it is something quite apart, additional, and wanting in all other living beings, is far beyond the question of intelligence. An answer to that main question would determine the whole trend of science and thereby influence its results."

We cannot but regret that our highly esteemed critic concludes with this declaration. It is true, the question, whether animals are endowed with intelligence or not, is in the last resource connected with our respective views on the higher questions of the universe. But this is the case with almost any problem of natural philosophy. An unprejudiced comparison of the facts, connected with the psychic life of animals and of man, leads infallibly to the conclusion that man possesses an essentially superior principle of psychic activity, a spiritual soul. However, we judge the facts by no means $a$ priori from the standpoint of this necessary conclusion, as Emery imputes to us; but we infer this conclusion from a thorough examination of the facts. 


\section{CHAPTER VII!}

\section{A UNIFORM STANDARD FOR COMPARATIVE ANIMAL PSYCHOLOGY.}

$\mathrm{W}^{1}$

ITHOUT entering into particulars, another critic, Dr. C. Smalian ${ }^{1}$ appreciates the importance of exact definitions of instinct and intelligence. His psychological views are closely allied to those of $\mathrm{H}$. E. Ziegler, Forel and Emery, and do not call for further discussion at our hands. Smalian believes that the so-called anthropine translation, the tendency of attributing the psychic activities of man to the animal, goes beyond all lawful limits, when conscious intention is assumed to explain any psychic phenomena in the life of ants. It cannot be denied that they have experimental knowledge, that they are aroused to certain actions by sensitive impulses, that they have memory images which reappear with the recurrence of the stimulus that originally gave rise to them (p. 37). So far we fully agree with Dr. Smalian. Although he is an adherent of the Darwinian theory of evolution and vigorously combats our deductions from the distinction between instinct and intelligence, he is fair enough to make the following acknowledgment: "Wasmann's book is a model of exact, scientific procedure which holds the fancy chained and does not allow it to go astray during his examination of natural phenomena" (p. 45).

1) See his detailed account of the book, "Die zusammengesetzten Nester und gemischten Kolonien der Ameisen" in the "Zeitschrift fuer Naturwissenschaften," Vol. 67, 1894. ("Altes und Neues aus dem Leben der.Ameisen. Oeffentlicher Vortrag, gehalten am 18. Jan., 1894, im Naturwissenschaftlichen Verein fuer Sachsen-Thueringen.") 
In our "Vergleichende Studien ueber das Seelenleben der Ameisen und hoeheren Thiere" we shall return to the special objections by which Smalian attempts to invalidate some of our facts in disproof of ant intelligence. For the present we restrict ourselves to a few points of universal significance and to questions of principle.

Smalian thinks, as Forel did, that we require of ants "ratiocinations similar to the human, which they, of course, cannot make," and says : "In using the term intelligence, Wasmann seems constantly to think of a degree of that power too high for beings which are so widely different in organization from the highest vertebrate. In my opinion, he demands too much of ant intelligence."

This objection is due to a misunderstanding. We do not demand, nor have we ever demanded, that intelligence in ants be equivalent in degree to that of man. Still the essential characteristics of intelligence must be met with, if the so-called intelligence of ants is to be considered as intelligence at all. Our critics cannot confute our doctrine by insinuating that we require a ciegree of intelligence in ants equivalent to that of man. Our only demand is that the term intelligence be not trifled with in an arbitrary manner by designating as inteligence what is no intelligence in its proper interpretation. Both Forel and Smalian use the term in a very loose and analogous sense, and what they call intelligence is not inteliigence in its right meaning. We all know that a resemblance or analogy is not the same as a difference in degree. Still the modern theory of evolution is very fond of passing off analogies for differences in degree, in order to do away in the most 
convenient manner with essential differences that actually exist. Yet more than a hundred years ago we were warned by no less an authority than Reimarus, not to take mere similarities between different things for differences in degree of one and the same thing. It might be well, therefore, to draw the attention of modern writers on the psychic life of animals once more to $\S \S$ I5, I6, I22 and I23 of Reimarus' "Allegemeine Betrachtungen," a work of undoubted psychological merit. We have shown in detail that human and animal intelligence are not identical in their nature, but merely analogous, and that consequently no difference in degree can exist between them. We have proved that any intelligence, even the lowest, which is essentially identical with that of man, necessarily implies the power of formal conclusion. Consequently any intelligence in animals, even the lowest, must include "ratiocinations similar to the human," i. e. formal judgments and general concepts. Therefore, he who wishes to ascribe intelligence to animals, ought not to forget the exact meaning of the term, and should not claim intelligence for them and deny it in the same breath.

Of greater importance is another objection advanced by Mr. Smalian. (It is likewise borrowed from Ziegler, and was also mentioned by Forel in a somewhat different form). It is the following: Ants are so different from higher mammals and from man in their whole organization, and, especially, in the structure of their nervous system, that their psychic faculties cannot be compared with those of the latter.

These words can be taken in a twofold sense. Let us try to distinguish between their legitimate and their wrong meaning. 
Ants are articulates, whereas mammals and man belong to the class of vertebrates. Now there is no true (inatomical uniformity (homology), but only a greater or a less similarity (analogy) between the sense organs of these two classes. The most perfect sense of the higher vertebrates is undoubtedly that of sight. Yet the eye of vertebrates is totally different in structure from that of the compound (faceted) eye of insects. Whilst it forms only one reverse optic image on the retina of each eye, there is a great divergence of opinion as to the optic effect of the faceted eyes of insects. The older theory of Joh. Mueller, which has been recently supported by such authorities as Exner, Grenacher, etc., holds that the light impressions which are received in the different facets combine behind the point of convergence of the crystal-cones, whose number corresponds to that of the facets, in the form of a sort of mosaic total perception. This is the so-called theory of mosaic sight. Of late, however, Claparède and Patten maintain that a real image of the object is formed in each of the crystal-cones and that all these images are united to one single sight perception through the combination of the different branches of visual nerves. ${ }^{1}$ The anatomical structure of the compound insect eye, which is so different from ours, easily explains the fact which has been proved by numerous observations, that the sight perfections of insects are far more sensitive of objects in motion than of objects in rest, and more susceptible for differences of color than for differences of shape. An interesting instance hereof is furnished

1) See E. Jourdan, "Die Sime and Sinnesorgane der niederen Thiere" (1891), p. 286 ff. 
by the striking resemblance (Mimicry) between many ant-guests (Lomechusa, Atemeles, etc.) and their hosts. It is primarily a resemblance of color, and only secondarily a resemblance of figure, and is far more due to illusive light-reflexes than to a real resemblance of form. ${ }^{1}$

Moreover there is no doubt that many insects are endowed with the sense of hearing. Even ants seem to possess it. Still it is adapted only to the perception of higher and finer sounds. ${ }^{2}$ Nevertheless we have a very limited knowledge of the organs of this sense in ants. The olfactory sense is strongly developed in insects. Ants possess it in a high degree. Its primary organs are the feelers, whilst the variously formed olfactory bulbs, smell-hollows, etc., of the palpi subserve the same purpose in a secondary measure. The activity of the olfactory sense of insects is much greater than that of vertebrates; the more so, as, in their feelers, ${ }^{3}$ insects possess even a "movable nose." The setaceous "touch-bodies" of these feelers furnish, moreover, excellent organs of touch. Forel appropriately called the

1) See "Die Myrmekophilen und Termitophilen" (Leiden, 1896), p. $428 \mathrm{ff}$; also "Die psychischen Faehigkeiten der Ameisen" (Stuttgart, 1899), pp. 34-58. Mr. Lubbock has acquainted us long ago with the fact that ants perceive the ultra-violet rays which are invisible to us.

2) See D. Sharp in: "Transactions of the Entomol. Soc. of Lon. don" (1893), P. 2, p. 199 ff.; Ch. Janet in: "Ann. Soc. Ent. France," 62 (1893), 159 ss.: G .Adlerz, "Stridulationsorgan och Gudförnimmelser hos myror, in: Ofvers. of Kongl. Vetenskap-Akad. Förhandl" (1895), n. $10 ; J$. Weir, "The ears of worms, crustaceans and ants," in: "Scientific American" (April, 1898), p. 282. See also "Stimmen aus MariaLaach," 40 (1891), 214 on uttering of sounds by Myrmica ruginodis and the sense of hearing of Formica rufa; besides see "Biolog. Centralblatt," II. (1891), 26 and 13 (1893), 39.

3) See "Die Fühler der Insecten" in "Stimmen aus Maria-Laach," XL. (1891). 
peculiar combination of the olfactory and tactile senses on the feelers of ants the "smell on contact" (odeur au contact). The sense of taste has likewise been identified in many insects. Ants undoubtedly possess it. It resides mainly in the so-called taste-buris of the tongue and the maxillae. Lastly, the sense of touch is well and variously developed in insects, and especially in ants, in the form of setaceous touch-bodies spread over the whole body, but mostly over the extremities.

These few remarks are sufficient to show that the anatomical structure and the respective physiological activity of the sense organs of ants cannot be regarded as homologous but only as analogous to the structure and the activity of the sense organs of higher animals and of man. Nevertheless we can and must state that ants have sight perceptions, smell perceptions, taste perceptions and touch perceptions in the proper, and not merely in a metaphorical sense of the term. The difference between them and the corresponding sense perceptions of man is, it is true, mostly one of quality and not of quantity. However, a sight perception of an object is, and ever will be, a real and true sight perception in the strictest sense of the term, whether it takes place through the eye of a vertebrate or through a faceted organ of sight. The notion of "sight perception" is a generic term. It includes various specific notions, all of which contain the characters of the generic term, not only in an analogous or metaphorical, but in the real and proper sense of the word. Now, one characteristic element of all sight perceptions is, that the colors of an exterior object act through reflected light rays upon an organ expressly adapted to their optic reception and 
physiological transformation, and thereby convey the colors of the object and, in some degree, its form and figure to the perception of the subject whose sight organ receives them.

What has been said of the outer organs of sense perception is equally applicable to the nervous system of ants. Let us compare it with that of the higher mammals and of man. The central nerve system of all vertebrates is a cerebro-spinal, and that of all articulates a cerebro-ventral medulla. Dr, in other words, the position of the medullary cord is dorsal, along the back, in vertebrates, whilst it is ventral, along the front, in articulates. The brain of insects is an oesophageal nerve-centre, and consists of two double ganglia, one above and one below the oesophagus. The upper couble ganglion is more developed and takes the place of the cerebrum (anterior brain) of vertebrates. This analogy between the cerebrum and the supra-oesophageal ganglion of insects is the more perfect, the stronger the latter is developed. It displays its highest perfection in the "workers" of social insects, and in other art-loving Hymenoptera, whose supra-oesophageal ganglion is not only relatively large, but marked, moreover, by peculiarly developed parts called "peduncles" (corpora peduncula). Still the point at issue in comparative animal psychology is not so much the anatomical difference of the nervous system of insects and vertebrates, as rather its centralization and the relative size of the brain and the supra-oesophageal ganglion, in comparison to the other secondary ganglia. The unity of sensitive consciousness in animals is in direct proportion to the centralization of the nervous system; 
and the perfection of the imner senses, of the sensile memory, of the sensile imagination and appetite depends on the relative development of the brain.

Now, it is undoubtedly true that the centralization of the nerve apparatus even of bees and ants is inferior to that of dogs or simians. This is particularly applicable to the connection of the abdominal ganglia with one another and with those of the thorax, a connection which is effected only by a tender double longitudinal commissure. It is the probable cause of the greater frequency of mere reflex motions in insect life than in that of higher mammals; it accounts for the less perfect unity of sensitive consciousness in insects, manifested by such facts as that of the ant which continues to struggle even after the loss of its abdomen, or that of the bumble-bee which does not cease to suck honey after being deprived of its abdomen, or that of a dragonfly which bites off her own abdomen, when it is bent forward and thrust between her jaws. According to Ch. Janet's conscientious observations ${ }^{1}$ one can even cut off the abdomen of a hornet in the act of sucking honey, without disturbing the occupation of the animal in the least. The fact that any lesion, the loss of limbs or of such parts of the truncus, which are more remote from the head, mostly causes only slight changes in the immediate activity of articulate animals, suggests that very little pain is connected with such lesions, and the slightness of the pain argues the imperfect unity of sensitive consciousness and consequently an inferior degree of centralization of the nervous system.

It is true, great precaution is needed in identifying

1) "Sur Vespa crabro" (Mèm. Soc. Zool, France, 1895), p. 104. 
such phenomena. One can get an angry dog to snap at its own leg or tail by holding them before its mouth. Still the dog undoubtedly feels a physiological pain similar to what we would feel in being injured. It is evidently the want of intelligence, of reflective mental self-consciousness that induces the dog to act so foolishly. This case has affinity with an observation I made on June I7, I896, when engaged in the study of a very "intelligent" species of ants, the formica sanguinea. With a pair of pincers I put back a worker that had strayed from a nest under observation. Thereupon she tried to bite the pincers, and in doing so chanced to get one of her fore-legs between her jaws. On being returned to the nest, she began to fight with her own leg, bit it, pulled it, and even bent up her abdomen in order to eject poison upon the offensive member, and only regained her tranquility after the lapse of one or two minutes. Even higher animals often act in a similar manner in fits of rage.

The brain of ants and of bees is relatively little inferior in size to that of dogs and monkeys; and even years ago $\mathrm{Ch}$. Darwin called attention to the physiological importance of the mighty development of the cephalic ganglia in the "workers" of social insects, particularly of ants. ${ }^{1}$ Especially remarkable is the development of the peduncles, ${ }^{2}$ the foldings of which make them resemble the cerebral convolutions of higher vertebrates in a remarkable degree and seem to represent, as it were, even physiologicaily, the grayish matter of the cerebrum. According ito Vitus Graber the volume

1) Darwin, "Descent of Man," I. (2d German edition), p. 125.

2) See Aug. Forel, "Les fourmis de la Suisse," p. 122, ss. 
of those peduncles (which he calls "Beihirn") makes up no less than one half of the whole brain. If we take the proportion of weight to volume, we find that almost the same proportion exists between the weight of body and brain in ants, as in dogs, one of the most "intelligent" species of higher animals; it varies between I :200 and I :300.

The experiments of scientists whose specialty consists in the anatomy and physiology of the brain, have proved the existence of an essential connection in vertebrates between the cerebral cortex and the power of association. Louis Edinger" maintains that "all those activities which can be acquired by training, and nearly all those which are performed by the aid of memory images depend on the normal condition of the cerebral cortex"; and that "all those mental processes which are termed associations are especially connected with it." $\mathrm{He}$ repeats the same statement in another work, ${ }^{2}$ and says: "We know for certain that the higher mental functions, and particularly those of an associative nature, are in direct proportion to the normal condition of the brain-cortex." But as the power of association is, according to most modern physiologists, equivalent to "intelligence," this proportional dependence is expressed in these terms: In the animal kingdom intelligence begins with the existence of a cerebral cortex, and with the more perfect development of the cortex a more perfect development of intelligence is necessarily connected.

1) "Vorlesungen ueher den Bau der nervoesen Centralorgane des Menschen und der Thiere" (5. Aufl, Leipzig, 1896), S. 169.

2) "Neue Studien ueber das Vorderhirn der Reptilien" (Frankfurt ค. M.. 1896). S. 6 . 
As we have shown in previous chapters of this essay, a confusion of ideas is answerable for these propositions. The power of association is unwarrantably taken for intelligence. Even in man it is only the basis of intelligence, the essence of which is not constituted by associations of sense representations, but by the perception of their mutual relations. As the brain-cortex is the necessary material organ of the power of association in vertebrates, we readily admit that an essential, although exterior connection exists, also in man, between the normal condition of his brain-cortex and his intelligence. This fact is abundantly proved by the inmates of our insane asylums. Indeed, the essential connection between the brain-cortex and higher psychic activity is even interior in all other vertebrates whose sensitive power of association does not attain to the level of spiritual intelligence. Still in admitting this connection we warn against the danger of over-valuing it. Thus the brain-cortex of birds is less developed than that of reptiles. ${ }^{1}$ Nevertheless, the power of association of many birds is not only superior to that of reptiles, but even of lower mammals, whose cerebral cortex shows a far more perfect development.

As so much reserve is required in rating the psychic endowment of an animal, even a vertebrate, according to the thickness of the brain-cortex, the error of judgment is apparent on the part of those who transfer this standard from vertebrate to articulate animals, and maintain for instance that: "as ants have no braincortex, they cannot have a power of association: and that is is consequently wrong to compare their 'intelli-

1) See Edinger, op. cit., p. 152. 
gence' with that of vertebrates." The following conclussion which is almost identical with the above, will show the fallacy of this mode of argumentation: "The continuation of the spinal cord within the cerebrum (medulla oblongata) is the most essential organ of all vital functions in vertebrates; but this continuation of the spinal cord is wanting in ants: consequently they have no vital function, and we cannot compare the vital functions of ants with those of vertebrates." This argumentation is false, because it entirely ignores the very important fact that the nervous system of articulates is built on a different anatomical plan from that of vertebrates, and that,consequently, the vegetative, as well as the psychic functions of articulates, depend on very different central organs of the nervous system, which are merely analogous to those of vertebrates, although they fulfil the same biological purpose. Edinger himself has proved that the nerve-centers of articulates are the organic foundation and condition of psychic association. In examining the anatomical structure of the first abdominal ganglion of a crawfish he pointed to the nerve-cells joined together by various filaments, and exclaimed: "How many possibilities of association are furnished by this single ganglion!"1 Yet the brain of an ant is the central organ of a nervous system far more perfect than a ganglion in the abdomen of a crawfish! Why then, deny to ants the psychic power of association "for anatomical reasons"? If the lack of a cerebral cortex like that of vertebrates were a reason

1) Op. cit., p. 28. Whether the ganglion-cells or the fibrillar tissues are regarded as the organs of nervous activity, is of no importance in our present discussion. 
for doing so, the normal vital activities of the ant ought to be just as "brainless," as altogether awkward, as the actions of a higher vertebrate would be, that had been deprived of its cerebral cortex by artificial amputation. But this conclusion is an apparent contradiction to biological facts. Therefore the argumentation on which it rests is likewise untenable.

Perhaps science will some day succeed in investigating the anatomy and physiology of the insect-brain as accurately as it has investigated the brain of vertebrates. The difficulty is of course immense on account of the minute proportions of the object under examination. In the mean time the foliowing considerations must serve as a sufficient safeguide in comparing vertebrate with articulate animals. It is an incontestable fact, that many insects and especially ants have a sensitive power of association which suitably guides the exercise of their instincts, and which is modified in many ways by individual experience. In our different works ${ }^{1}$ we have furnished much evidence in proof of this fact. Moreover the anatomical discovery of the far more perfect development of the socalled by-brain, the peduncles of ants and of other insects whose psychic capabilities surpass those of insects of inferior psychic endowment, is in perfect harmony with the above-mentioned psychological fact. Hence we may conclude with much probability, that there is a similar connection between the "by-brain"

1) Especially in the "Vergleichende Studien ueber das Seelenleben der Ameisen und hoeheren Thiere" (1. Aufl., Freiburg, 1897), and in our recent work, "Die psychischen Faehigkeiten der Ameisen" (Stuttgart, 1899). 
and the associate power of insects, as between the braincortex and the associate power of vertebrates. And thus, I think, the objections made against our argumentation by modern brain-anatomists have been sufficiently discussed and refuted.

Consequently the comparative morphology and anatomy of the nervous system justify the application of a uniform standard to the psychic activities of articulate as well as of vertebrate animals. Even the mere zoological standpoint permits us to exact almost as much from the sensile cognition and appetite of ants, as from the same faculties of dogs. And as modern animal psychology terms this essentially sensitive associative power the "intelligence" of animals, we are equally entitled to apply the same critical standard to the "intelligence" of ants and of higher mammals.

But before we test this conclusion we must prevent a misunderstanding which might arise from speaking cif the "unity of the sensitive consciousness in animals." It is nothing unusual on the part of modern psycholcgists to identify sensitive consciousness with spiritual self-consciousness and with consciousness of the end. Yet, these two psychological concepts are entirely different, as will appear from the following analysis.

Any sense perception, indeed any "perception," includes, as a secondary element, a cognition of the impression which the object makes upon the sensitive condition of the agent. We call this latter element "apperception." These apperceptions are not unfrequently more vivid in animals than the perceptions themselves. This arises from the fact, that the subjective element generally predominates over the ob- 
jective in the cognitive process of animals. The reason for this fact is to be found in the end and purpose of sense perceptions in animal life. It is to represent to the animal's sensitive nature as subjectively agreeable what is objectively suitable for the preservation of the species, and, for the fulfilment of its natural destination; and to represent as subjectively disagreeable whatever is objectively injurious. This result is obtained by apperception; for the suitable disposition of the sensitive powers of cognition and appetite-which we call instinct-causes the perception of useful and convenient objects to make an impression which is sensually agreeable to the animal, and the perception of noxious objects a disagreeable impression upon its sensitive appetite. In man, however, whose sense perceptions primarily subserve a higher spiritual cognition, the objective element prevails under normal conditions over the subjective impression, even in his sense perceptions. Daily experience enables us to observe this fact. When we are in a bad humor we view everything through a "smoked glass," because our subjective condition is abnormal and diseased. Still the apperception, or the subjective element of perceptions is, generally speaking, subordinate in man to their objective element. But in animals the very contrary happens, because the purpose of their sensile power of perception demands it. Even under normal conditions the subjective impression prevails over the objective contents of the representation.

The sensitive consciousness of the animal is due to apperception; indeed it is identical with the latter in its activity. For the sensitive power of perception is unable to distinguish between the objective and the sub- 
jective elements of sense perceptions. Intelligence alone can thus discriminate. By virtue of his intelligence and free will, man is able to free himself from the impression which objects make upon him. His spiritual nature enables him to disregard it. $\mathrm{He}$ is not forced to follow the sensitive impressions of his good or bad humor, and when he does, he acts unreasonably; he follows the animal, not the human side of his nature. Intelligence, and it alone, is able to discover the true relations which exist between the object and the subject, and again between the subject and its activities, and is able to reflect on them. It alone compares them, one with the other, draws conclusions from them, and is thereby raised to self-consciousness and adaptive activity. Reason alone, this mental "introspection," renders self-consciousness and consciousness of the end possible. Hence man alone truly and properly apprehends himself as the uniform subject of his different perceptions, affections and actions. The animal does lot; because it cannot reflect. It perceives the actual unity of its sensitive nature only in as far as it experiences by way of apperception the actual connection of certain sensitive impulses with certain exterior sense impressions. This connection determines the activity of the animal with necessity; because the latter is unable to make it the object of intelligen reflection. Pseudo-psychology, of course, regularly confounds the sensitive consciousness of the animal with mental selfconsciousness and the consciousness of intention in human beings. However, this confusion hinders a clear analysis of psychological phenomena, and must be discarded as unscientific. These remarks may suffice to 
explain the so-called "unity of the sensitive consciousness" in animals.

We have seen that a uniform, critical standard in comparative animal psychology exists, and must exist in spite of the anatomical difference between the sense organs and the nervous systems of ants and of the higher vertebrates. The development of the organs of sense perception and of the central nervous system in ants is such, that it can well stand the comparison with the development of the sense organs in mammals. The sense perceptions of ants are true and proper sense perceptions, no less than those of dogs, monkeys and even of man. Furthermore, the relative perfection of the principal parts of the central nervous system of ants is well proportioned to a highly developed interior sensitive power of perception. Indeed from an anatomical point of view the latter may be inferred with certainty. And as this sensitive power of perception is nothing else than the mis-named "intelligence" of modern animal psychology, we have given the proof, that no solid argument can be advanced from an anatomical standpoint against a comparison of ant-intelligence with monkey, or even with human intelligence. If any of our modern opponents succeed in proving that the anatomical structure of the ant-brain a priori excludes all intelligence in the true sense of the term, we would be deeply indebted to him. Meanwhile we are convinced that such a proof is impossible. The question whether ants have intelligence or not, is, and finally ever will be a psychological and not an anatomical question. For its legitimate solution we may and must even apply the same standard of a critical psychological analysis, as for 
the solution of the other question, whether dogs, elephants or monkeys are endowed with intelligence or not.

If then some of our opponents deny the legitimacy of a comparison between the intelligence of insects and that of higher vertebrates on the pretext that they "represent totally different branches of the great trunk of the animal kingdom," ${ }^{1}$ it looks very much like trying to shirk a clear analysis of psychological concepts. But we insist on equal rights for the psychological criticism of all sensitive beings, and we must apply to each and all of them the same critical principles. Psychic activities which are dubbed intelligent in the case of dogs or monkeys, can and must be called intelligent in the case of ants, despite the anatomical difference between the eyes of ants and monkeys, or between the formation of their brains. We must necessarily use the same psychological standard in judging the actions of ants who post sentinels, in order to guard themselves against sudden hostile attacks, as we apply to monkeys who do exactly the same, when they are about to pillage a banana-grove. Anatomical reasons will never justify anyone in dubbing one and the same action "intelligent," when performed by monkeys, and "instinctive" when performed by ants. The psychic manifestation on the part of the dog that meets a dreaded rival, growls, shows its teeth and gets out of the way, is fully equivalent to that of the ant which chances to run against a warrior of a hostile camp, opens her jaws in a menacing manner and sneaks away from the combat. The small

1) Ziegler, "Naturwissenschaft und socialdemokratische Theorie" (1893), p. 186. Smạlian, op. cit., p. 39. Forel, "Gehirn und Seele," pp. 28 and 29. 
size of the ant does not justify us in applying a different standard to her psychic faculties. Nor does the anatomical difference of sense organs or nervous systems in dogs and ants entitle us to do so; for the gist of the question in estimating the psychic import of an animal's action is not so much which organic instruments are called into play, as rather how they are employed.

Smalian quotes a sentence from Darwin's "Origin of Species," 1 in which this author sketches the difference between the psychic activities of ants and those of man: "Ants work by inherited instincts and by inherited organs or tools, whilst man works by acquired knowledge and manufactured instruments." And Smalian continues: "This difference cannot be emphasized too much: the activities adapted to the preservation of an antcolony result from necessity, those of man, however, irom free will." These are very gratifying and correct concessions. But we call attention to the fact that they reach much further than Darwin, Ziegler and Smalian are inclined to think. For the very same difference which raises a psychological barrier between ants and man, necessarily distinguishes dogs and monkeys from the human species. They, too, work only with their instincts, with natural organs and instruments; no dog or monkey ever works with an artificially manufactured implement. Ants, as well as higher vertebrates, are able to employ acquired individual sense perceptions in order to perfect their natural instincts, and many instances will be adduced in my last chapter in support of this plea. Let one instance suffice for the present. I had a nest of Formica sanguinea under observation, and kept it for

1) "Origin of Species," p. 362, 1, 6 and last English edition. 
many years in my room. Desiring to disaccustom the ants from emerging through a certain opening of the nest and falling upon a table from which it was difficult for them to find the way home, I only had to grasp with my pincers a number of ants, which happened to be outside, dip them into water and put them back, wet as they were, into the nest. I could then be pretty sure that not one of the several hundred ants of this colony would dare to leave the nest for one or more days through the dangerous opening. This fact proves that ants are undoubtedly able to make use of sensitive experiences, and to communicate them to others of their species: indeed, we do not find more "intelligence" even among higher vertebrates. He who says that in such cases ants perform unconsciously adaptive actions, whilst similar actions of monkeys are consciously adaptive, makes an arbitrary assumption that is not warranted by any reason or argument. From equal effects we can and we must infer equal causes. Consequently both ants and monkeys act only instinctively, or both of them perform intelligent actions. There is no other possible medium.

It is, therefore, an unwarrantable inconsistency to abandon the intelligence of ants, in order to save that of the higher mammals. He who, with Ziegler, Smalian and almost all modern animal psychologists styles all those actions intelligent, which are due to the individual experience of the animal, involves himself in an obvious contradiction, by attributing "intelligence" only to higher mammals and not to ants and other insects. For this pretended intelligence is nothing more than the natural exercise of innate instincts, by means of individual sense perceptions. And for this reason all animals have more 
or less intelligence according to this modern definition; but most of all those which, like ants, have highly developed instincts. Darwin was far more consistent than many a recent zoologist, when he wrote in his "Descent of Man":1 "Those insects which possess the most wonderful instincts are certainly the most intelligent."

But did not Mr. Alb. Bethe in his recent work that has been so widely spoken of, ${ }^{2}$ prove that ants have no "psychic qualities" whatsoever, and that in consequence a far wider gap exists between them and the higher vertebrates, than between these and man? Lethe's essay relates, indeed, many clever experiments with ants and bees, it is of undoubted scientific merit compared with many pseudo-psychological treatises which humanize ants, it even helps to prove our statement that ants are not a sort of intelligent human beings in miniature. For these achievements we owe Mr. Bethe a debt of gratitude. But we regret so much the more that he went to the opposite extreme and tried to transform the ant into a mere reflex-mechanism, devoid of all sensitive cognition and feeling. We have elsewhere examined Bethe's reflex-theory in detail, ${ }^{3}$ and in disproof of his views on the psychic faculties of ants and of higher animals, we have instanced many new facts from our own observation in a larger work, ${ }^{4}$

1) Op. cit., 1, p. 37.

2) "Duerfen wir den Ameisen und Bienen psychische Qualitaeten zuschreiben"? ("Archiv fuer die gesammte Physiologie," 70 [1898], 15-100.)

3) "Eine neue Reflextheorie des Ameisenlebens" ("Biologisches Centralblatt," 18, 1898, No. 15, S. 577-588).

4) "Die psychischen Faehigkeiten der Ameisen" ("Zoologica Heft," 26, Stuttgart, 1899), 134 S. Folio with 3 plates. 
which was called forth by his essay. Hence a brief notice of it is sufficient for our present argument.

The fundamental principle in Bethe's psychological essay is that all activities of animals, which have "not been learned," are mere reflex actions, and that it is unlawful to speak of psychic qualities, unless the animal be able to modify its inherited activities by individual experience. ${ }^{1}$ This arbitrary principle changes all activities hitherto regarded as instinctive in the strict sense of the term into reflex action, and eliminates from the sphere of psychic functions the sensitive feelings and cognitions which guide them. Bethe tries to justify his novel procedure by stating that these psychic qualities fulfil their purpose only when they enable the animal to modify its activity by individual experience. But is not the first and primary end of sensitive feeling and perception the immediate and present welfare of the animal by enabling it to seek suitable, and avoid injurious objects, the former of which they represent as agreeable and the latter as unpleasant, while they simultaneously guide the performance of the respective activity in a suitable manner? It is only as a secondary purpose that they are the means of gathering experimental knowl-

2) The same fundamental principle is maintained by Dr. Jacques Loeb, professor at the University of Chicago, in his book "Einleitung in die vergleichende Gehirnphysiologie und vergleichende Psychologie, mit besonderer Beruecksichtigung der wirbellosen Thiere" (Leipzig, 1899). The refutation of Bethe's views contains a refutation of Loeb. Loeb's mechanical explanation of instinct has been critically examined in the following essays: "Einige Bemerkungen zur vergleichenden psychologie und Sinnesphysiologie" ("Biolog. Centralblatt, 1900, n. 10, pp. 341-348), and "Zur mechanischen Instincttheorie" ("Stimmen aus Maria-Laach," Freiburg i. B. 1901, Heft, 1 und 2). 
erige, and thus enabling the animal to modify its subsequent mode of action. The very fundamental principle of Bethe's new reflex-theory is erroneous; and for this reason we cannot admit the structure which he has built upon it. His constantly recurring argument, that such and such an activity of ants and bees has not been learnt, and must consequently be regarded as a mere reflex activity, proves absolutely nothing.

In applying his reflex-theory to the life of ants Bethe has unfortunately altogether overlooked the psychic element of the activities which he mentions. Moreover he simply denies facts that escaped his personal observation, or which did not seem to fit into his system. Thus he denies the power of communication (p. 65), or, at most, admits its possibility in the marauding expeditions of the so-called slave-making species. Nevertheless the existence of this mutual communication which is accomplished by taps of the feelers has been previously demonstrated in many other happenings of ant life. That ants frequently modify their actions through individual experiences, as when they grow familiar with new genuine guests, and learn to treat as enemies guests which had been previously tolerated with indifference, and even to seize and kill them,such facts as these are all unknown to $\mathrm{Mr}$. Bethe, although scientific literature furnished abundant material in proof of their existence. He even appeals to my own writings in support of his statement that no single fact clearly demonstrates the existence of "psychic qualities in ants" (p. 69). Verily, this appeal cannot be understood except for his error in taking sensitive perception for intelligence. 
Whilst Bethe regards ants as "reflex mechanisms" without sensitive feeling and cognition, he tries to raise the psychic endowment of higher animals nearer to that of man. Thus he affirms (p. 69) that: "The dog and the monkey must first learn everything in the same way as man does"; whilst he had just stated that the natural disposition of the ant contains everything that she does in her lifetime." We shall dwell upon both statements more closely in the following chapter in which we treat on the different methods of acquiring knowledge. Stili wc wish to point out the consequences that would follow from the consistent application of Bethe's reflextheory not only-as he would prefer-to non-vertebrate, but also to vertebrate animals.

If we lay down the principle with Bethe and Loeb that "what is not learned, must pass for reflex activity," we must conclude that all hereditary instincts, and all those sensitive feelings, perceptions and imaginations, which govern the exercise of these instincts in higher animals, are necessarily mere reflex phenomena. But as the so-called intelligence of animals is nothing more than the combination of different sense perceptions and acts of the imagination, subject to the hereditary laws of association, and mediated by individual experience, we must consistently maintain that it is also a mere reflex, though perhaps more complicated activity. What would then be left of the psychic life of animals but a "complicated reflex mechanism" that is capable of analysis? The whole animal kingdom would be reduced once more to the famous animal mechanisms of the Cartesian school.

Therefore it cannot be denied that there is a uniform 
standard in comparative animal psychology; for the attempt to judye the psychic activities of non-vertebrate animals according to a standard a priori different from that applied to higher vertebrates, has proved a signal failure. Bethe pretends (p. 69), that we demand a mniform and consistent standard of discrimination for the psychic life of all animals only, "because he (Wasmann) must prove, that ants do not essentially differ in their vital activities from higher vertebrates, and because he fears lest the final issue of his researches would lead him to admit a progressive development of psychic qualities, which places the human being, not in a category of his own and different from animals, but only in the highest grade of a long chain of beings subject to the laws of evolution." However, in our opinion the only question is not what we must prove according to Bethe's fancies, but what we have actually demonstrated on the ground of existing facts. Our expositions are not refuted by mere appeals to modern views. ${ }^{1}$

1) See also the Introduction to Bethe's paper, p, 16. 


\section{CHAPTER VIII.}

ON THE DIFFERENT FORMS OF ACQUIRING KNOWLEDGE. ${ }^{1}$

$M \begin{gathered}\text { ODERN animal psychology establishes the ac- } \\ \text { quirement of knowledge as the criterion of intel- }\end{gathered}$ ligence in contradistinction to instinct, or, as we shall hereafter briefly call it, the power of learning, in the widest sense of the term. We have already shown in detail that by no means every modification of instinct acquired by the individual is the result of intelligence. But in order to understand the true value of this criterion, we ask, what is meant by "learning"? We must try to analyze and separate the different notions that are commonly connected with the word, and too frequently confounded with one another. It will soon become apparent which kind of "learning" furnishes an argument for intelligence and which does not. In conducting this investigation we shall not be influenced by any philosophical system, and be guided solely by the natural explanation of biological facts.

Well established facts in the psychic life of man and animals manifest six different ways or "forms," of learning: three forms of learning by one's self, and three of learning by foreign influence.

I. The first form of learning is met with in those abilities which are acquired by the mere exercise of reflex motions. It is due to hereditary reflex mech-

1) A inore detailed discussion of this subject will be found in "Die rsychischen Faehigkeiten der Ameisen" (Zoologica, Heft 26, 1899), pp. 82-114. 
anism, and has nothing to do with intelligence. Under this heading falls, for instance, the manner in which ants and higher animals "learn to walk" ; indeed, hereditary reflex mechanism is the most essential and the principle element of learning even for a child that begins to take its first steps. The motions of walking are, as such, reflex activities. It is true that nerveand muscle-mechanisms work more perfectly and quicker through practice. But this does not result from the sensitive experience of the animal or of man, but from the increased mechanical and physiological functional power of the respective reflex mechanism which is due to exercise. Still one psychic element comes into play. The animal as well as man has an instinctive impulse to use its motory mechanism. This impulse includes the psychic element of so-called muscular sensations; and as these muscular sensations actuate the instinctive impulse, the whole process cannot well be called a mere reflex activity. Moreover, if the motion is occasioned by the sense perception of some exterior object which the animal approaches or avoids, the psychic elements of sensitive cognition and appetite come into play likewise; and man on coming to the use of reason is often guided in his motions, as experience confirms, by intelligent knowledge, or an intelligent intention. But we have no valid reasons to ascribe the latter motives to animals; nor has anyone ever thought of tracing back the art of "learning how to walk" to intelligence, either in animals or in man. On the other hand the instinctive practice of walking is much more dependent on foreign influence in man than it is in animals. At 
the very most the instinct of imitation cooperates in the latter by the impulse which it imparts; and this influence belongs to the fourth form with which we shall become acquainted later on. But an infant must be guided by the hands of another person, or else it will take a long time in learning to walk. This never occurs with animals. It has never been observed in ant colonies or in herds of monkeys, that the young were guided by their mothers' hands in order to be taught the art of walking.

But all these elements are of secondary moment in man and animals, compared with the chief and most essential element in acquiring this art. It is the lowest and simplest form of learning, the exercise of reflex motions, which has its origin in instinctive impulse and is actuated by muscular sensations. Young lambs frisk about, because they are stimulated by their muscular sensations, and thus they learn to move all the quicker and steadier. The play of pups and kittens is naturally explained in the same manner, as well as the gambols of ants which cluster together on the surface of the nest, when the first warm rays of the sun shine upon them in early spring. ${ }^{1}$

2. The second form of learning occurs when a new line of action is acquired by the independent, sensitive experience of the individual. It is universally recognized that this form of learning is not unusual in man. But it is also very common with higher as well as lower animals. Thus in investigating the "international relations" which exist between Lomechusa, Atemeles,

1) See our "Vergleichende Studien" (1st edition), p. 42. 
Claviger, etc., and their hosts, I have met with instances of this second form of learning in the manner in which these ants become acquainted with their new guests. At first they are provoked to make an hostile attack upon the beetle on account of its strange shape and unwonted odor. But on chancing to touch its yellow hairtufts with their mouths, they make the agreeable experience of licking something highly aromatic, and change their hostile attitude into a friendly disposition often within a few minutes. In future they do not experience any hostile reaction through the odor and shape of the new guest, but tend and feed it, so that other individuals of the same species of beetle, which are subsequently put into the nest, are immediately admitted into the community, even though the odor of a strange species of ant may still adhere to them. We can explain this phenomenon only by saying, that the soothing experience made with the first beetle aroused a new association of representations in the sensitive powers of the ants, in virtue of which the second beetle made at once a very different impression on them, from that which was caused by its predecessor at their first encounter.

Another observation, that I made with this nest of Formica sanguinea, belongs undoubtedly to the same class of biological phenomena. A Dinarda dentata had been for some time a tolerated, if not a welcome guest of the community. But on account of experiences with a closely allied, but little larger species, the Dinarda Maerkeli, ${ }^{1}$ toleration turned into a hostile attitude.

1) See "Vergleichende Studien" (1st edition), p. 38; "Die psychị. schen Faehigkeiten der Ameisen," p. 84. 
The ants learned to attack, and to seize and kill their former guest. Now in this case a new psychic element, beyond the independent learning of the individual, evidently influenced the conduct of these ants. It was the stimulation of their imitative instincts, which was brought about by the behavior of their companions. We shall study this element more closely in the discussion of the fourth form of learning.

It need not be particularly mentioned that the second form of learning is also met with in higher animals. By its individual sensitive experience a hunting dog "learns to recognize" a new species of game which will in future be chased with special eagerness, whenever it is scented. But it is time to take up the question, whether this second form of learning furnishes a proof of animal intelligence.

A disciple of pseudo-psychology will naturally feel inclined to attribute the power of logical deduction to an an ant, that after a single experience admits a new, hitherto unknown, but genuine guest, let us say the Atemeles, into her nest. He injects his own thoughts into the ant's brain, and lets Formica reason as follows: "On account of its unwonted odor I at first took that strange creature for a hostile being, or for a Didelphys which it was my duty to devour; but, after all, I experienced a very pleasant sensation in licking it. Besides, it behaved exactly as a friendly ant would do, and tapped me gently with its feelers. I guess, it will be best to treat it as a welcome immigrant and admit it with citizenship papers into our community."

What an arbitrary humanization of the animal! The facts which evidently belong to the second form of 
learning prove that the animal is able to form new associations of representations from its own sense experiences. This they do prove and nothing more. But this ability results from sensile memory and not from intelligence. And only the most uncritical confusion of these two concepts can make it possible to propose this second form of independent learning as a proof of intelligence in animals.

3. The third form of learning occurs, when a new mode of action cannot possibly be explained unless we admit personal conchusions from former experiences and past conditions to the new state of affairs. This mode of learning furnishes a real argument in favor of intelligence; for the second form with its new associations of representations, which flow immediately from sensitive experience, is totally inadequate to explain the phenomenon. An additional and essentially higher element cooperates. It is the intelligent comparison of former conditions with the new state of affairs and the conclusions which flow from this comparison. This inode of learning necessarily implies the faculty of perceiving the true relations between cause and effect, between means and end. Consequently it presupposes intelligence in the true and proper sense of the term. Therefore we must examine very closely, whether a form of learning which evidently implies an operation of intellectual faculties, can be truly met with in ants or in higher animals; and it depends on the result of this investigation, whether or not we may legitimately call them intelligent.

We have previously shown in many of our publica- 
tions, ${ }^{1}$ that ants lack the power of intellectual reasoning. Not only are there no facts which cannot fully be accounted for without attributing this power to them, but, on the contrary, there are many facts which are incompatible with such an assumption. The firm attachment of the "slaves," developed out of robbed pupae, to the ants which stole them; the inability of all ants to apply their architectural skill intellectually to new purposes, as to the building of a bridge in order to obtain honey; the constant and diligent rearing of the Lomechusa larvae in spite of the great damage the ants have subsequently to suffer from this ravenous brood,-these and many other phenomena tell forcibly against the assumption of intelligent reasoning in ants. Nor is this psychic factor less wanting in higher animals. ${ }^{2}$ Living, as they do, in the wide garden of nature, monkeys have never learned the use of fire during the past thousands of years; despite innumerable chance-experiences they have not even learned to cmploy stones or branches of trees as weapons of attack or defence; even higher animals manifest in their instincts of adoption features quite as unreasonable, as is the rearing of the Lomechusa by ants.

Thus we meet with the same mysterious contradictions in the habits of ants as of higher animals. On

1) Especially in our book: "Die zusammengesetzten Nester und gemischten Kolonien der Ameisen" (Muenster, 1891), 3 Abschnitt, I. Kap; then in our "Vergleichende Studien . . . ," above all in the chapters. "Ist die Bauthaetigkeit der Ameisen durch Intelligenz geleitet?" and "Die Adoptionsinstincte im Thierreich."

$\left.{ }^{2}\right)$ Compare the above mentioned chapters in the "Vergleichende Studien" and the chapter "Kriege und Sklavenraub im Thierreich." See also our essay: "Die psychischen Faehigkeiten der Ameisen," p, 92 , 
the one hand they are able to learn by independent sense experience, and thus develop, or modify their hereditary instincts within certain limits; and, on the other, they are unable to learn from agreeable or disagreeable experiences, however frequently the latter may occur. What is the solution of this riddle? It can be found only by insisting on the precise distinction which prevails between the second and the third forms of learning. The animal is able to learn without foreign help, whenever the new associations of representations which flow immediately from sense experience and do not demand reflection, are sufficient in themselves to modify its mode of action; but, whenever an intellectual power of inferring new conditions from the past is requisite for that purpose, the animal is not able to learn the least thing without foreign assistance. In other words: The power of learning is limited in animals to their sensile memory; it fails entirely, where intelligence ought to set in, that noble psychic faculty which carries man constantly onward on the path of progress. Consequently the essential difference between the powers of learning in animals and in man must be sought in the third form of acquiring knowledge. It is as characteristic of the latter, as it is lacking to the former. The next three forms deal with the modes of learning by foreign influence.

4. The fourth form is that of learning by instinctively imitating the behavior of surrounding beings. It is the lowest stage of learning by foreign influence. As the first form of independent learning is closely connected with reflex processes, whence it proceeds to real psychic activities, so it is with this form of learning by 
instinctive imitation. When any member of a social gathering chances to yawn, his action is "spontaneously," or, may be, reflexively imitated by those who see it. The perception of his motion actuates a similar reflex activity on their part. The simplest instinctive imitations of animals may be explained in this manner. The psychic element of sight perception serves as the releasing moment. The less, however, the activity which is imitated be purely reflex, as it is in yawning, the more will psychic elements participate in the imitation. Hence we are fully justified in speaking of "learning by imitation."

It may be anticipated that this form of learning is prominent in animals of social habits. We find, indeed, many instances of it in ant life. The above mentioned attacks upon the Dinarda, that occurred in the nests I had under observation, and especially in one large nest ${ }^{1}$ of Formica sanguinea, in which several kinds of slaves were kept, clearly manifests the influence of this instinct of imitation. When one or a few ants commenced to pursue the Dinarda which met them, their example soon proved so catching, that many of the others, masters as well as slaves, that had not happened to meet the unfortunate beetle, or had even previously ignored it, began to hustle and search for the intruder. $^{2}$

This mode of learning by imitation can be still better observed, when ant colonies and particularly mixed colonies of Formica sanguinea receive genuine guests into

1) A cut of which is given in the "Vergleichende Studien" (1 Auf., p. 15).

2) See "Die psychischen Faehkeiten der Ameisen," p. 93 ff. 
the community. The beetle Atemeles emarginatus was always amicably received, when one or the other of the following conditions was verified. Either a number of fusca had to be kept as slaves in the colony, or I had to isolate a few of the sanguinea in a little glass, to quarantine them for some days with the new guest, before introducing him to the company of the other ants. In the first case the fusca received the beetle, and introduced him to the sanguinea; in the latter case he was introduced by the sanguinea which had allowed him to approach and touch them during the period of isolation, and had finally licked his aromatic secretions. I found out by experiments that it is not only the odor of the salivary gland-secretions of their companions which induces the ants to grant permanent admission into the colony to the beetle which has been licked by one of their number, but that it is a genuine instance of learning by imitation. ${ }^{1}$ The same happened in the admission given to an Atemeles emarginatus by a mixed colony of Formica pratensis and F. Fusca, in which case the former learned by the example of the latter, how to treat the beetle. ${ }^{2}$

The great importance of the social instinct for communities of ants follows from the fact that their sensile power of communication, their so-called feeler language, would be purposeless without it. ${ }^{3}$ For the result of tapping one another's heads consists principally.

1) "Die psychischen Faehigkeiten der Ameisen," p. 96 ff.

$\left.{ }^{2}\right)$ "Die zusammengesetzten Nester und gemischten Kolonien der Ameisen," p. 174. "Die psych. Faehigkeiten . . . ," pp. 99 and 100.

3) See "Vergleichende Studien" ( 1 . Aufl.), p. 10 and "Die psychi. schen Faehigkeiten der Ameisen," pp. 59-73 and 100. 
and primarily in arousing attention and thereby inducing the other to follow, or to take part in a given enterprise.

The importance of the instinct of imitation in the psychic life of animals is universally recognized. A dog is seldom heard to bark alone: his canine acquaintances in the neighborhood cheerfully chime in at the first sound of his voice. Through its instinct of imitation a young pointer or setter can learn many a trick from an older expert, which it would have found out only after a long time, or perhaps not at all, through its own sensitive experience. And as we have previously observed in discussing the first form of independent learning, this instinct of imitation greatly facilitates the practice of their innate reflex mechanisms in the offspring of higher animals that live in families or flocks. The so-called lessons which birds and carnivorous animals give their offspring are psychologically explained by the pleasure which the parent animals feel in playing with their young. Thus they instinctively show them how to do this or that trick. This performance is instinctively imitated, and the young are said to "learn." Kittens learn to catch mice by playing in company with the cat with a living mouse which the latter brought along and uses as the object of their common "game at hunting." The fact that under the influence of example the young make many sensile experiences sooner than without that influence, makes it plain that the fourth form of learning is supplementary to, and supports the second.

The impulse to imitate is so strongly developed in apes that it has become proverbial. But the very word 
"to ape" shows that we are not allowed to assume iindividual intelligence even in simians, if we wish to give a correct explanation of their imitative impulse. That the imitative power of apes is undoubtedly more extensive than that of ants is principally due to the greater perfection and variety of their sight perceptions. But this is no argument in favor of a faculty of thought, and consequently of intelligence in apes more than it is in ants. On the contrary, this fourth form of learning consists in all animals merely in the stimulation of the imitative instinct by outer sense perceptions and is restricted to the activity of sensile cognition and appetite.

5. The fifth form is that of learning by being trained. It is not a self-dependent form of learning, and thus it is opposed to the first three forms. It is learning by foreign influence, and herein it agrees with the fourth form which was learning by imitation. But it differs from the latter in as far as the modifying influence proceeds from an intelligent being whose influence alters the original instinctive activity of the animal. The training of animals is accomplished by two essentially different factors. As we have seen in our discussion of the second form of learning, we have sensile cognition on the part of the animal, through which it forms new complex representations and retains them in its memory, and on the part of the trainer we have intelligence which turns the powers of the animal to account by making definite sensitive impressions work upon them in regular succession. Thus he awakens in the memory of the animal those associations of representations which he intended to call forth by his system of training. Consequently the training of animals only 
proves the intelligence of man, and not that of the animal.

Even ants can be trained to some extent. I succeeded in taming a wild ant ( $F$. rufibarbis) in a short time, by accustoming it to lick honey from the tip of my finger. ${ }^{1}$ In the observation nest which contained the Formica sanguinea and their slaves I trained the ants to keep the apartments into which I introduced their food entirely clean, and to use another separate glasspipe as a place for refuse. ${ }^{2}$ The inclination of these same ants to persecute the Dinarda, and their skill in seizing them, was also due to some extent to training; for the very use I made of their nest to study the international relations of the Dinarda-races, gave the ants ample opportunity to improve their skill in hunting the Dinardas by individual sense experiences, which in all probability they never would have had in the freedom of their natural homes.

Still the possibility of training ants is far more limited than that of training higher animals. But the reason of this difference is not so much the psychic superiority of the latter, as the extreme difficulty on our part of finding suitable points of connection with these wee creatures, whereas this connection is given in the case of dogs and other vertebrates. There is an immense difference in the size of man and ants, and the difference is almost equally great in regard to the nature of the organs through which their sense impressions are mediated. But the difference in size between

1) "Vergleichende Studien" (1. Aufl.), p. 38.

$\left.{ }^{2}\right)$ For these and other examples see ${ }^{6}$ Die psych. Faehigkeiten der Ameisen," p. $103 \mathrm{ff}$. 
man and the higher animals is much less, and the sense organs of both are of similar structure. The senses of sight and hearing are, above all, most serviceable in the training of animals. Even Aristotle ${ }^{1}$ observed that only those animals can be trained that are gifted with hearing, because they alone learn to obey the voice of man.

Let us suppose that man were a being of the same size and form as an ant, and were equipped with the necessary sense organs, above all with a genuine pair of ant-feelers, but still possessed his intelligence, whilst the ants were endowed solely with the powers of sensile cognition and appetite. It would be much easier for this miniature man-ant to enter into communication with the genuine species and train them to his purposes. For if we consider that real ants, despite their want of intelligence, and guided only by individual sensitive experiences, recognize in certain species of beetles, as Atemeles, Lomechusa, Claviger, etc., genuine guests and agreeable associates, although these beetles belong to a totally different order of insects, it can hardly be denied that an intelligent man-ant of their own size, their senses and organs of communication, would in all probability succeed far better in training them than is actually the case. This whimsical fiction shows at least this much, that the greater facility of training higher animals cannot be attributed to an essentially superior nature of their psychic faculties.

We have previously examined in different chapters of this essay the psychological import of the training of

1) Metaphys. lib. 1, c. 1. 
higher animals. The result was constantly the same. The training of animals only furnishes a proof of the intelligence of man, and not of the animal. The point of contact is found in the powers of cognition and appetite on the part of the animal, and the activity of these powers is principally induced by hunger and the fear of corporal chastisement. The first and second forms of learning have shown us that the animal is able to acquire knowledge independently by the instinctive practice of its innate reflex mechanisms and by sense experiences which cause new combinations of representations. Nor must we forget to add the instinct of imitation which constitutes the fourth form of learning. This threefold basis is taken into account by the trainer. $\mathrm{He}$ forces the animal to practice certain reflex motions. Thus he teaches a horse to acquire the different equine movements. $\mathrm{He}$ forces the animal to imitate certain arbitrary motions which he shows it how to do, and to assume certain attitudes of the body which are otherwise unnatural to it. Thus a dog learns to stand on its hind legs and to fetch and carry different objects. Finally, he mechanically impresses upon the animal's sensile memory certain new combinations of representations by regularly repeating the same sensile impressions. Thus Lubbock's poodle Van finally learnt to "read," by being trained to fetch the card with the word "food," when it was hungry. There is not the faintest notion of animal intelligence in this whole process. The sole agents are the powers of sensile cognition and appetite and the sensile memory of the animal, and the intelligence of man.

6. The sixth form is that of learning by intelligent 
instruction. He who learns must not only retain those combinated representations, to which the teacher has given rise by regularly repeating a certain train of sense impressions, as is done in the fifth form, but he must continue to reason by his own actirity. This form supposes and rests upon the fifth, but at the same time it goes much further. Moreover, it comprises the fourth form of learning by instinctive imitation, nor is it independent of the first three forms, and certainly includes the second and third, which deal with learning by self-development. Its necessary supposition is, that he who learns be able to form new associations of representations from experience, as is done in the second form, and to infer new conditions of things from those which formerly existed, as is characteristic of the third. It is precisely through its relation to this third form of learning that the sixth essentially differs from the fifth, which consists in learning by training. For as it is impossible to learn to think independently and to infer, without the power of reasoning, and, consequently, without intelligence in the full sense of the word, so is it equally impossible to learn by instruction, if he who learns be not endowed with intellect. If he lack the power of reasoning, he will never do more than combine the different representations which arose from his own sense experience, or through the influence of his teacher; he is unable to rise higher in the psychic scale; he cannot learn by instruction to carry on independent conclusions: he cannot learn to think, because he has no power of thought.

When a child learns to read and write, it gradually ascends from the lowest to the highest stages of learn- 
ing. It not only learns to imitate certain sounds and written symbols mechanically and to combine them according to constant and definite rules, but it learns to understand the meaning of these phonetic and graphic symbols. Hence, after a certain time, it is able to express its own thoughts by pen or word of mouth in its own way. Even the child of the most uncultured savage possesses the power of learning new truths by instruction. It learns how to understand them more and more. This fact is fully establishec' by the history of civilization, and especially by the missionary annals of modern times. Therefore the only point at issue is, whether or not animals are likewise endowed with a similar power. Properly speaking, the question has already been answered, when we discussed the third form of self-dependent learning; animals are unable to infer new conditions of things from those which formerly existed; therefore, they are likewise unable to learn by instruction. For its necessary supposition, individual intelligence, is wanting in the psychic endowment of the animal.

Still, let us adduce some examples which are to the point. In spite of its long course of training Lubbock's poodle Van often brought the wrong card, when it was hungry, instead of the card with the word "food" written on it. This fact shows that it never understood the relation between the graphic symbols and their meaning. Nor did it occur to Van to give "reading lessons" to Patience, the lap-dog. Nor did Patience hit upon the idea of profiting by Van's experience, although she had often witnessed the reward which Van received for fetching the proper card. The reason is, because 
neither the one nor the other was endowed with the faculty of thought.

Stories are often told about instructions in walking, flying, eating, hunting, etc., which higher animals are said to impart to their offspring. ${ }^{1}$ However, on stripping these facts of all arbitrary additions, the pretended "lesson" turns out to be an instinctive stimulation of the impulse to imitate, which has been aroused by the parent animals, and helps the young to practice their natural reflex mechanisms. The latter in turn furnish the occasion for many individual sense experiences which the young animals would not have had, if left to themselves. Such phenomena belong to the fourth torm of learning, and include the first and the second. They do not furnish the slightest evidence in favor of an intelligent instruction on the part of the parent animals. Indeed, it is the purest anthropomorphism, even to apply the terms "instruction" or "lesson" to such phenomena.

There are still other striking anecdotes about parrots, starlings, and various birds which "learned to speak" by human instruction. But a closer examination of the recorded facts shows that they have nothing to do with an intelligent learning on the part of the animal. In training an animal we rely on its instinct of imitation, in order that it may learn to utter a certain succession of sounds. But there is not a single proof that any bird ever really understood the intelligent connection of those sounds. On the contrary, the wrong and awkward way, in which the animal generally applies its treasures of wisdom, is the cause of our amuse-

1) See Altum, "Der Vogel und sein Leben" (6th edition), p. 208. 
ment, and we must naturally find these misapplications very ludicrous. The facts we allude to must be explained by the sensile pozver of cognition of the animal. and by the formation of new combinations of representations in its sensile memory; whilst the seemingly intelligent order of these associations results from the intelligence of man who trains the bird to speak. But the pretended jokes which parrots are said to have $i n$ zonted, are the merest fairy tales. An enthusiast or a sentimental lover of animals may perhaps take pleasure in them, but they are of no value to an earnest naturalist.

But it is time to sum up the results of this discussion.

In view of true biological facts, the following forms of learning have to be distinguished:

\section{Self-Dependent Learning.}

I. Through instinctive practice of innate reflex mechanisms, which is released by the muscular sensations of the subject.

2. By sense experiences, in virtue of which new combinations of representations and impulses are formed without the aid of intervening reflection (sensile memory).

3. By sense experiences and the intelligent inference of new conditions from those which formerly existed (sensile memory and genuine intelligence).

\section{Learning by Foreign Influence.}

4. By the stimulation of the instinct of imitation which is brought about by the examples of others. 
5. By training, when man impresses on other beings that are endowed with senses new associations of representations and impulses, according to his individual plans.

6. By intelligent teaching (instruction), when one intelligent being teaches another not only how to form new associations of representations independently, but also how to infer new conclusions from previous knowledge.

The conclusions that follow from this exposition, are:

I. All six forms of learning are found united only in man. Animals, possess the first, or the first and the fourth, or the first, second, fourth and fifth, according to the degree of their psychic endowment.

2. In ants as well as in higher animals the first, second, fourth and fifth forms of learning can be actually identified.

3. Only the third and sixth forms prove the existence of intelligence in the full sense of the word on the part of him who learns; whilst the remainder do not furnish such proofs.

4. Hence, the statement of modern animal psychology that "Learning by individual experience is a criterion of intelligence" must be abandoned, as fully unwarrantable.

5. As the third and sixth forms are not found in animals, we must state that "animal intelligence" does not exist. 


\section{CONCLUSION.}

$T^{H E}$ critical examination of the notion of intelligence, as employed by modern animal psychology, has shown us that the latter designates as "intelligence in animals," what is no intelligence at all. It evidently belongs to the sphere of instinctive sentiency. No trace of intelligence, that is to say of a spiritual power of $a b$ straction, is to be found either in higher or in lower animals. Spiritual life begins only in man. It is indeed closely connected with, although essentially different from sensitive life, which man shares with the higher vertebrates. Intelligence reaches far beyond sensitive life. This is evident, above all, from the gift of speech which is the expression of the logical activity of man. It is speech that externally distinguishes the psychic endowment of man from that of the animal; but it is intelligence that makes man what he is,-a human being. His sensitive-spiritual soul makes man the crown of the visible creation. His reason and liberty give him a position immeasurably higher than that of the irrational animal, which follows its sensile impulses without reflection, and cannot do otherwise. Through his spiritual soul man is the image and likeness of the Supreme, Uncreated Spirit, of God, his Creator.

But here we stand before that well-known stumbling block which modern science cannot remove in spite of all its endeavors: before the assumption of a personal God, the Creator of the world. This is not the place to develop, in detail, the theistic views of nature and to justify them against the pleas of material- 
istic and monistic theories. But we would modestly advise all modern naturalists to subject these theistic views and doctrines to a thorough study, ${ }^{1}$ before declaring them untenable. Such is the modern "fashion." Otherwise we might justly reply that their opinions are the result of ignorance and prejudice. It is a pity to behold, how even naturalists who reason logically, deem themselves free from this earnest duty in endeavoring to solve the highest metaphysical problems. Instead of disproving these theistic views in their real and true shape, they frame for themselves scme fantastic caricature. Then, of course, they easily arrive at the conclusion, that the claims of theism have been brushed away and must necessarily yield to monism. Even Mr. Aug. Forel fell into this very error in his lecture on "Brain and Soul." Although we must acknowledge that he strove with full conviction to retain the notion of God in science, we earnestly regret that he entertained very imperfect ideas concerning the theistic notion of God. Prof. Emery likewise deemed it necessary, towards the close of his treatise on instinct and intelligence in animals, to oppose our previously established conclusion, that the study of "animal instinct" naturally led to the assumption of a personal Creator. He would rather return to the "ignoramus," than "assume the interference of a mystical Creator." If Emery's assertion were true that the incompleteness of a mechanico-biological explanation of nature forces us to choose the "ignoramus" or to "deify the unknown causes of natural phenomena

1) For this purpose we recommend Tilmann Pesch's "Die grossen Weltraetsel," 2d Vol. 
as supernatural forces, or to personify them and make of them a Creator endowed with thought like man"then we, too, would certainly prefer the "ignoramus" to such preposterous metaphysical views. However, the rational assumption of a spiritual being of infinite wisdom and power which is the reason of its own necessary existence, and must, therefore, be the reason and the first cause of all finite existence,-this assumption is entirely different from the anthropomorphic caricatures of a "personal creator" framed by monistic scientists. If modern naturalists did not draw their knowledge of theistic views from the writings of such men as Ernest Haeckel, who cannot fancy the God of Christianity other than "a gaseous vertebrate," but from the solid works of Christian philosophers, many prejudices would soon disappear. 




JUN 101903 



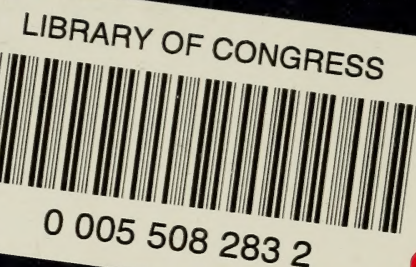

